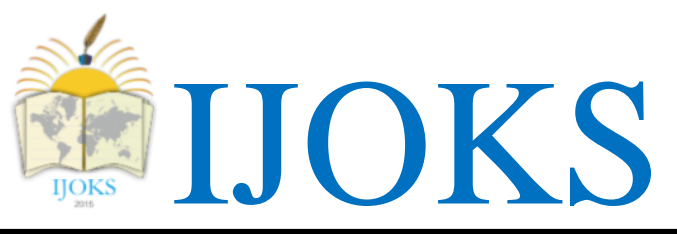

International Journal of Kurdish Studies

(ISSN:2149-2751)

5 (1), pp. $137-166$

http://www.ijoks.com

\title{
The style of personal structure of the Development and simple in the novels: Karwan Omar Kakasor
}

\author{
Sardar Ahmed Hassan GERDI ${ }^{1} \&$ Awara Kamal SALEH ${ }^{2}$
}

Received: Jun 09, 2018 Reviewed: Nov 02, 2018 Accepted: Dec 21, 2018

\begin{abstract}
Personality is an important element in the creation of a novel. Because it has a special place in the novel and the element of compilation and development all other elements of the novel. So the character within the novel according to the stages of the technical progress of the novel and there has been a significant change on the concept, and that the portrayal and clarification of the features and qualities of the actor and in a technical need to the skill writer of the novel. Personality is the conversation of the novel and embody it and often express the look and knowledge of the author of narration.

From this point of view, we dedicated this research to show how the sophisticated and simple personality in Karwan Omar Kakasor's novels is used to show this pattern. The novelist sought to portray the personal components and, as needed, we have benefited from several examples of his novels. This research consists of the introduction and two parts: in the first section explain the pattern of personality formation and in the second section showed the types of characters and development and simple theoretical and practical. In conclusion, we presented a result, a list of sources and a summary of the research in both Arabic and English.
\end{abstract}

Key words: Personal Structure, Karwan Omar Kakasor, Kurdish Novel, Narration, Kurdish

\section{Recommended citation:}

Gerdi, S.A. H. \& Saleh, A.K. (2019). The style of personal structure of the Development and simple in the novels: Karwan Omar Kakasor. International Journal of Kurdish Studies 5 (1), 137 - 166 DOI: $10.21600 /$ ijoks.516498

\footnotetext{
${ }^{1}$ Prof., Dr., Department of Kurdish Language, College of Education, University of Salahaddin Erbil, Kurdistan Region of Iraq. E.mail: dr.sardargardy@gmail.com,

${ }^{2}$ Correspondent Author:Lecturer, Erbil Technology Institute, Erbil Polytechnic University, Kurdistan Region of Iraq, Email: awarakamal@epu.edu.krd, ORCID NO: https://orcid.org/0000-0002-1829-7688
} 


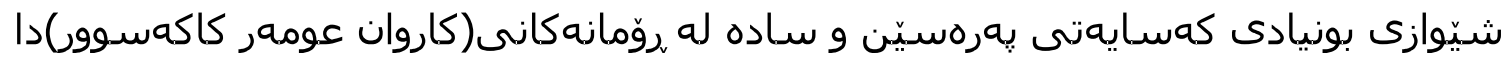

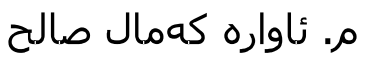

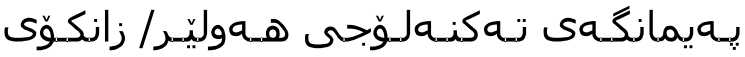

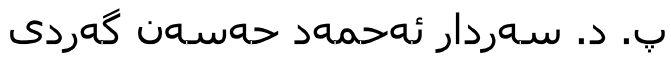

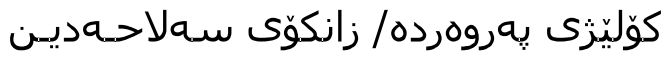
يوّليتهكنيكى هوليّر

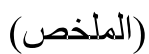

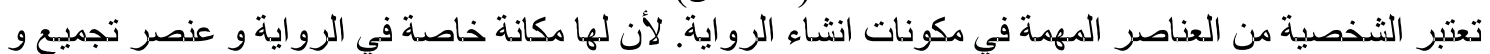

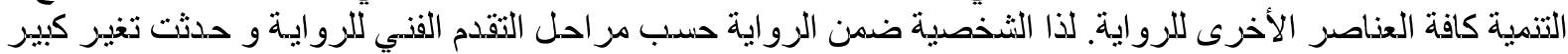

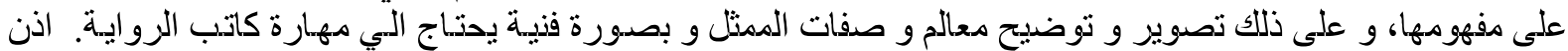

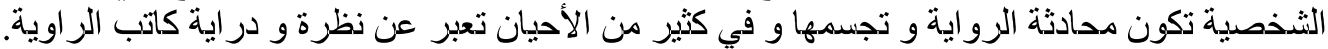

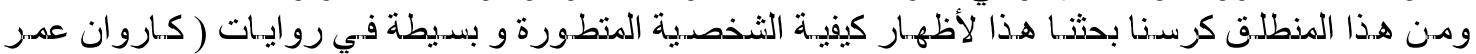

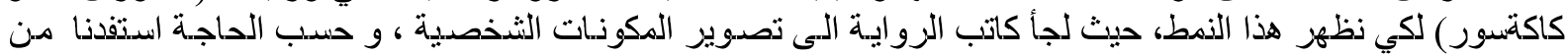

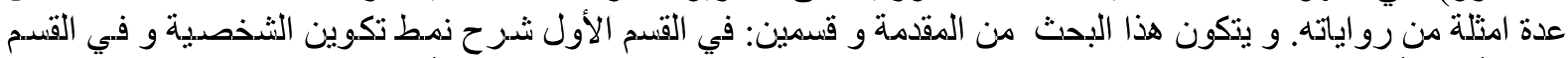

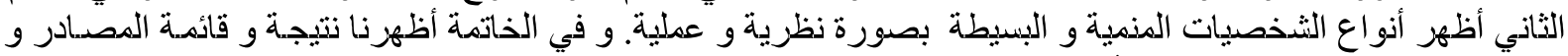
ملخص البحث باللغات العزبية و الأنكليزية و التركية البرية.

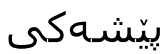

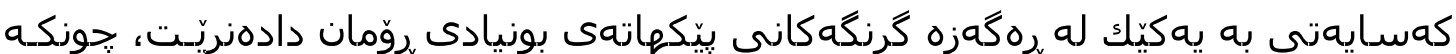

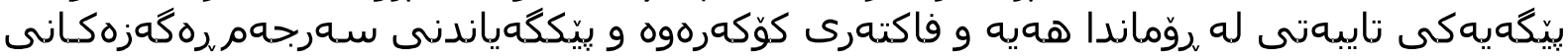

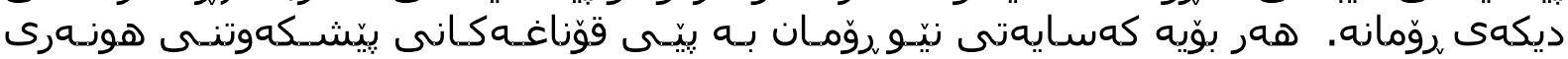

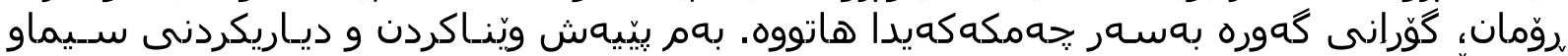

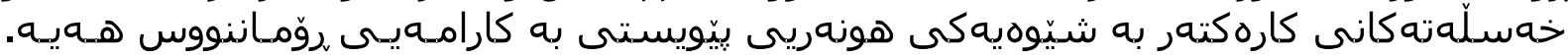

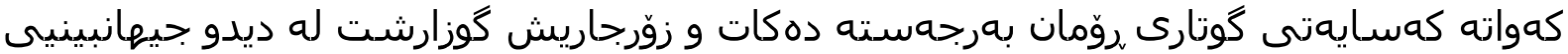

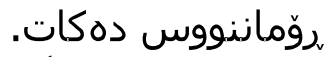

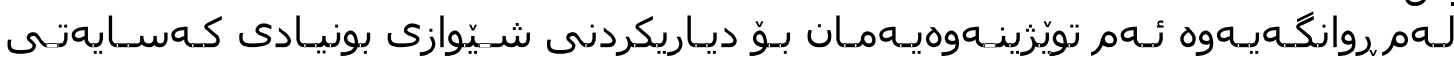

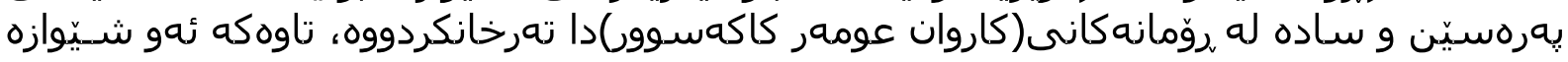

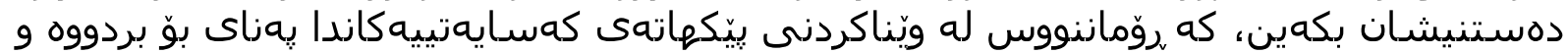

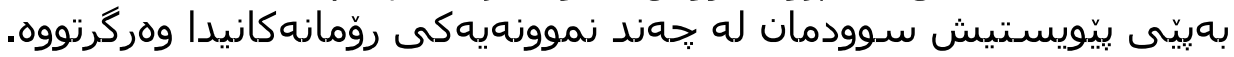

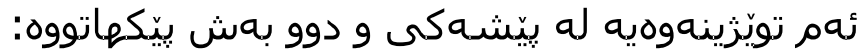

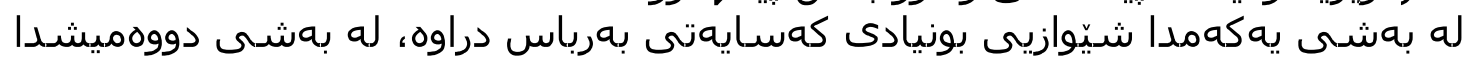

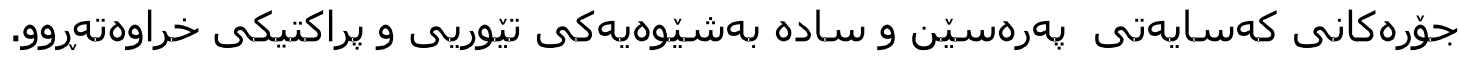

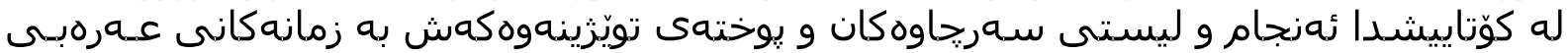

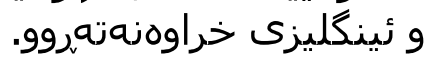

$$
\begin{aligned}
& \text { بوشى يaكaمر: }
\end{aligned}
$$

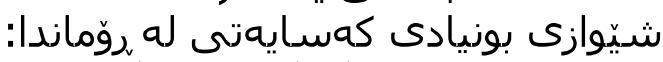

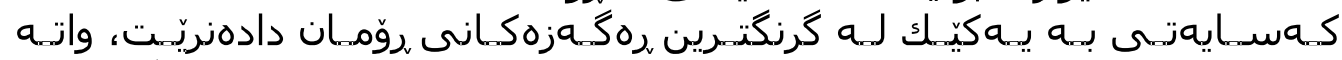

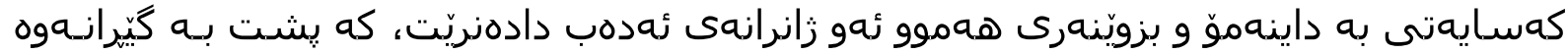

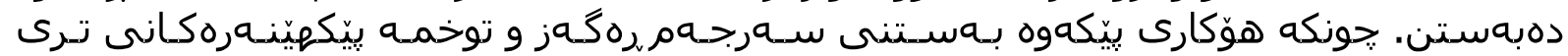

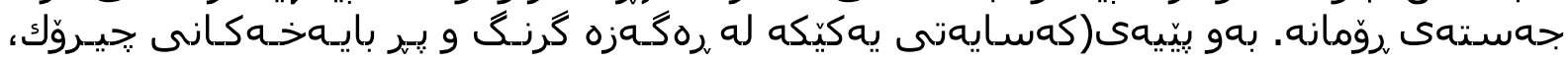




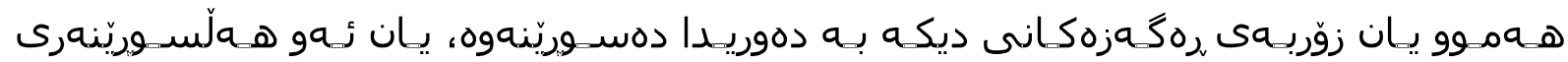

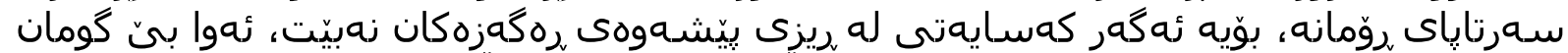

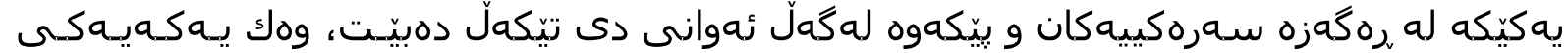

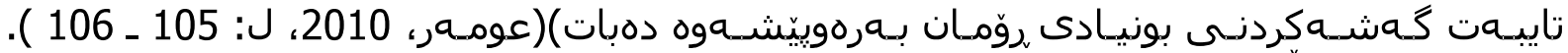

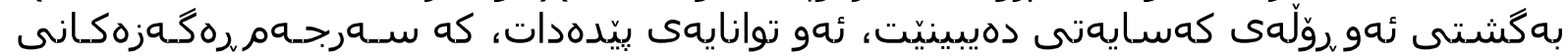

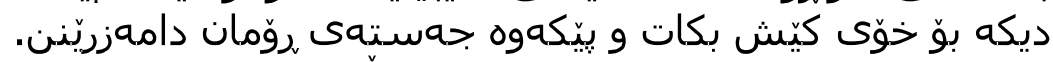

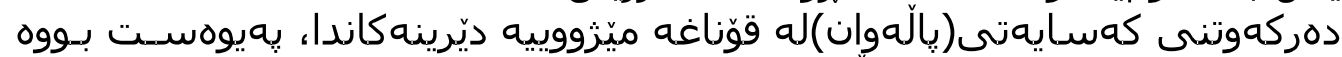

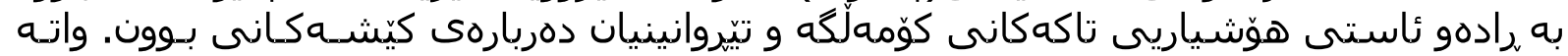

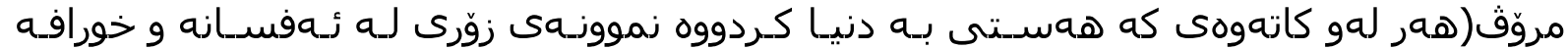

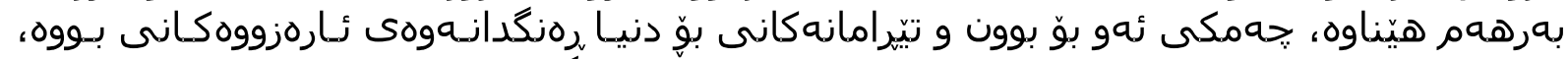

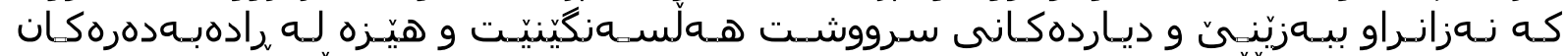

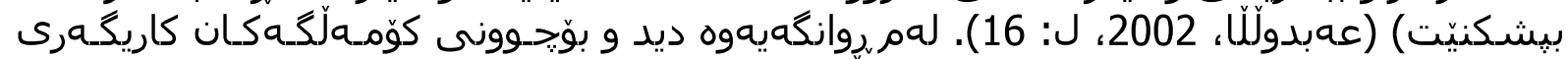

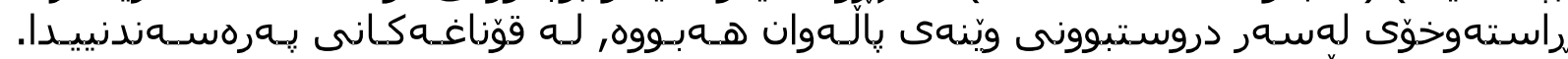

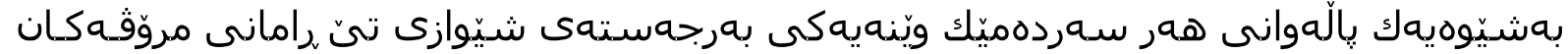

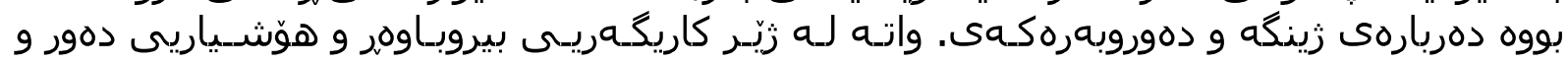

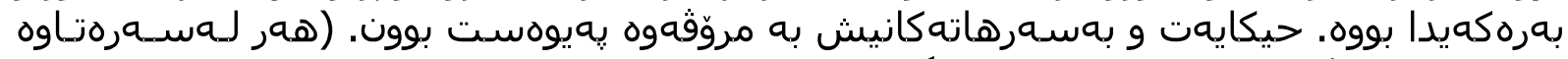

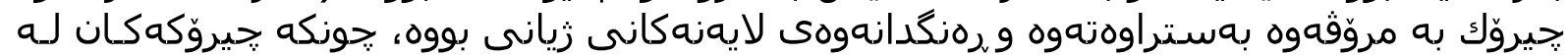

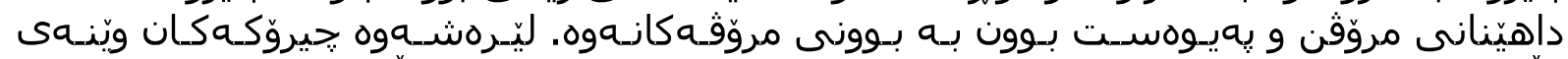

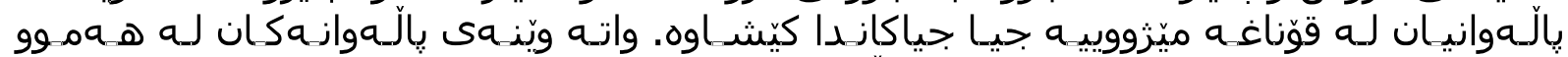

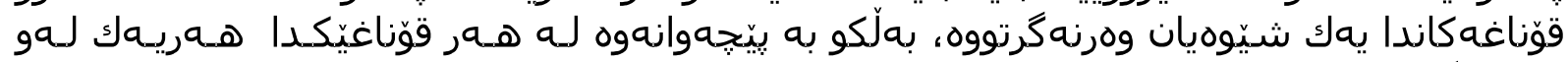

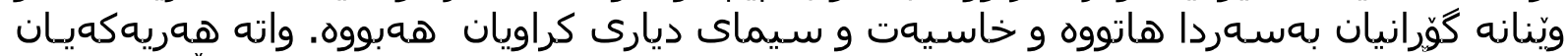

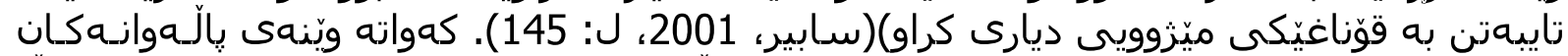

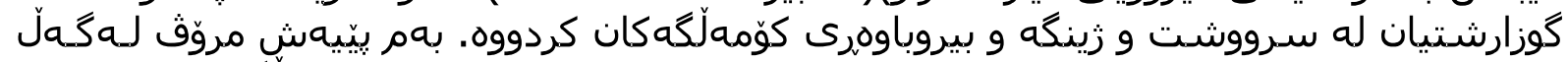

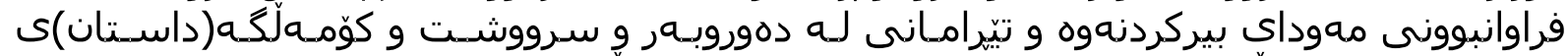

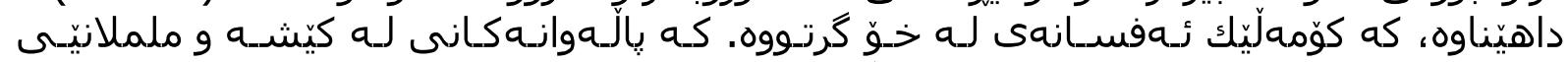

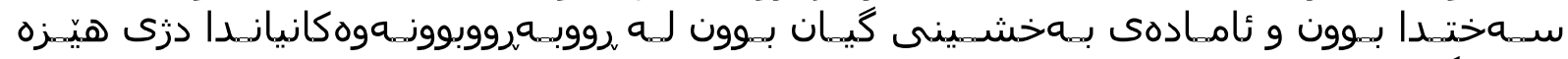

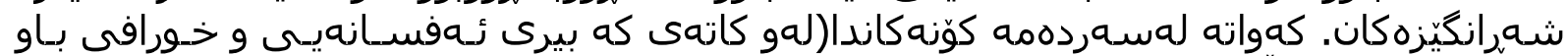

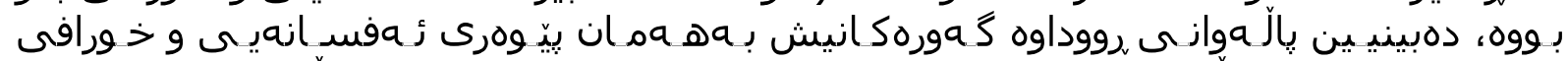

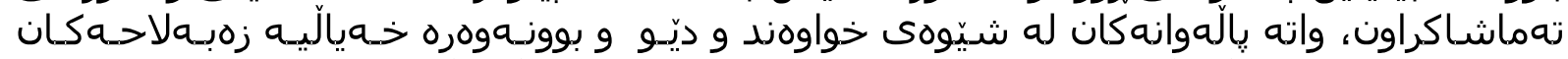

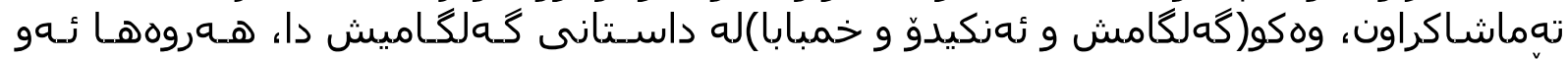

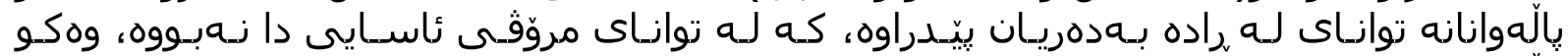

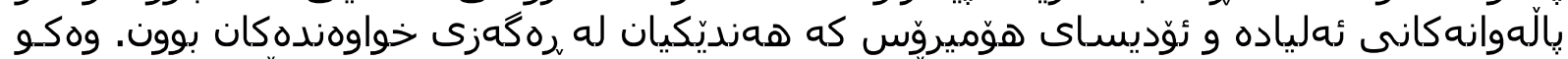

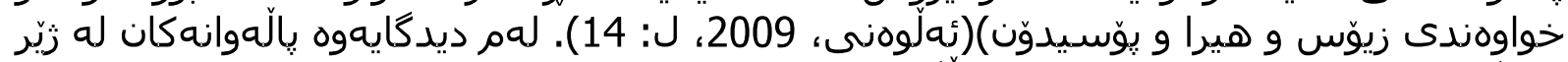

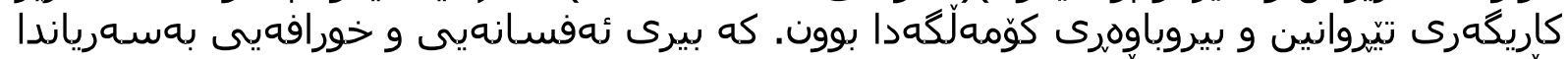

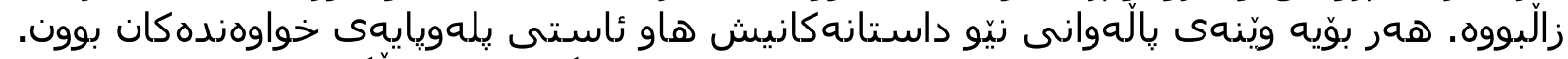

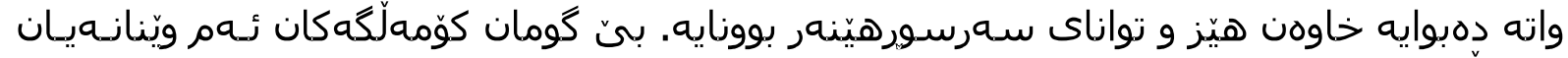

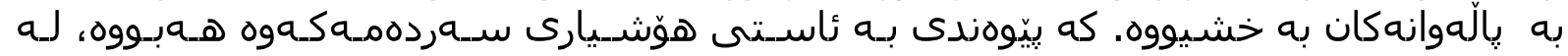

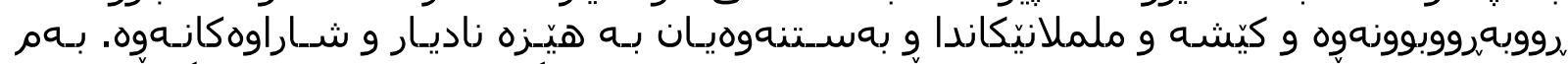

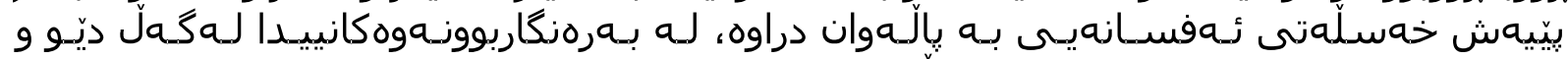

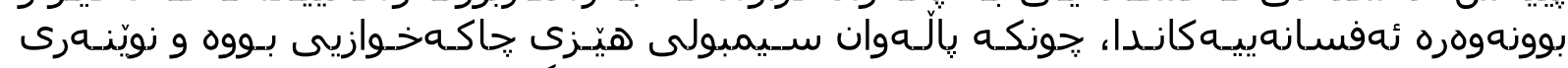

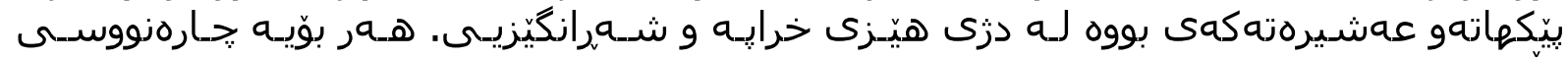

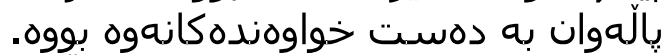

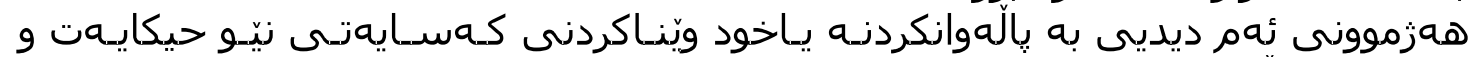

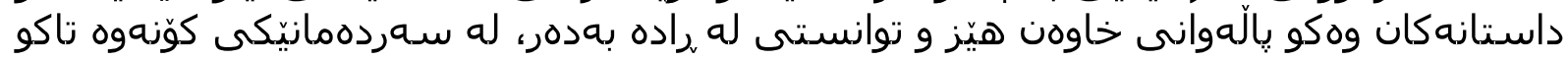

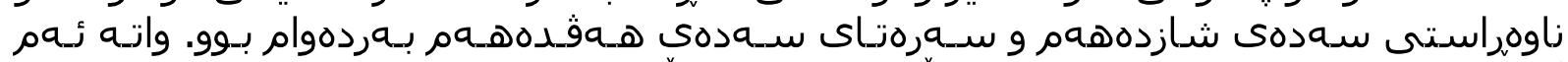

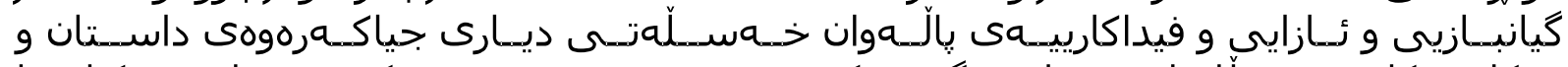

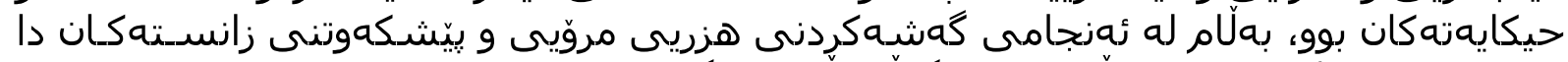

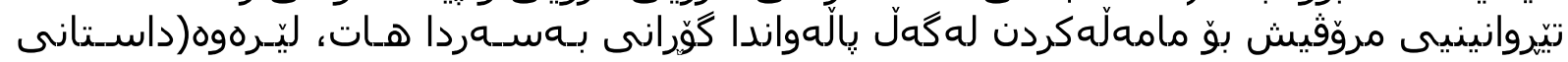

International Journal of Kurdish Studies Vol.5/1 ( January 2019) 


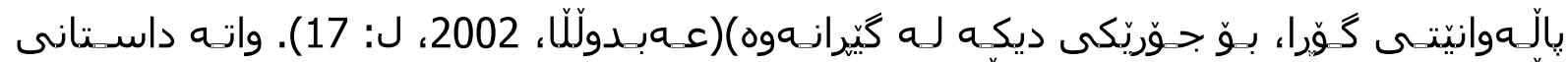

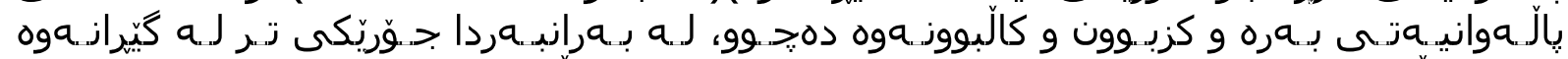

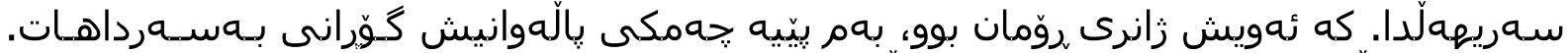

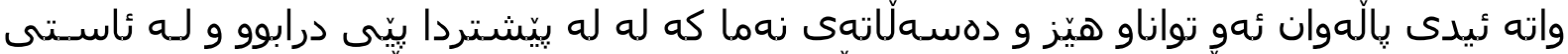

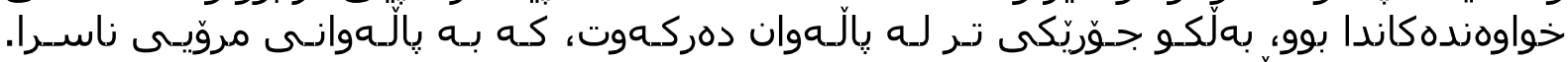

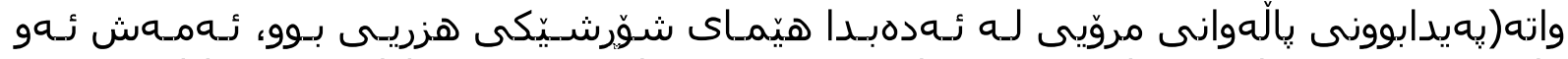

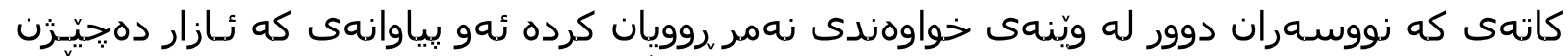

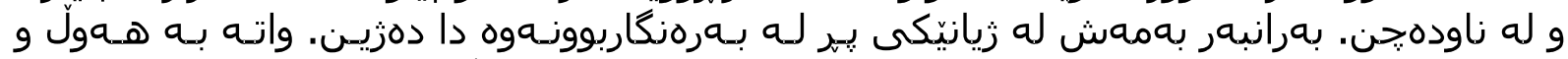

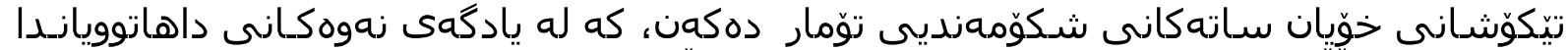

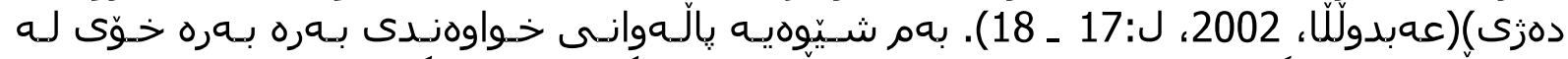

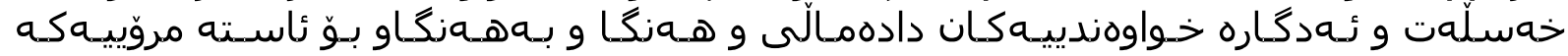

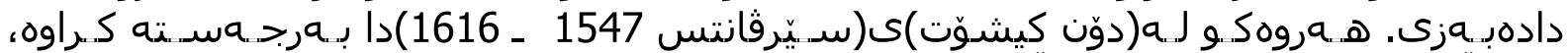

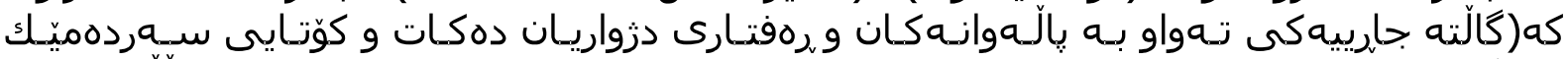

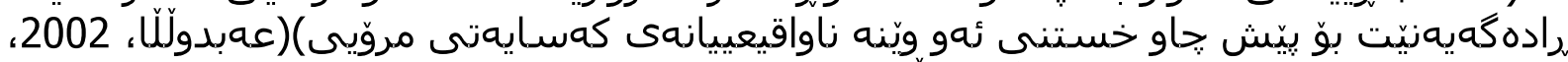

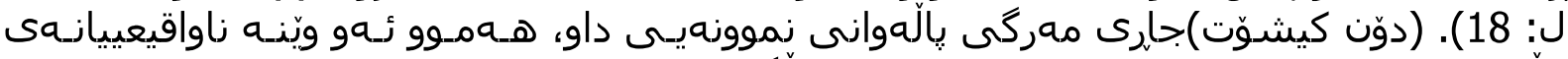

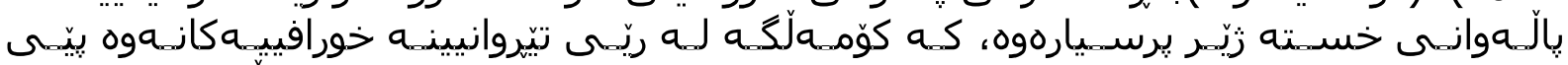

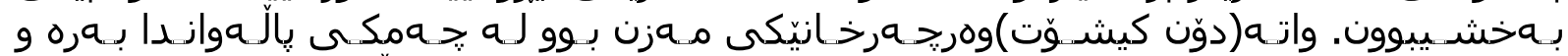

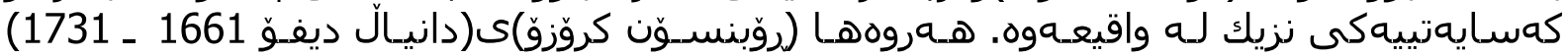

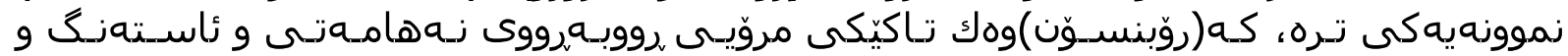

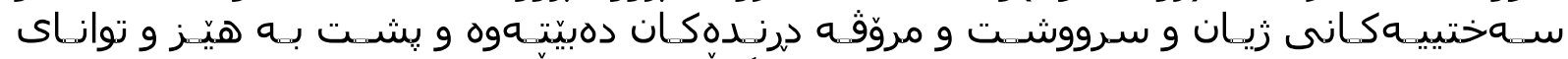

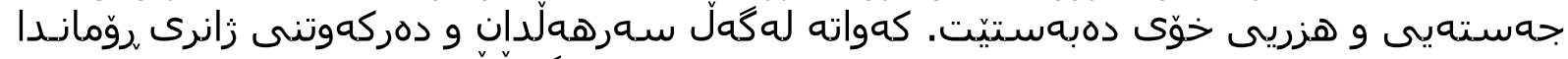

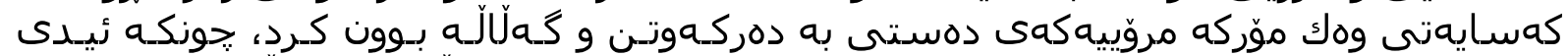

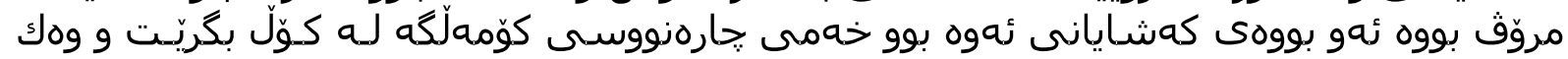

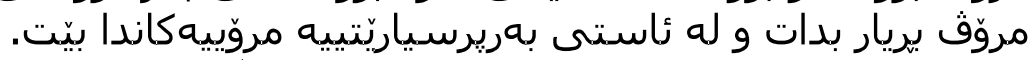

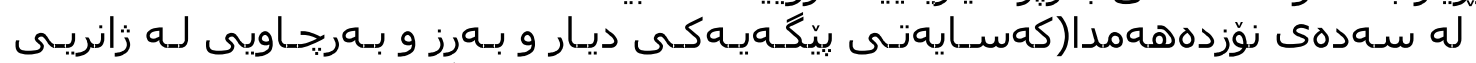

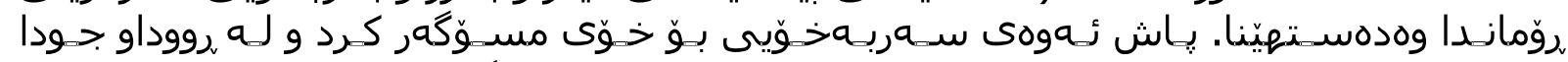

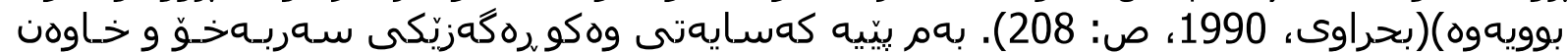

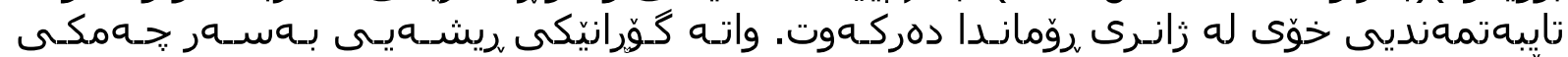

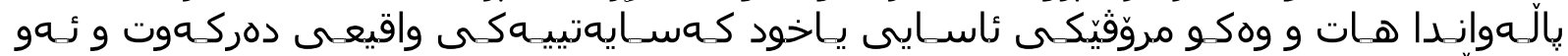

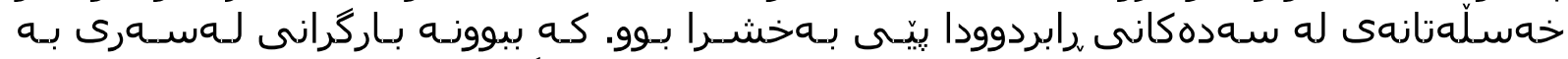

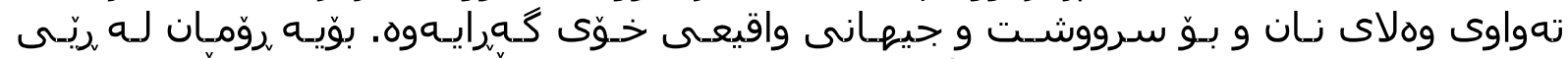

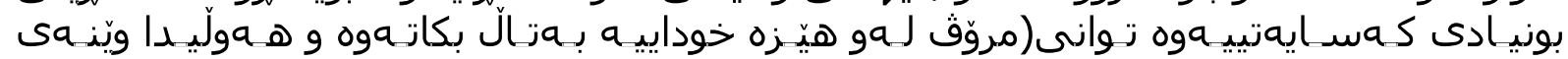

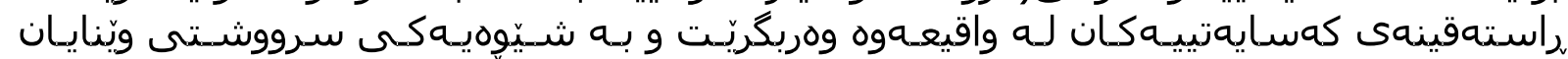

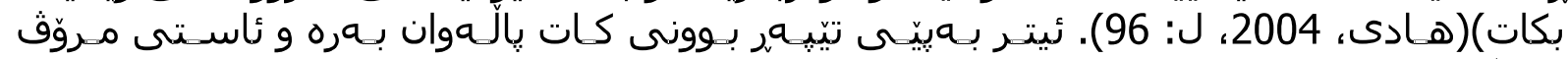
هaزkاوى دهنا.

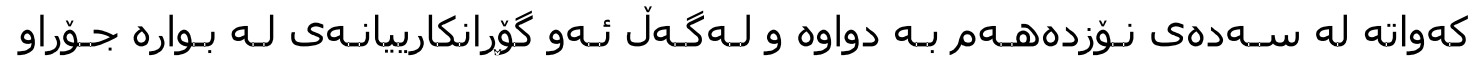

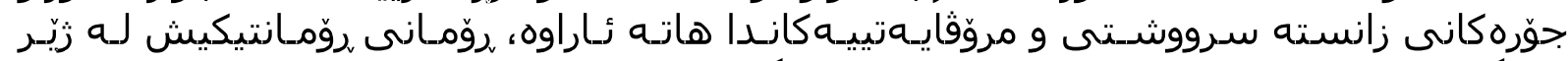

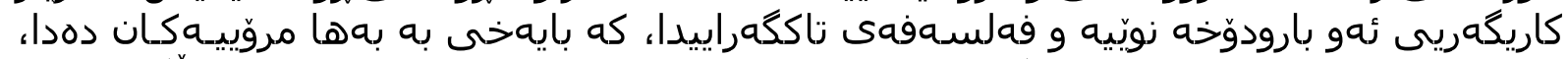

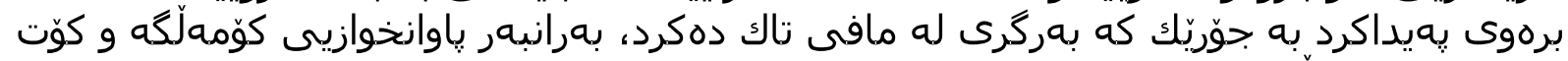

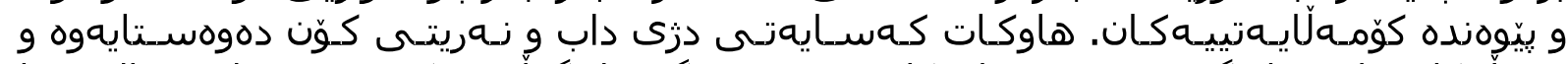

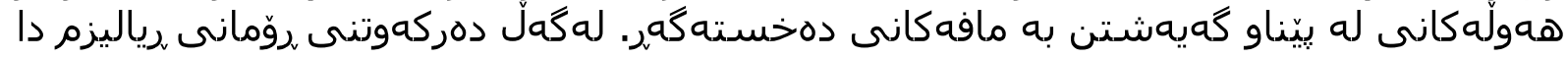

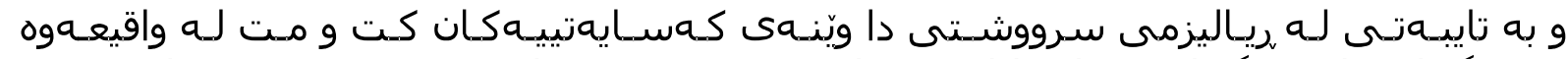

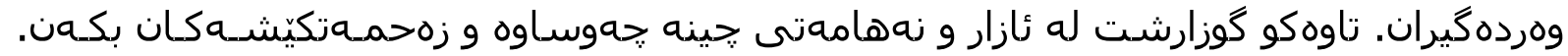

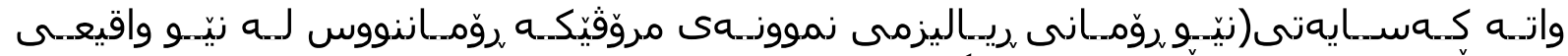

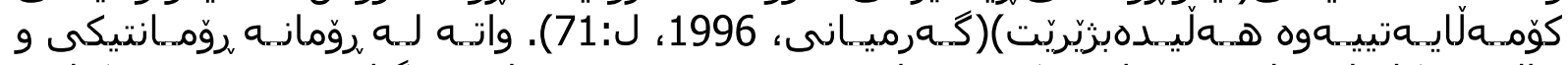

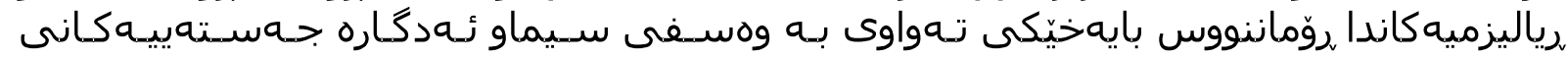
كaسايaتى دهادا. 


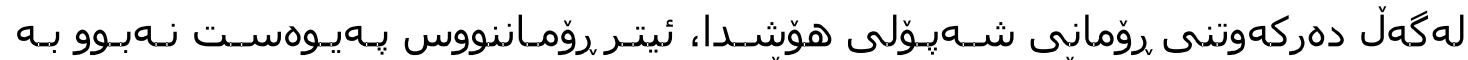

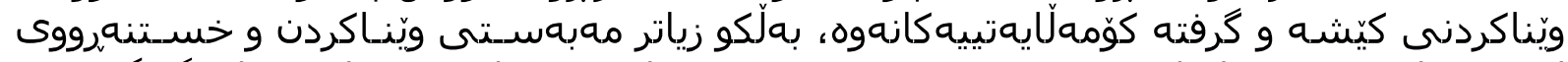

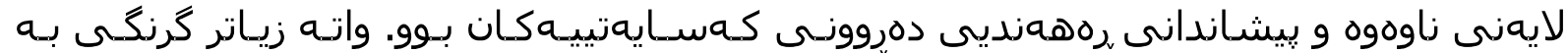

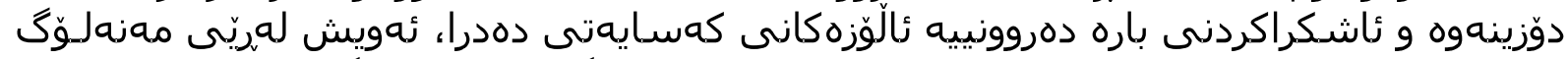

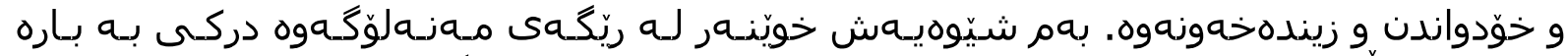

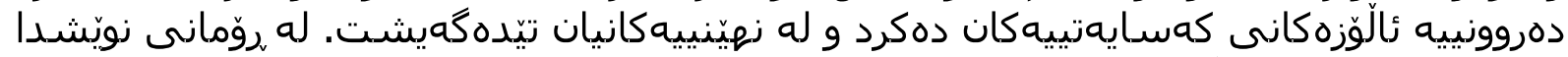

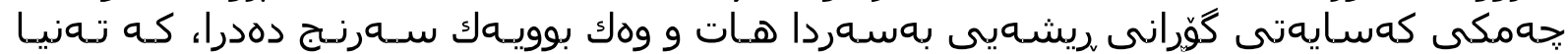

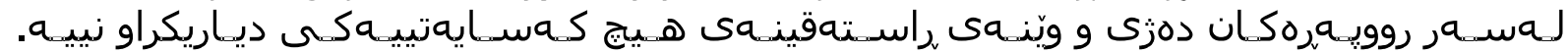

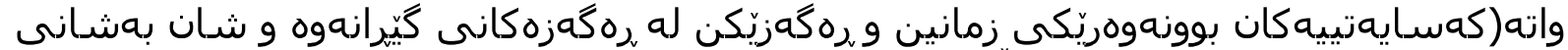

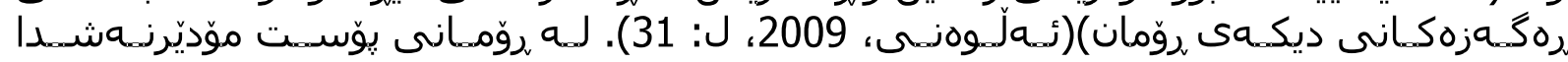

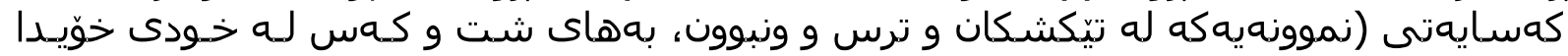

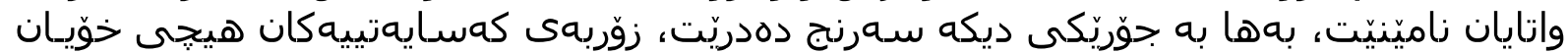

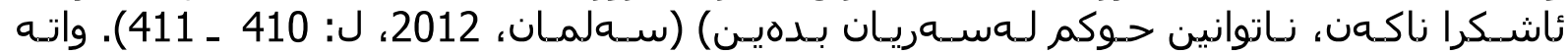

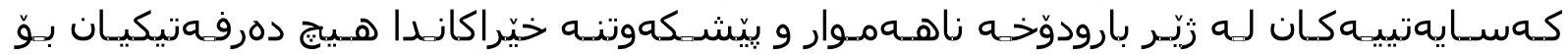

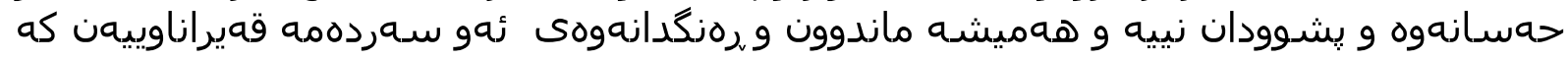

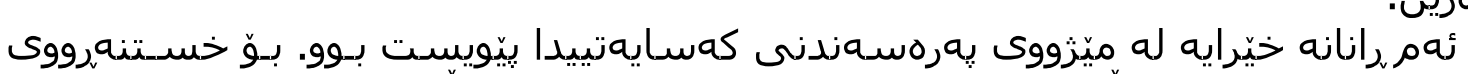
تيّيدا دهرين.

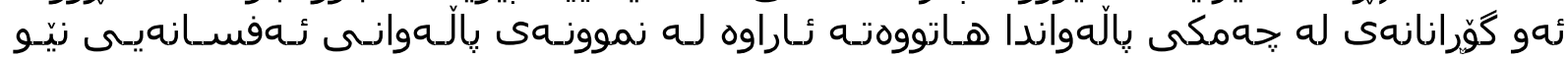

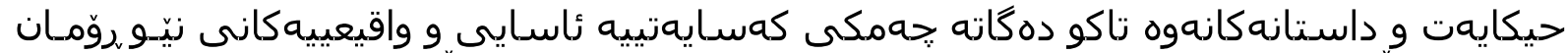

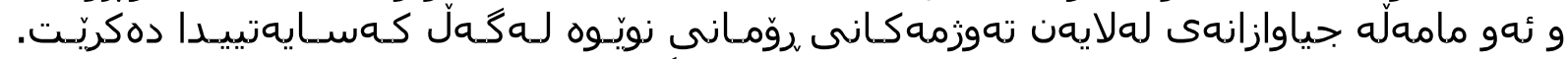

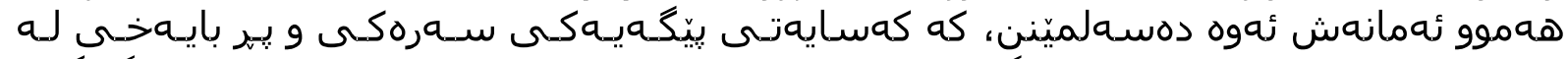

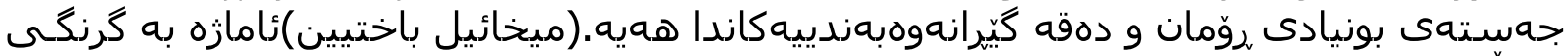

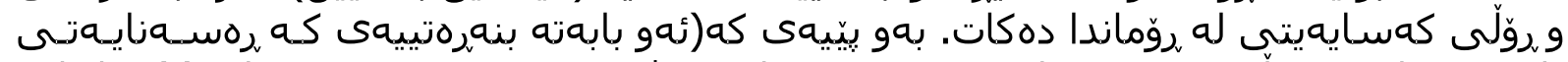

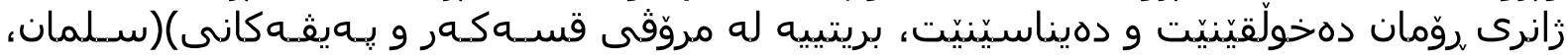

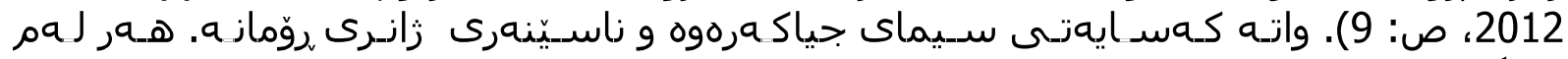

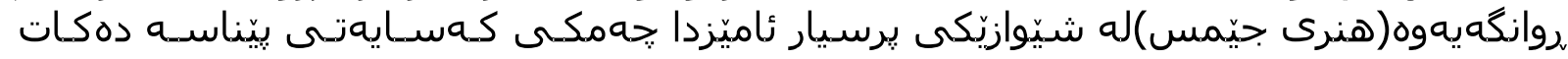

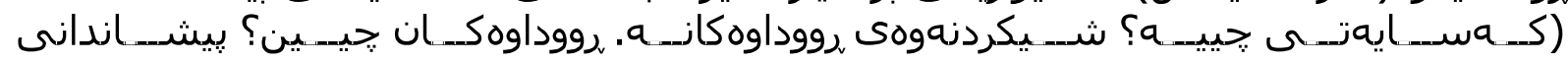

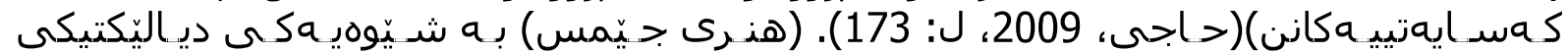

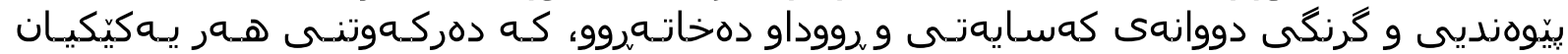

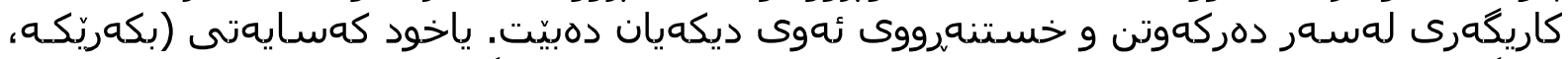

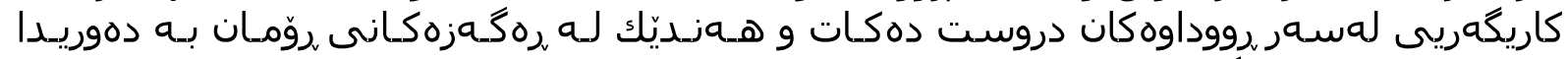

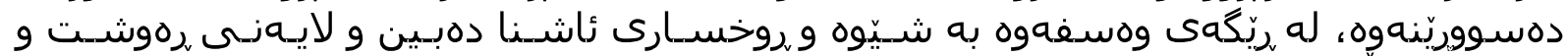

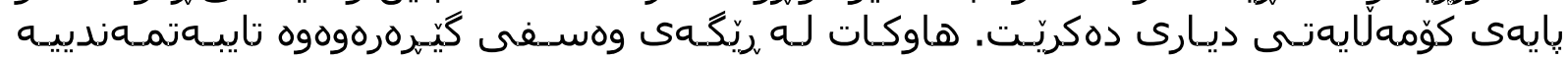

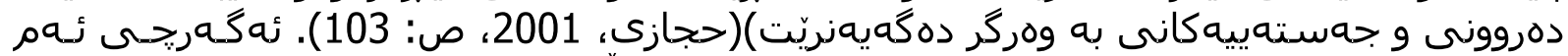

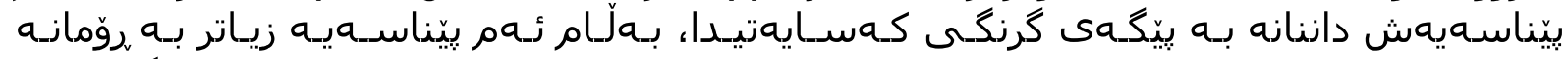

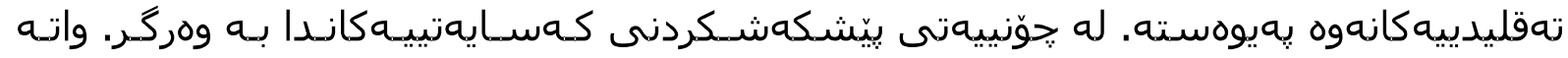

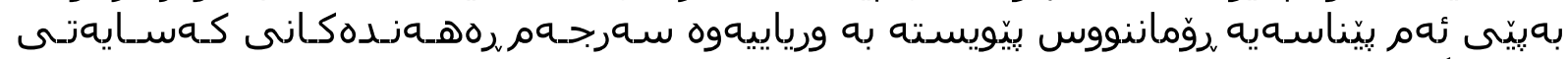

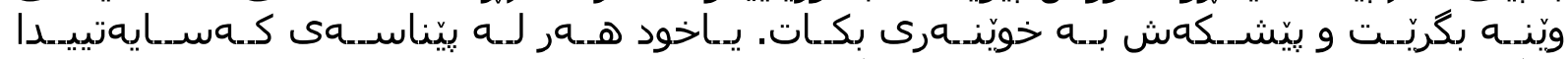

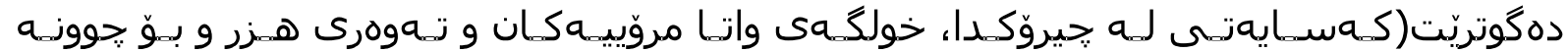

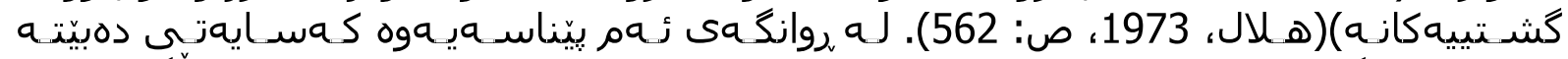

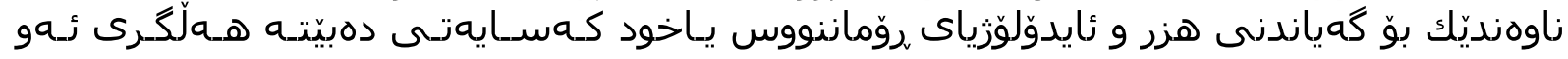

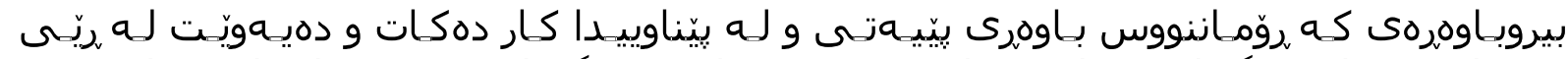

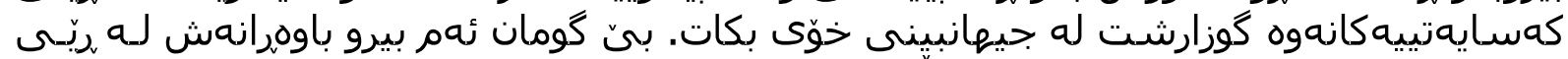

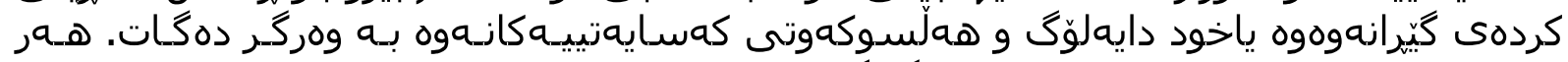

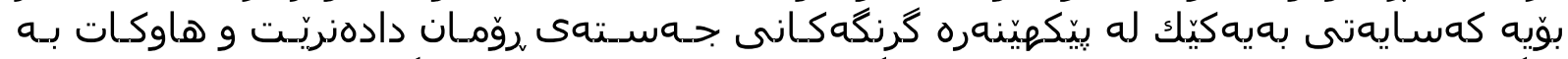

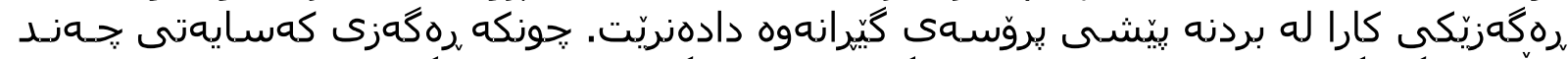

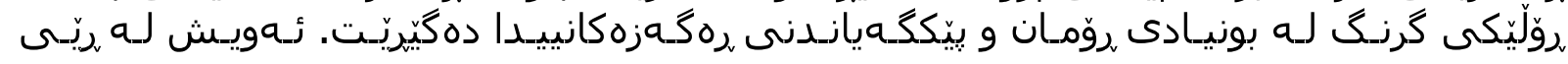




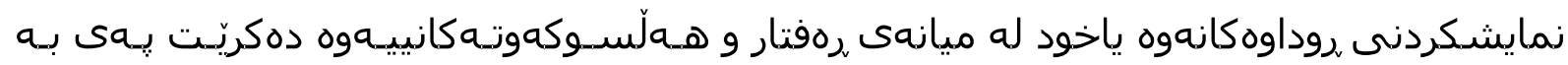

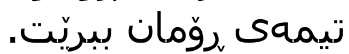

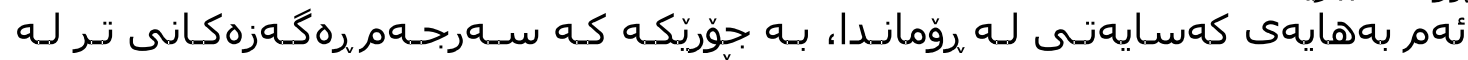

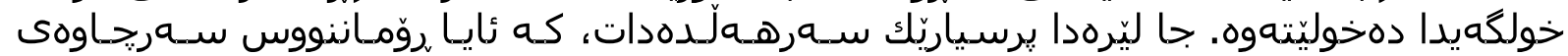

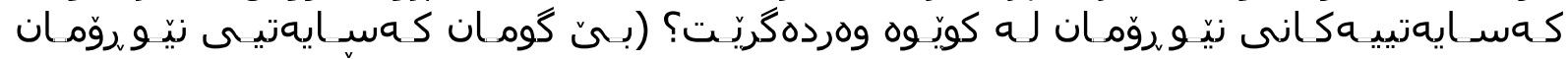

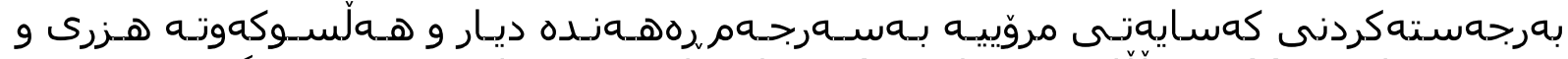

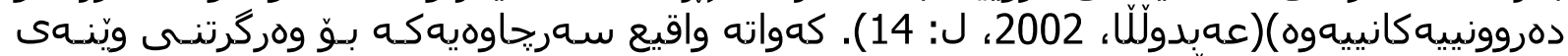

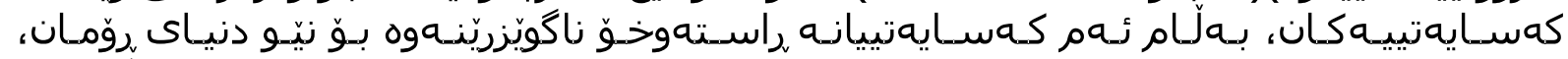

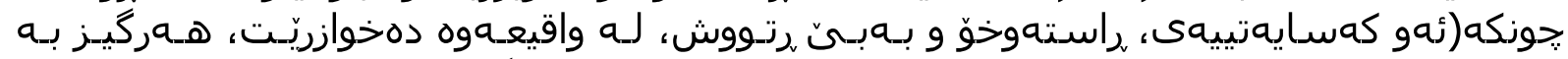

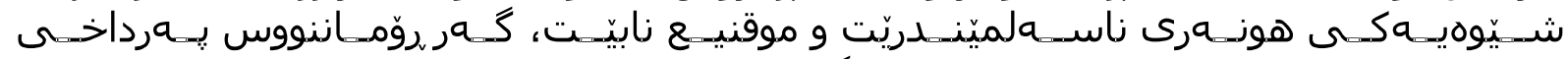

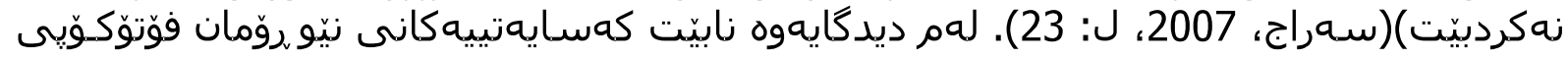

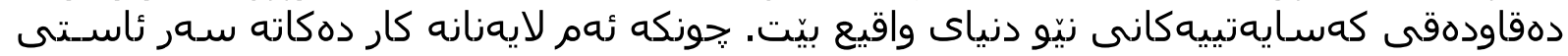

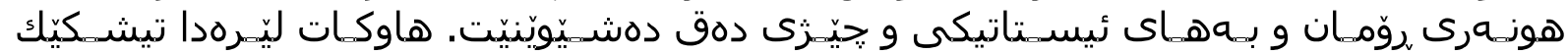

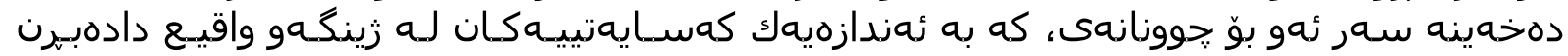

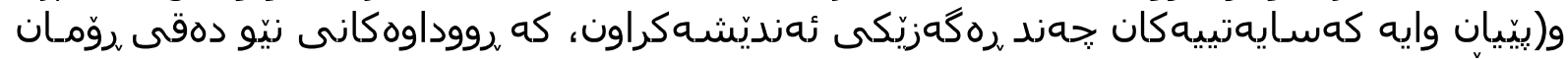

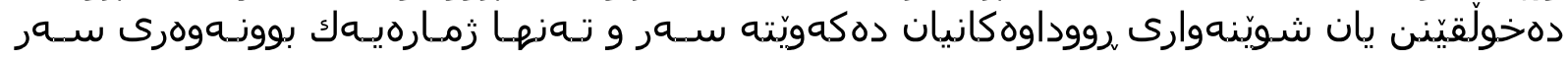

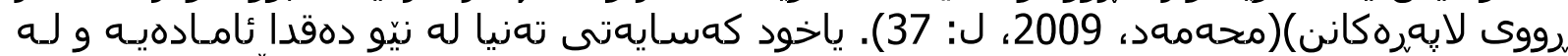

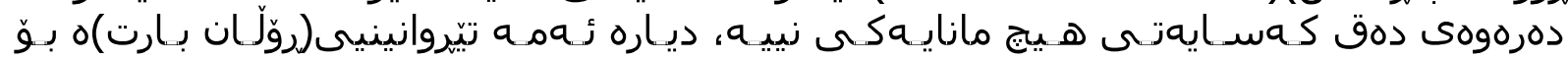

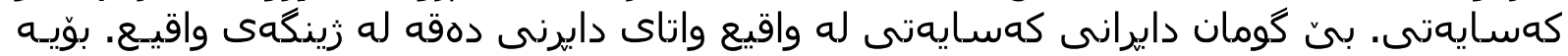

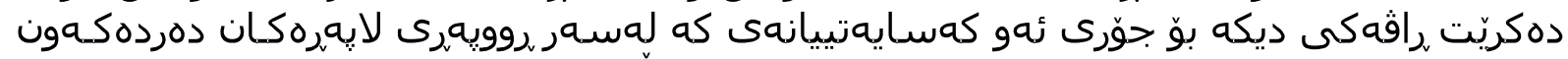

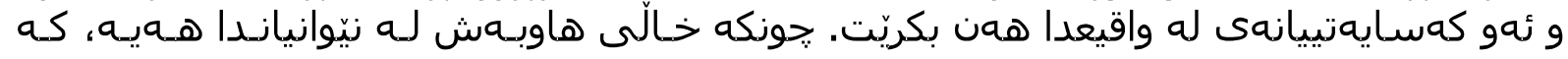

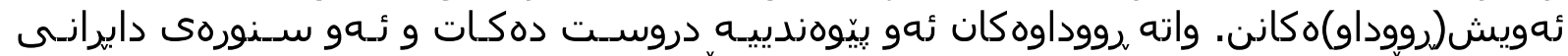

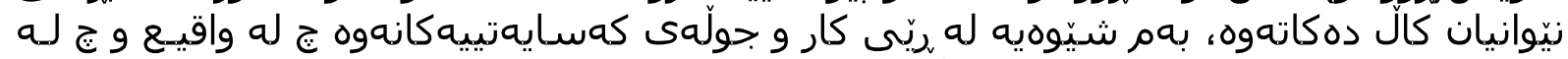

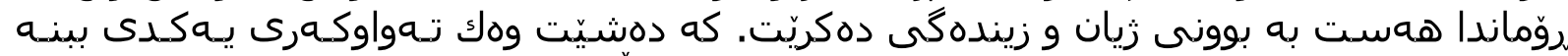

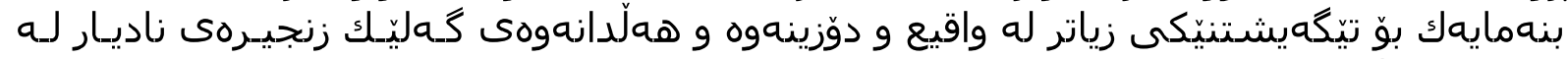

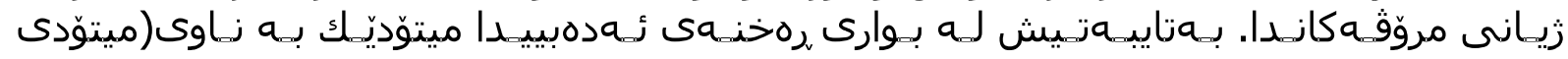

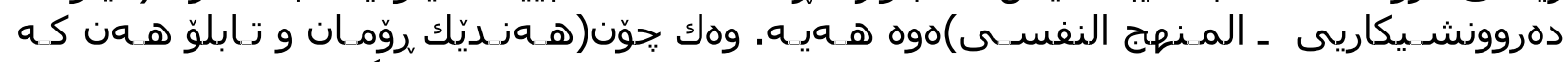

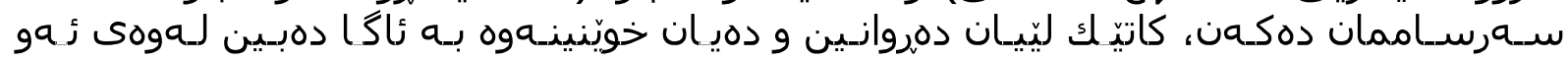

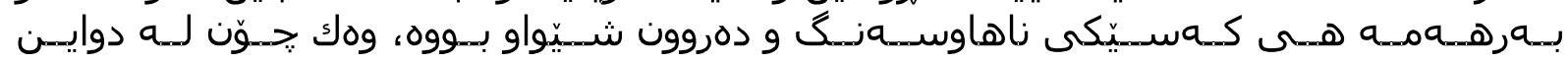

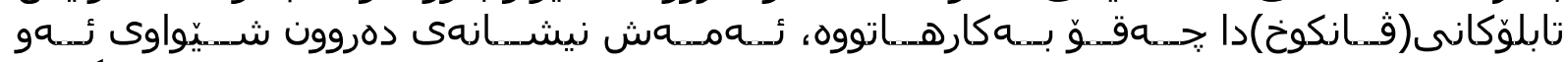

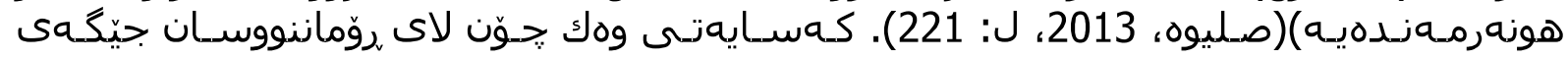

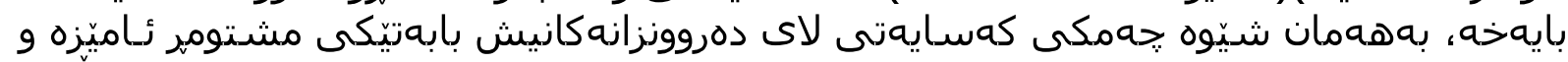

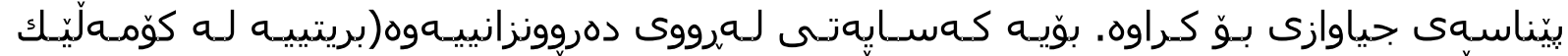

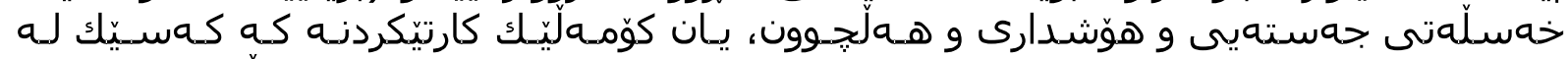

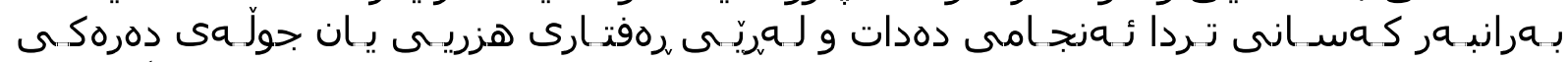

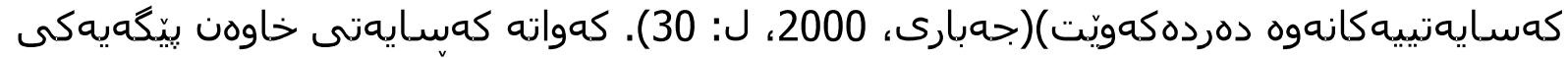

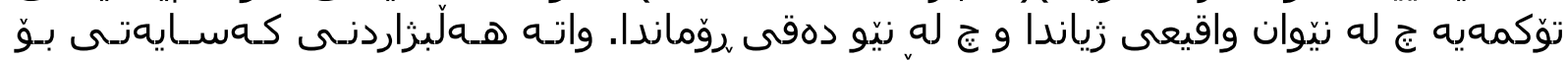

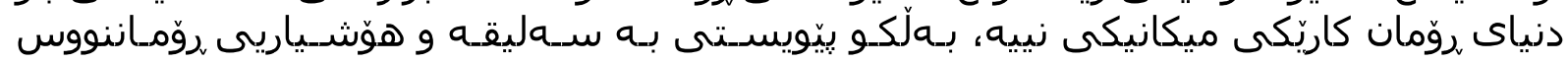

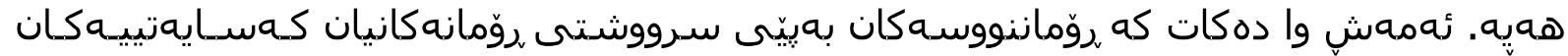

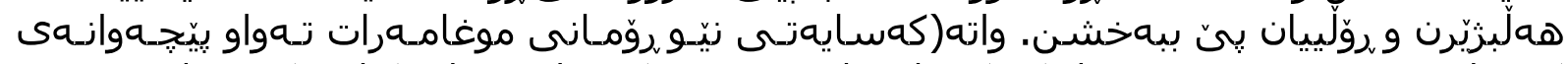

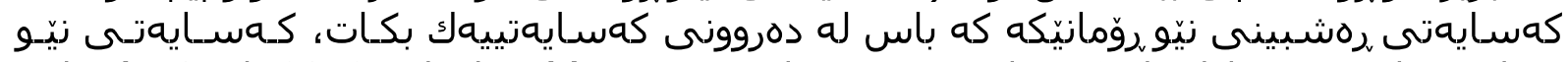

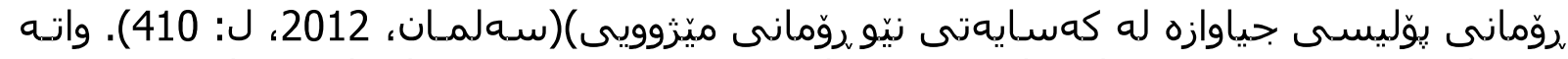

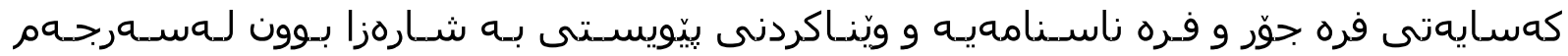

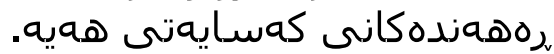

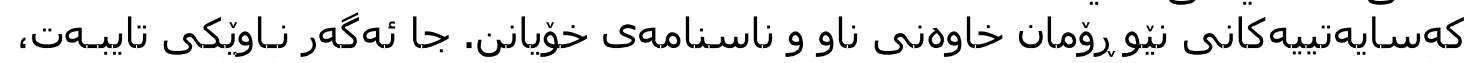

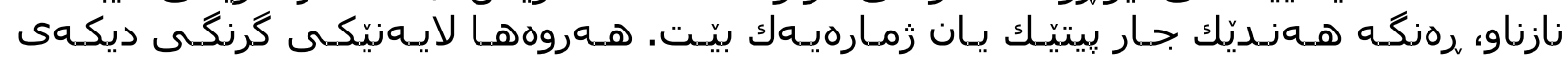

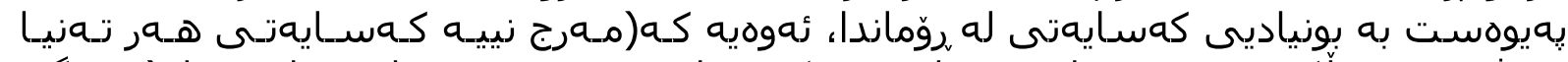

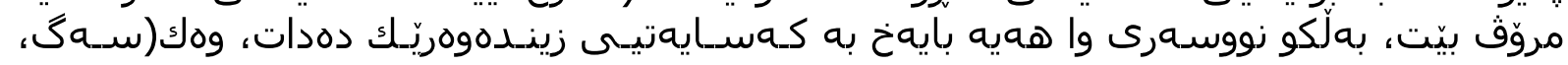




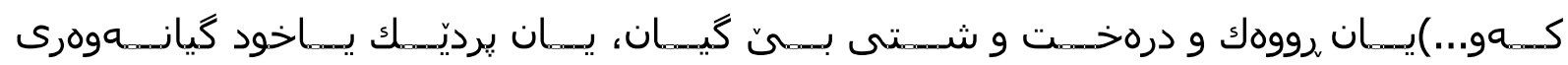

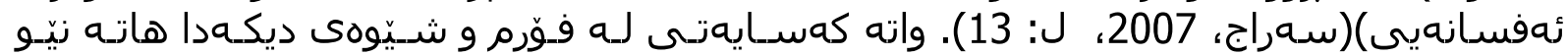

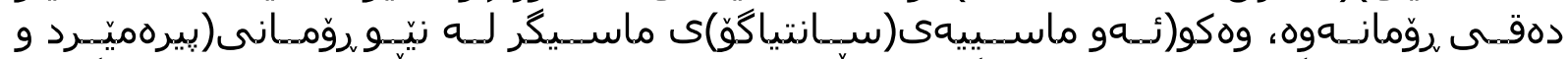

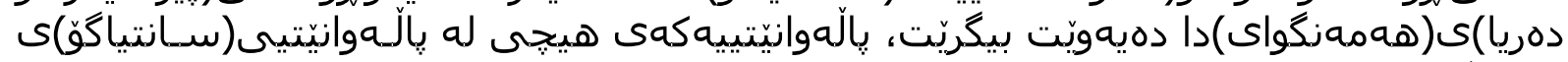

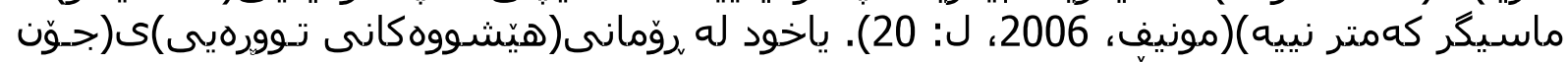

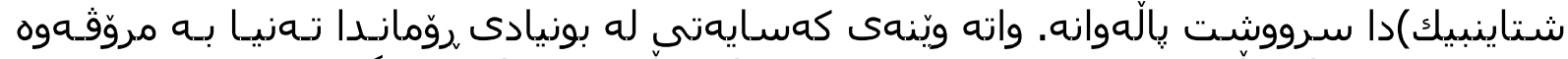

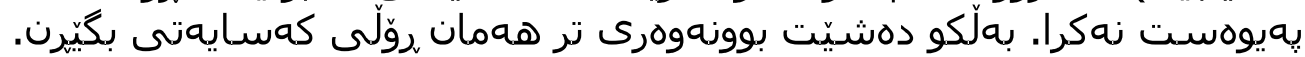

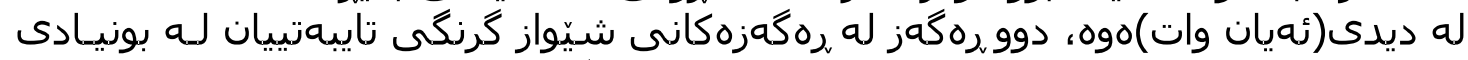

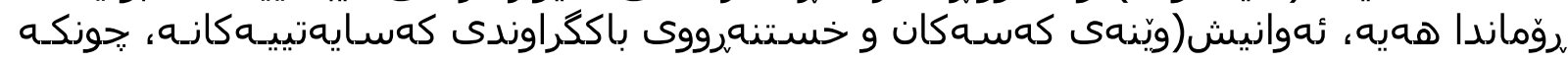

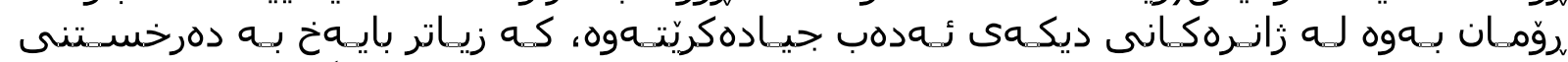

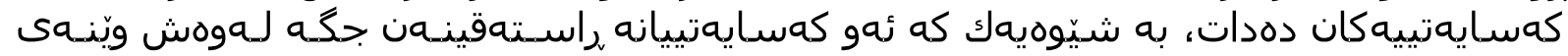

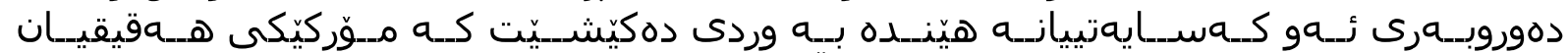

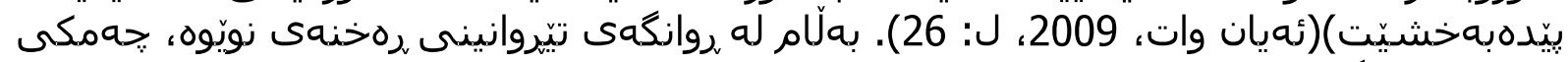

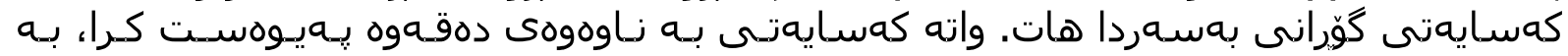

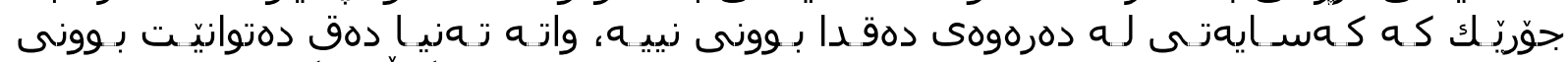

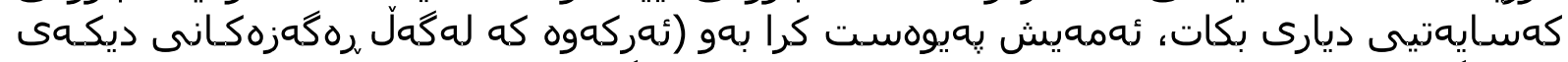

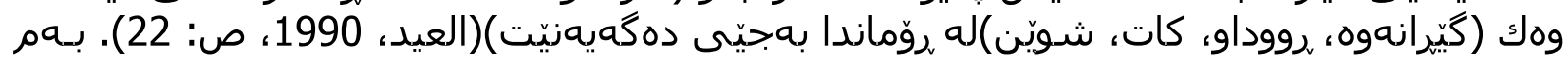

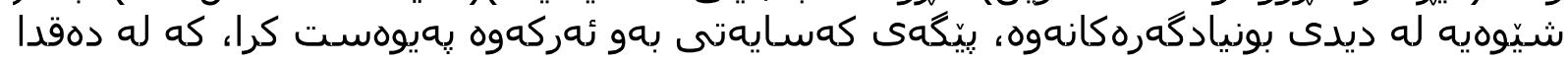

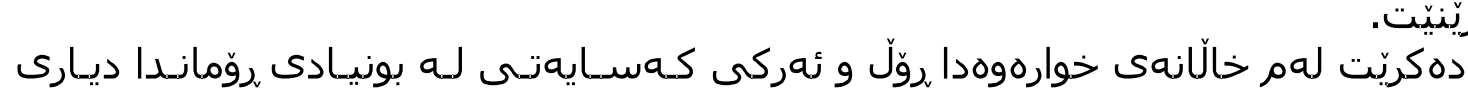

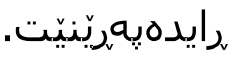

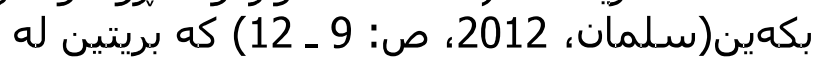

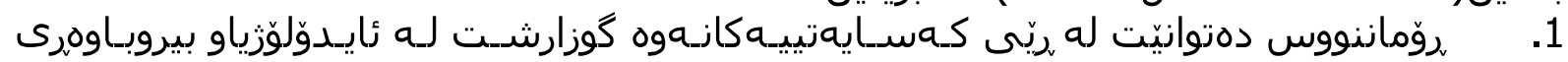
خوّى بكات.

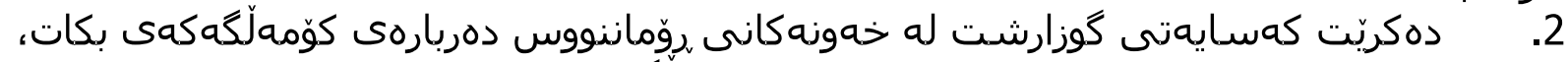

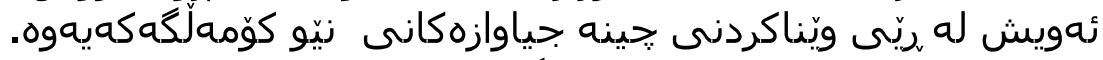

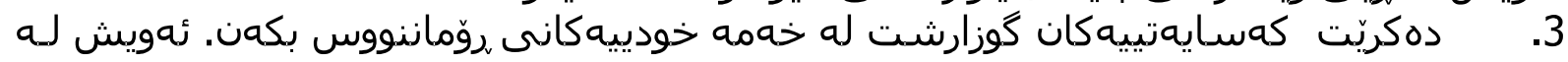

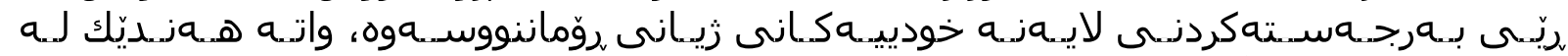

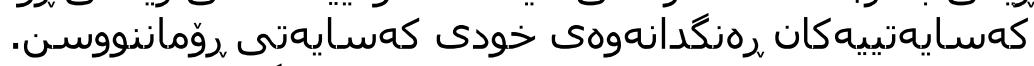

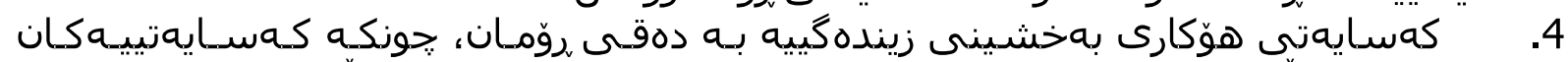

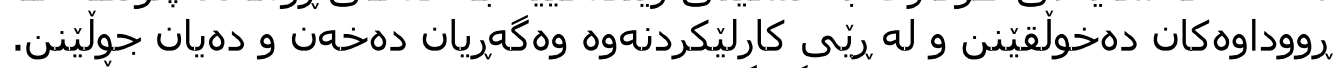
5.

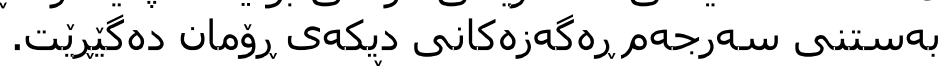

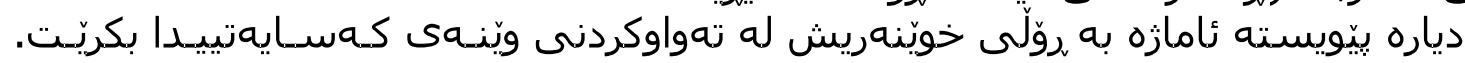

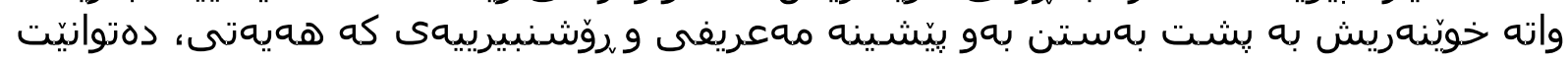

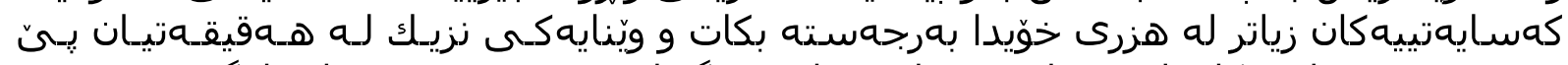

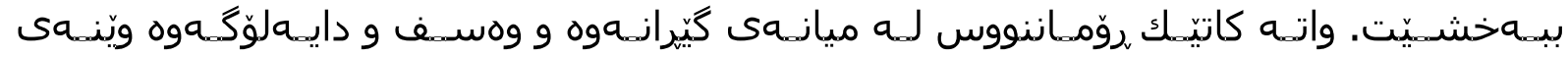

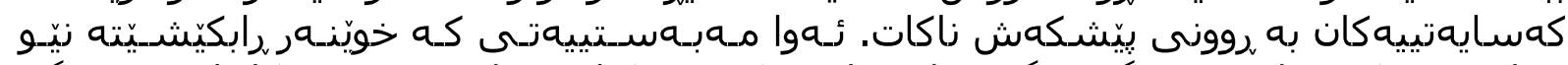

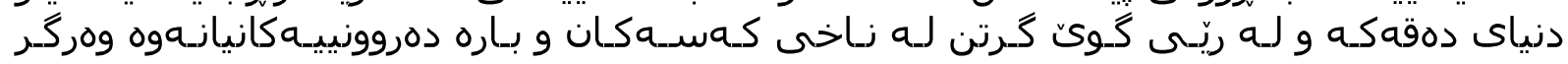

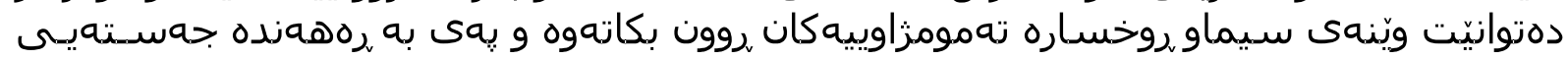

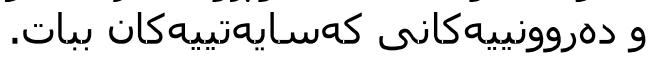

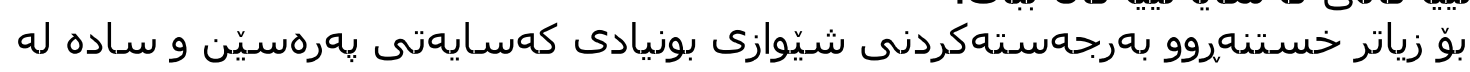
بهشى دووهمدا دهخهينه بهرباس.

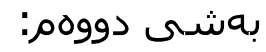

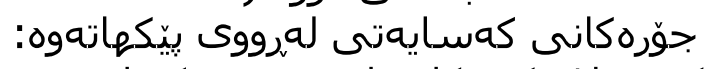

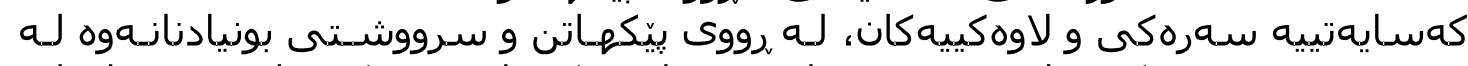

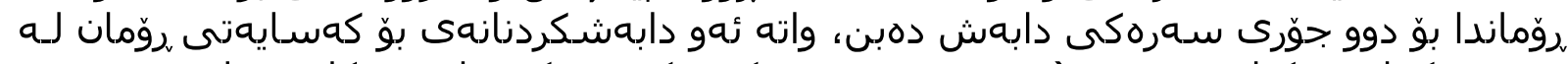

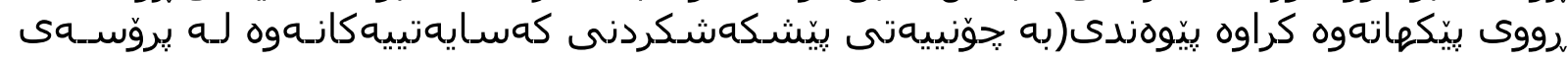

International Journal of Kurdish Studies Vol.5/1 ( January 2019) 


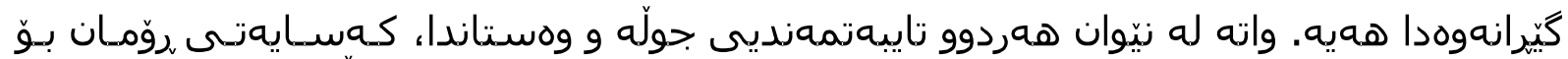

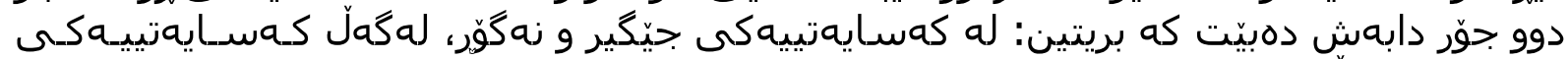

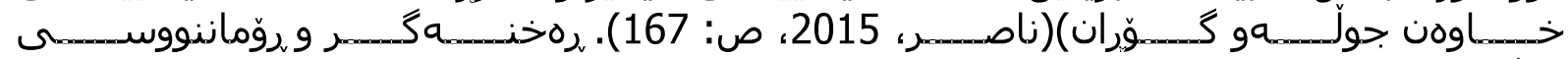

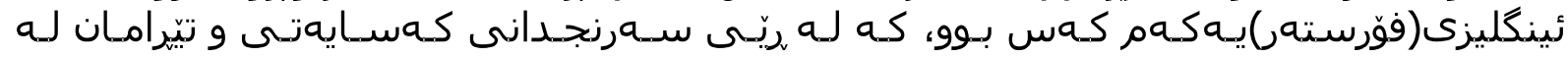

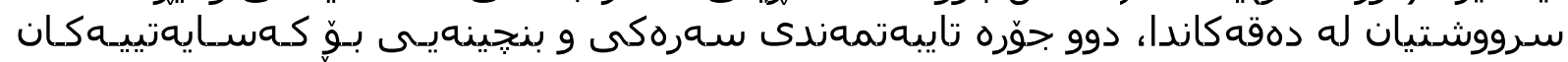

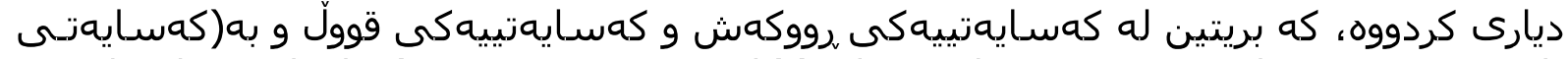

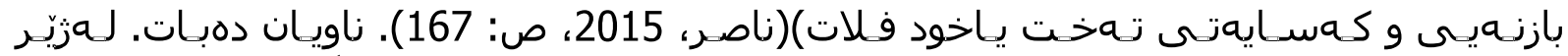

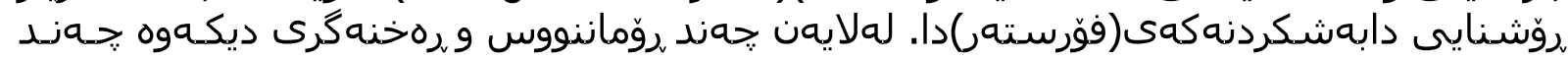

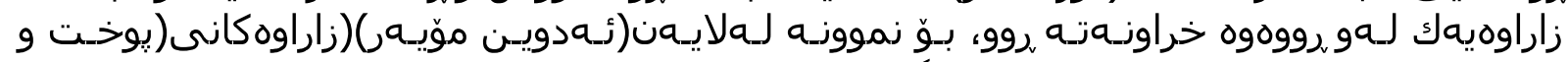

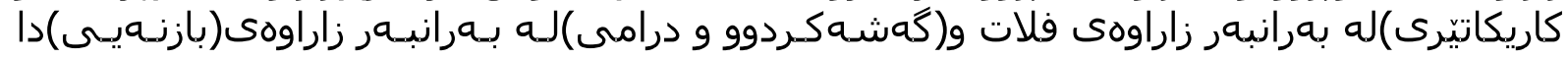

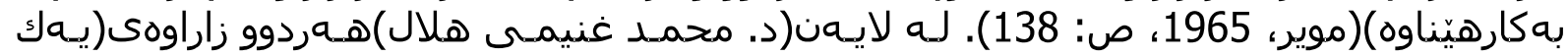

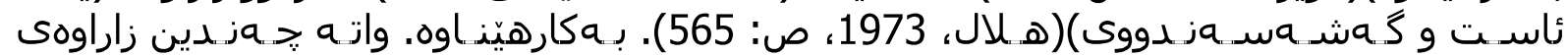

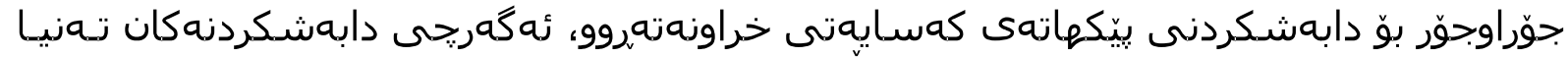

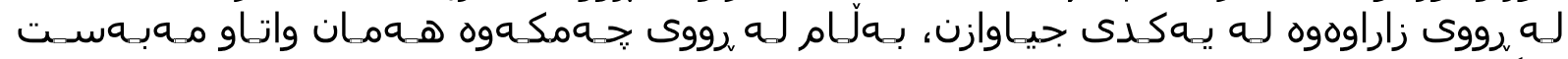

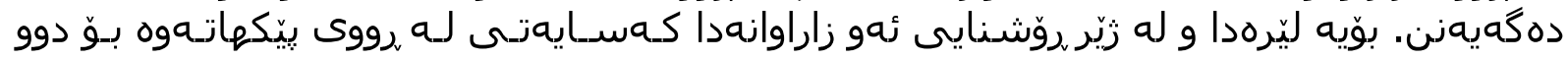

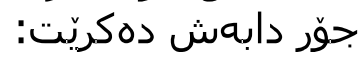
1

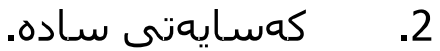

كaسايaتى بِaرهسيّن: .1

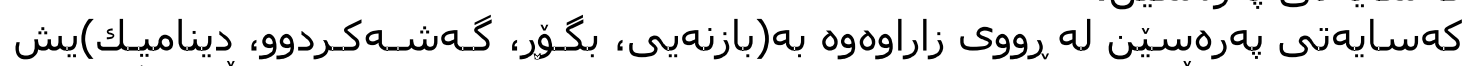

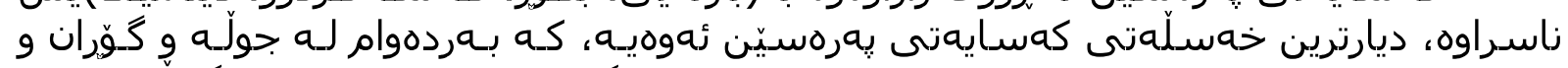

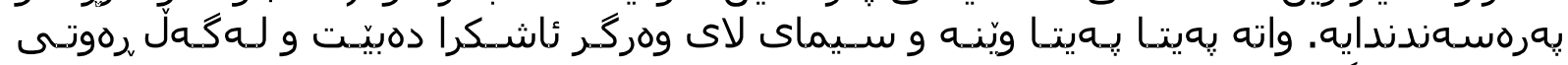

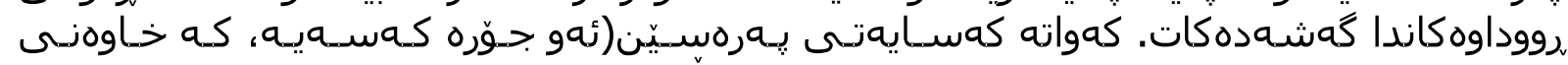

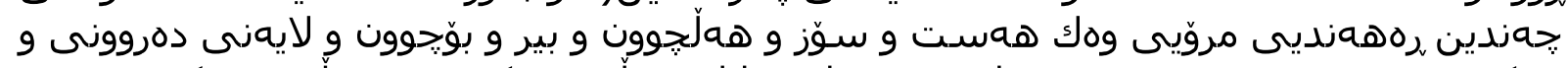

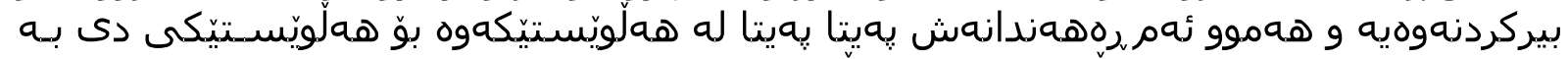

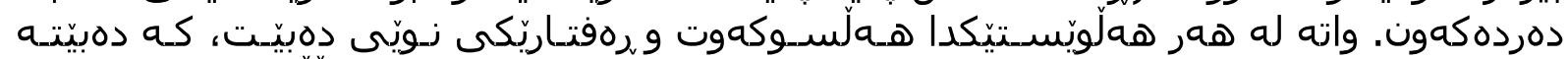

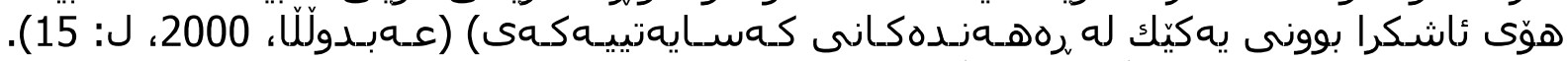

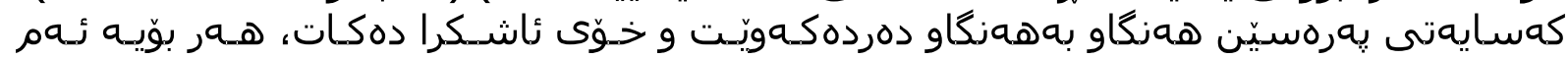

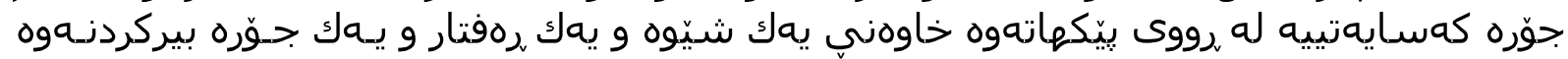

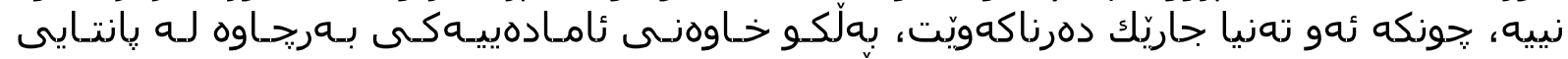

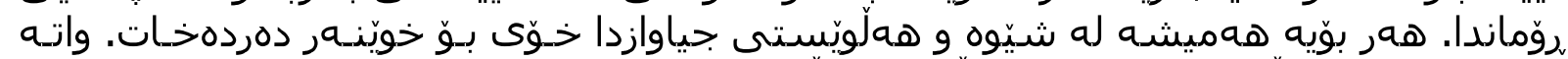

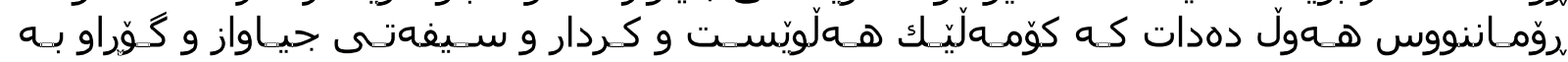

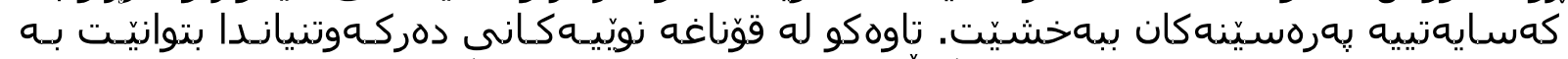

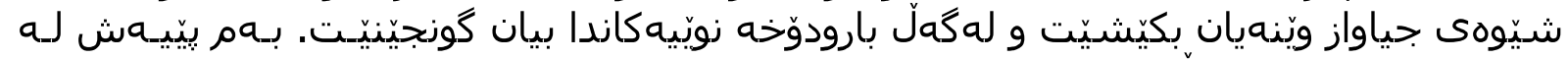

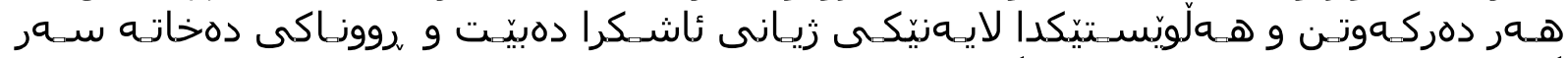

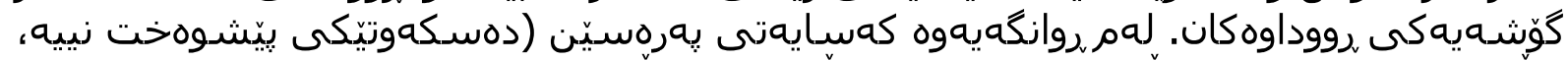

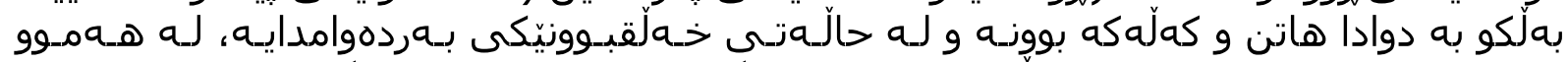

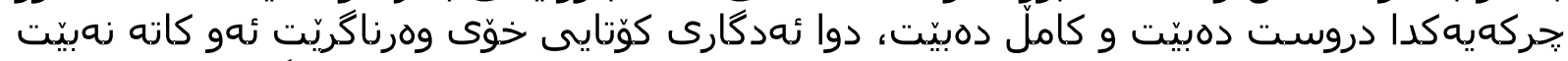

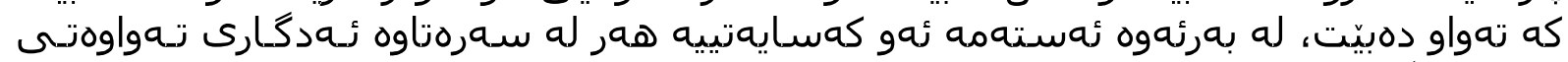

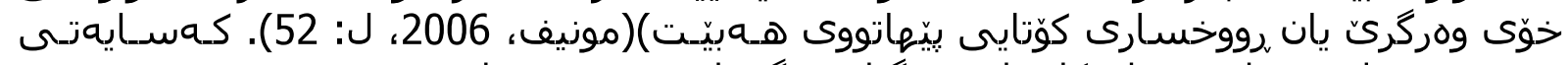

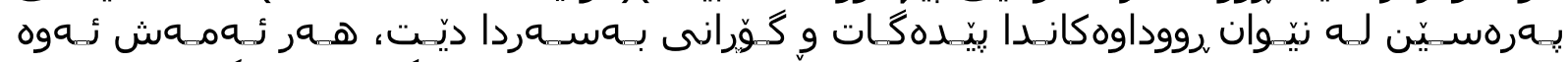

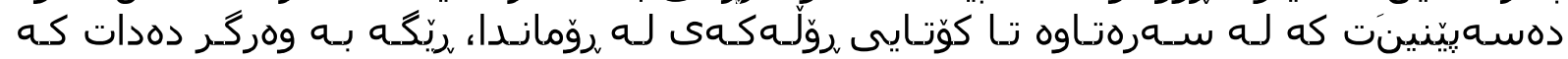

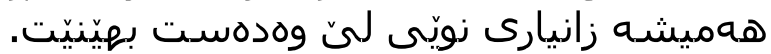

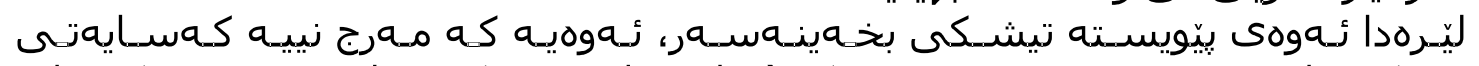

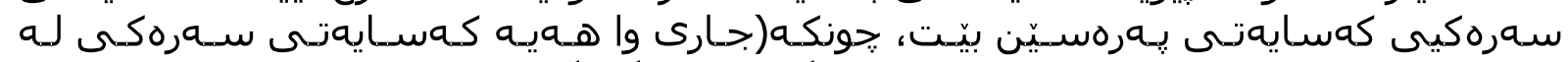

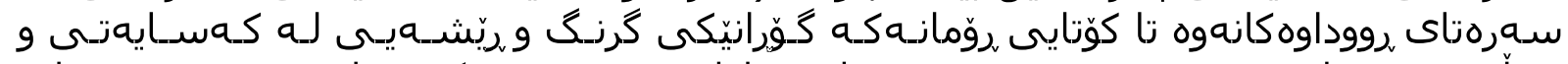

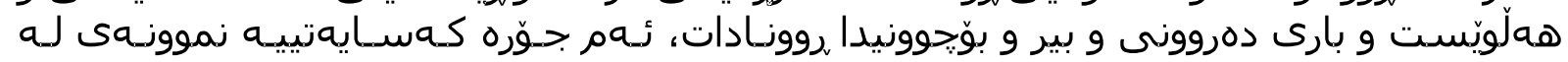




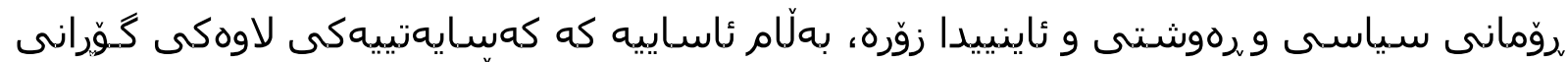

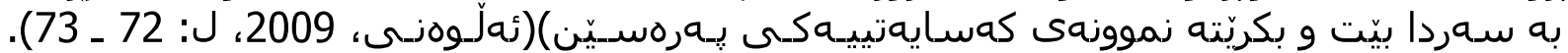

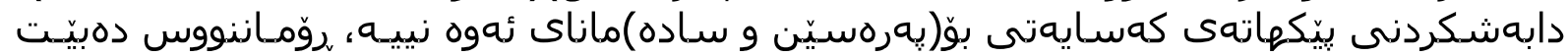

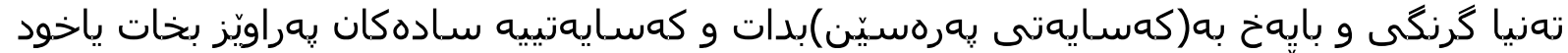

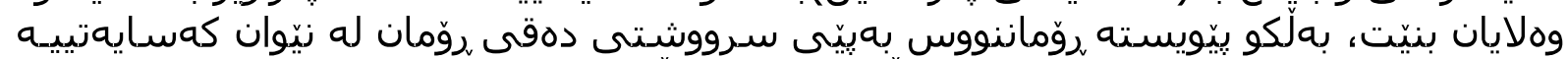

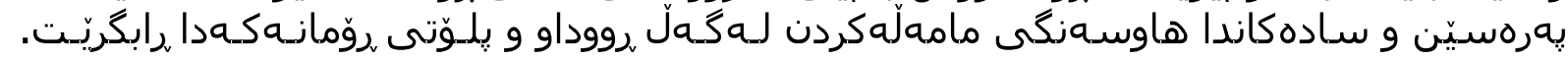

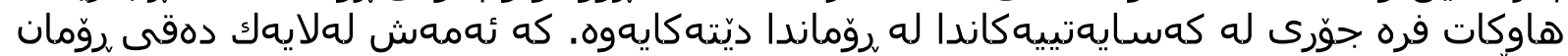

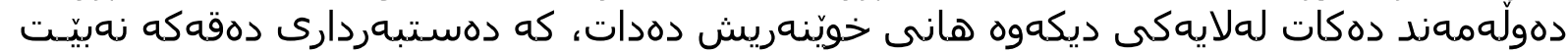

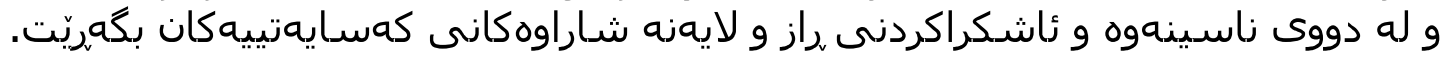

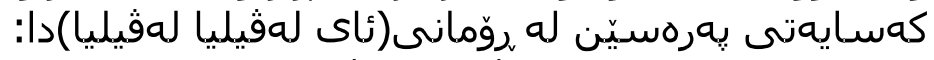

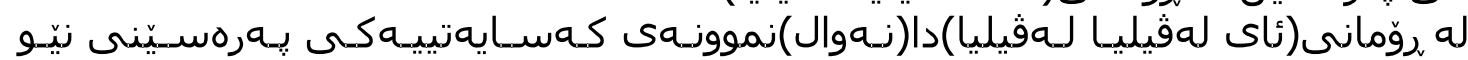

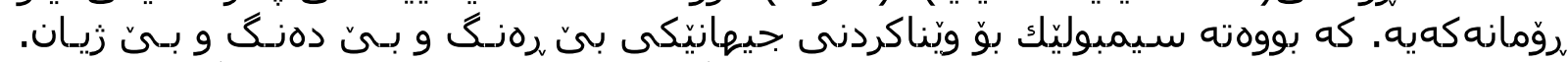

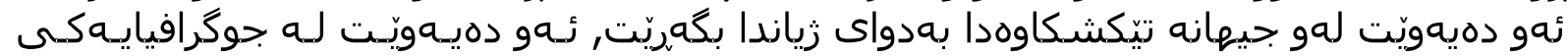

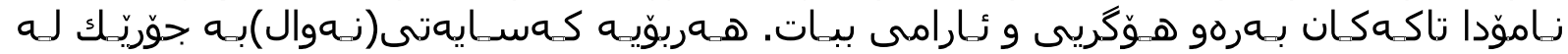

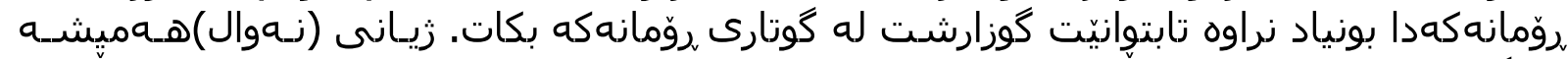

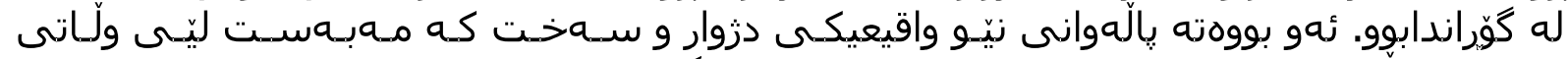

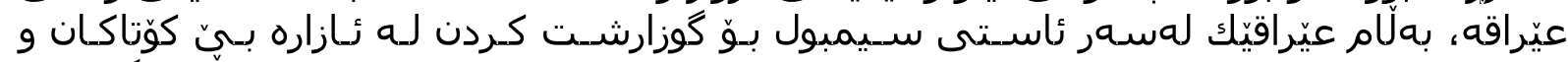

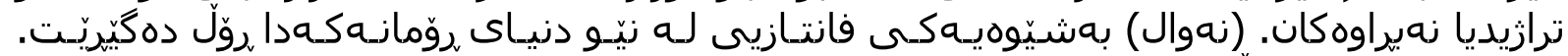

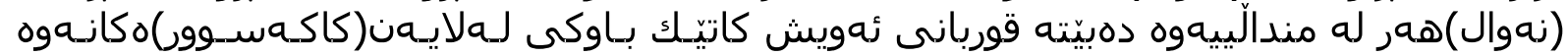

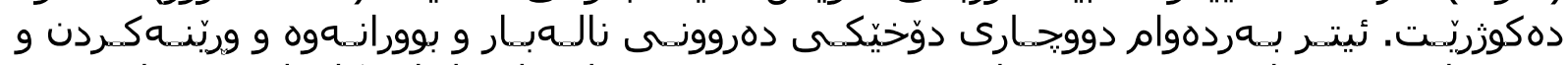

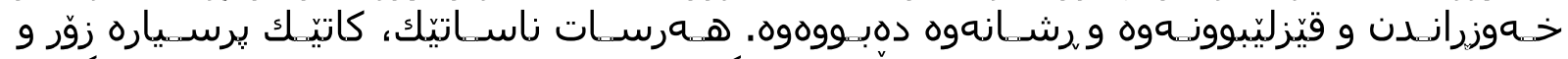

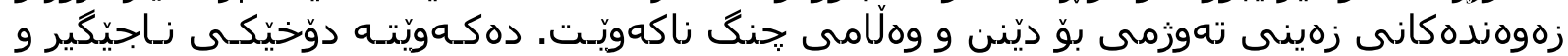

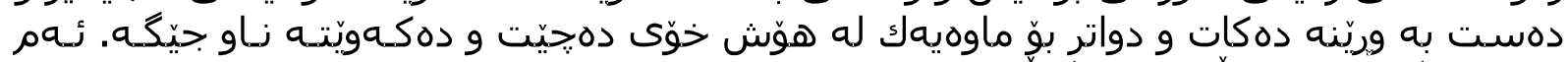

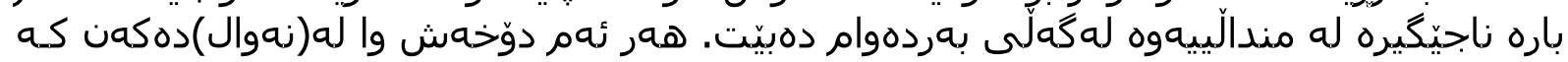

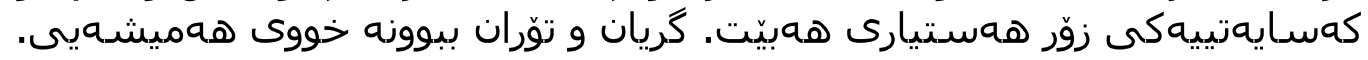

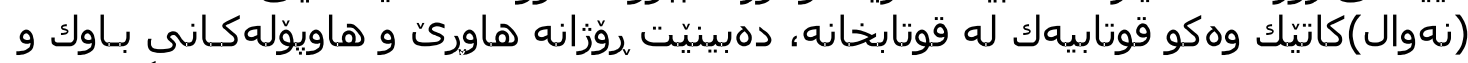

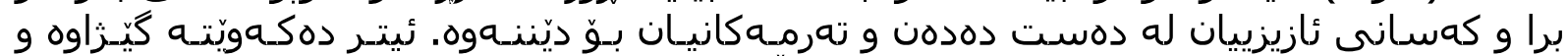

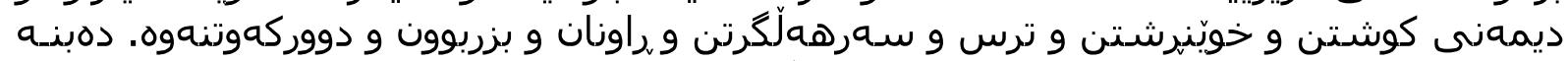

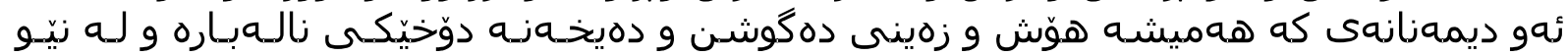

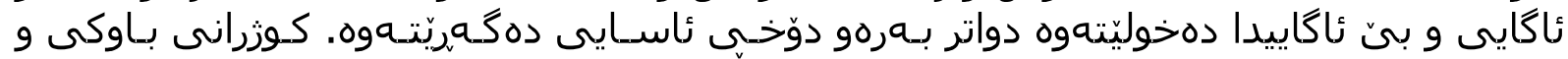

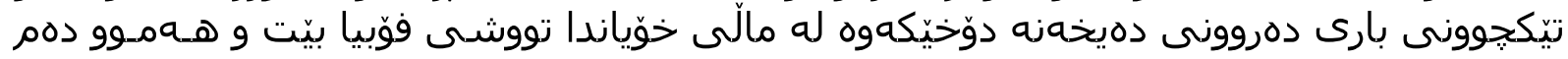

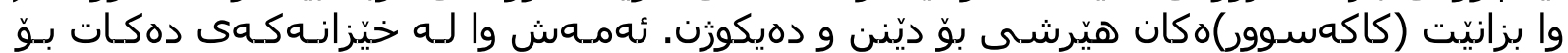

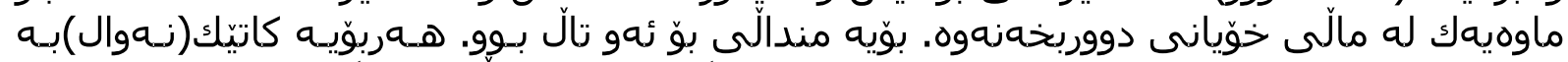

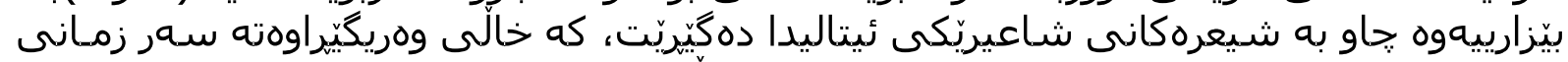

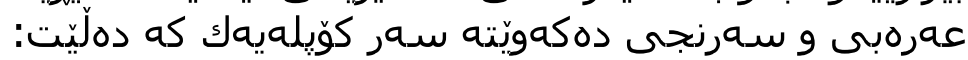

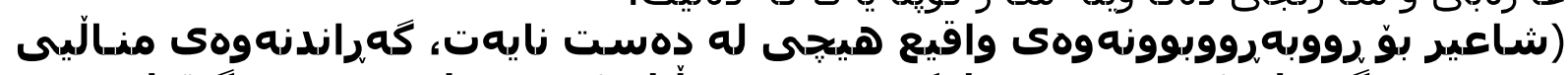

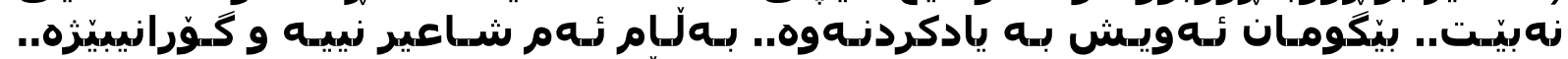

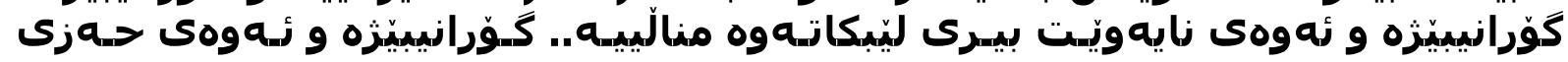

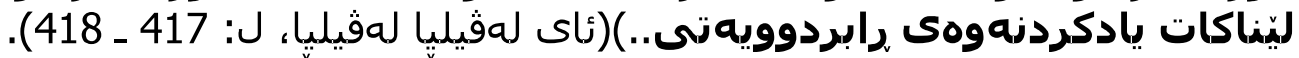

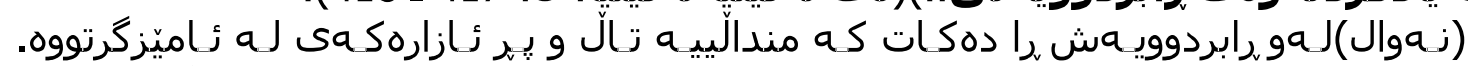

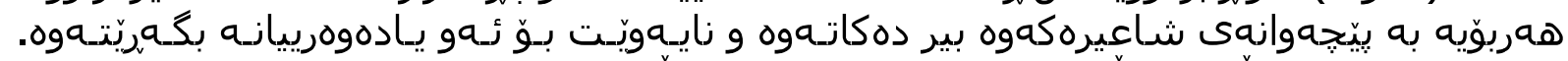

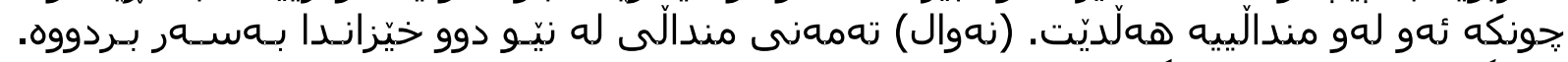

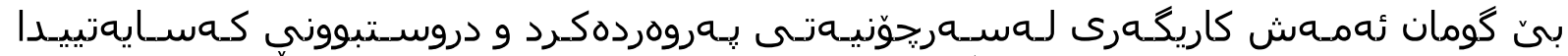

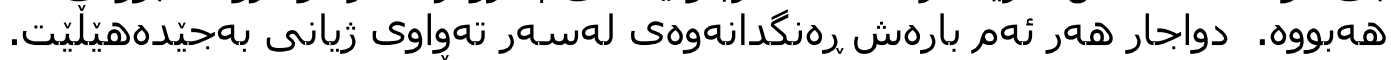

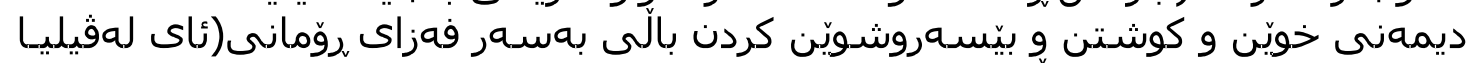

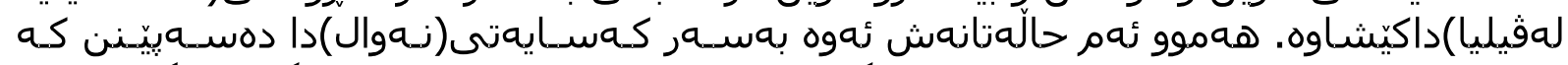

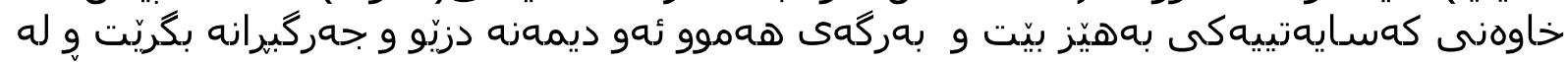

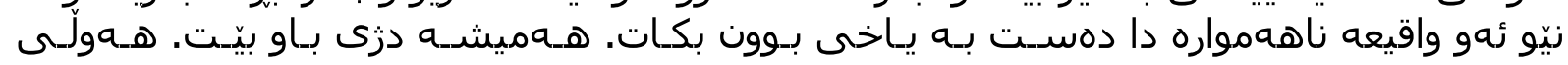




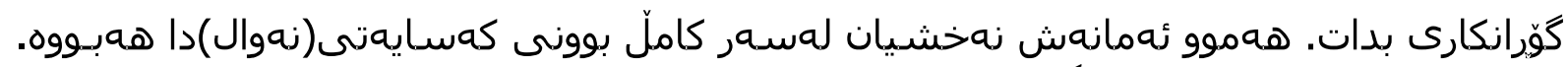

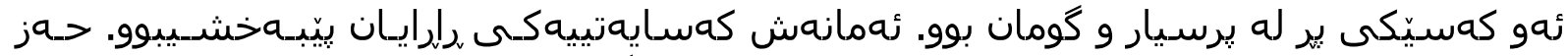

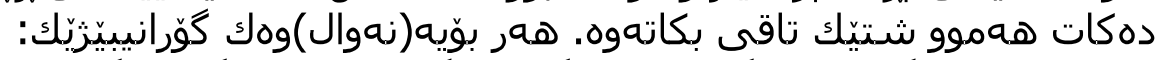

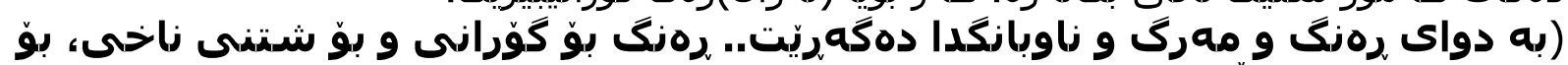
لابردز

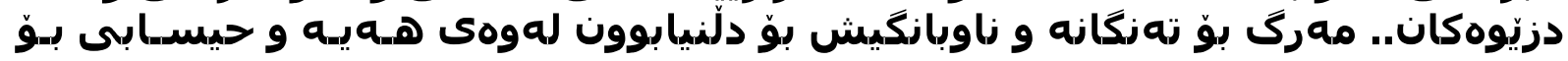

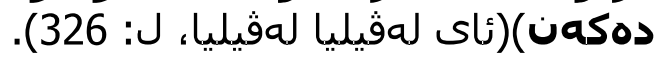

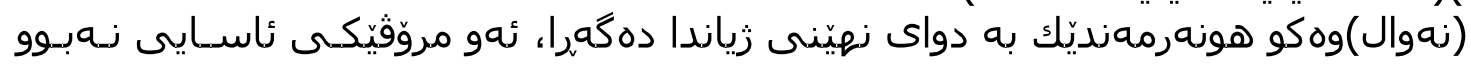

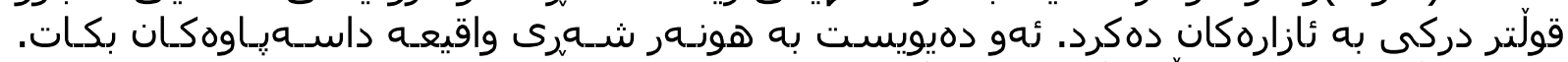

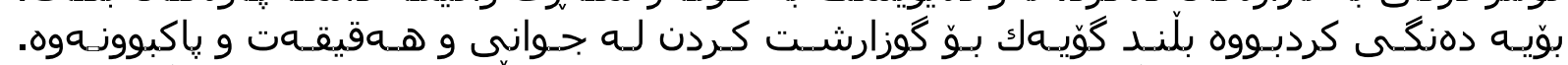

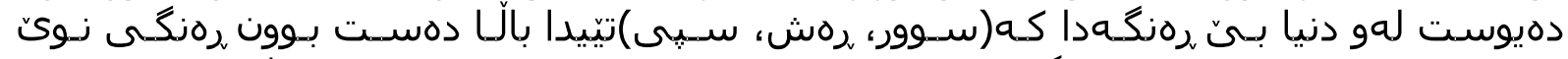

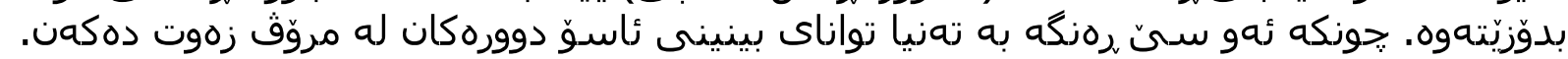

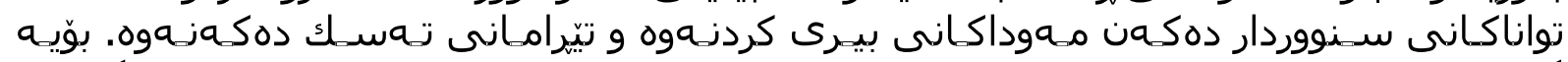

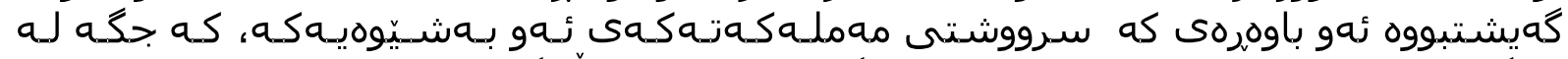

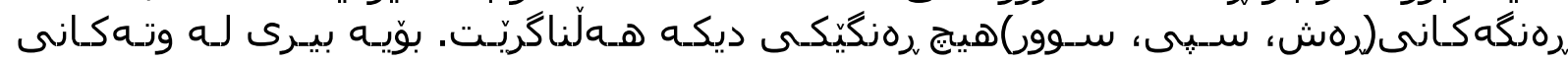

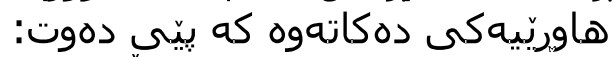

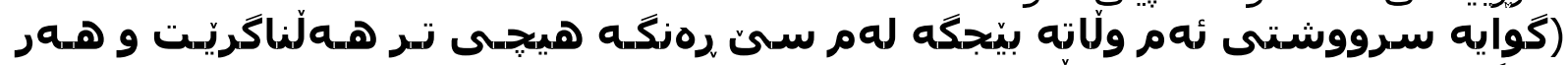

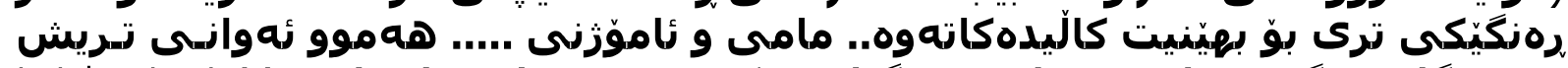

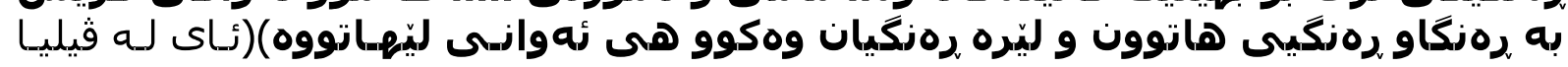

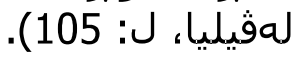

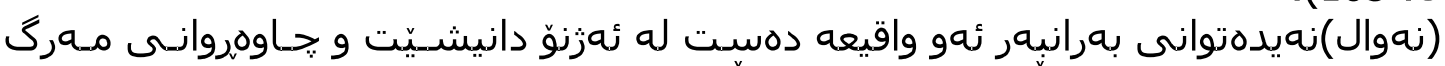

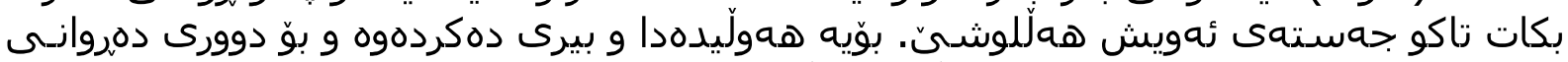

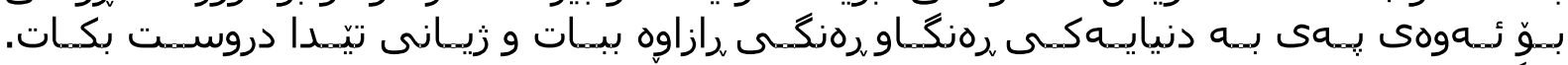

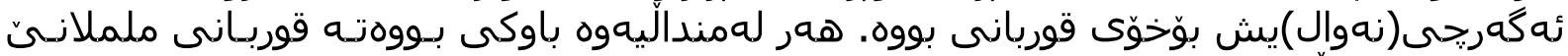

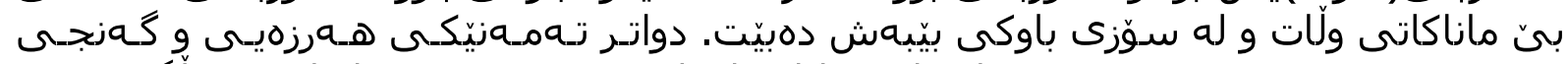

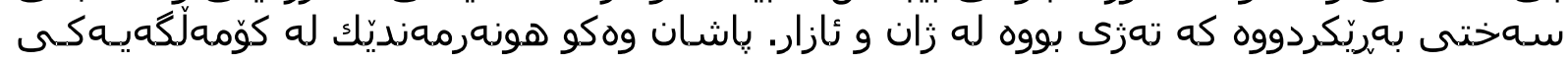

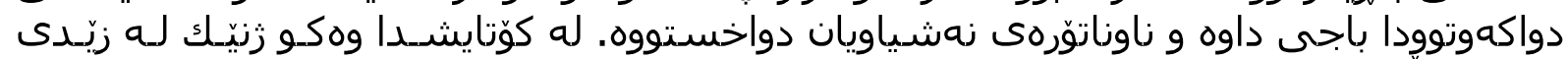

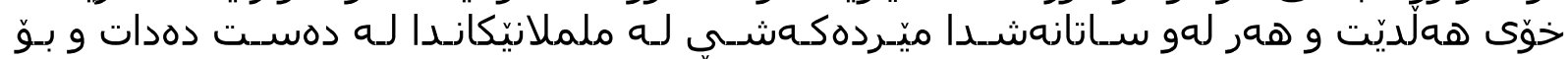

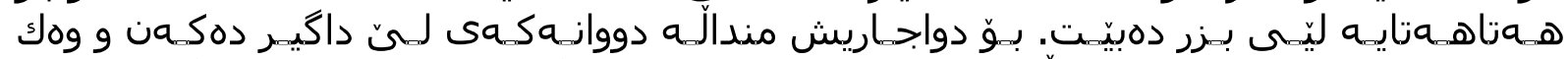

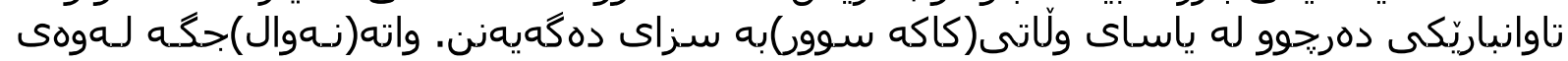

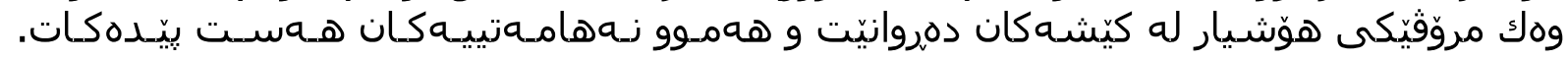

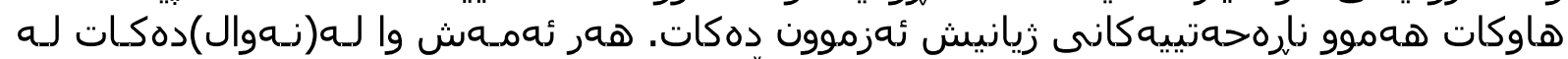

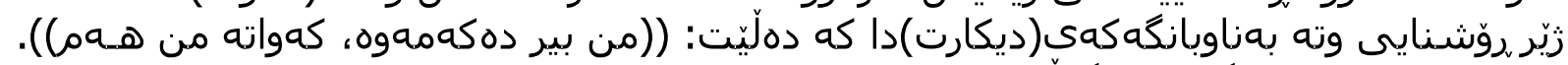

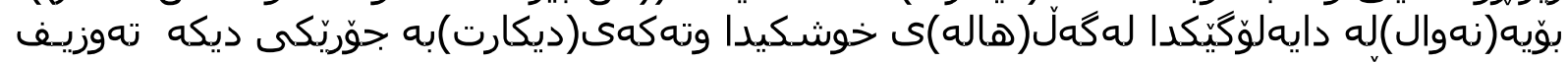
دهوكات و دهلّيّت

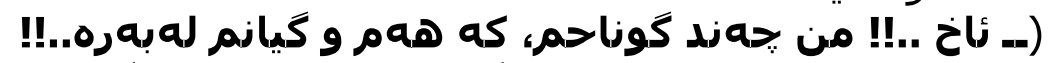

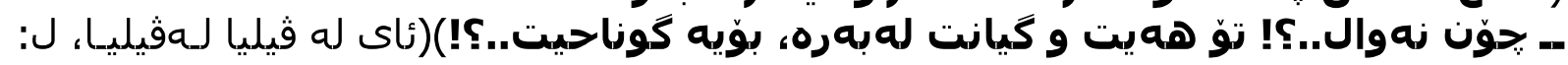

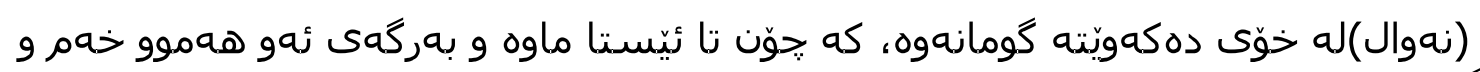

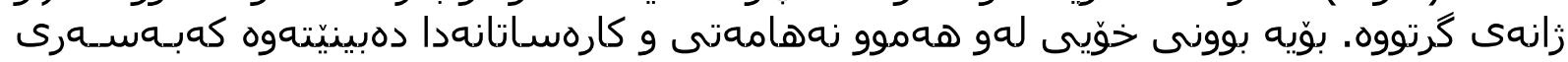

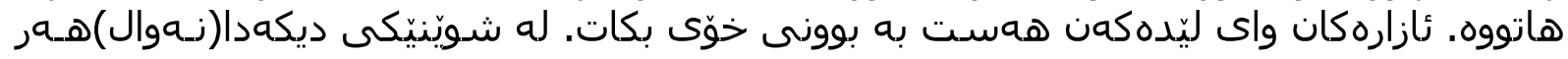

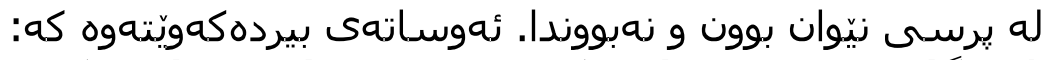

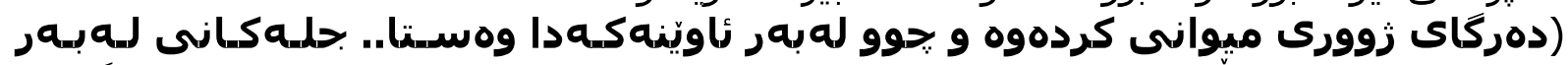

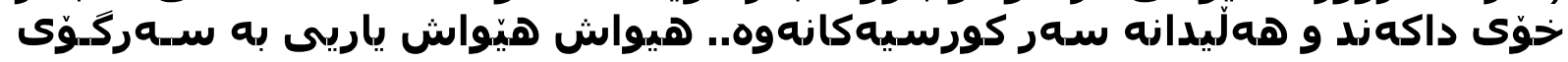

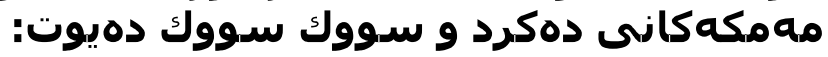

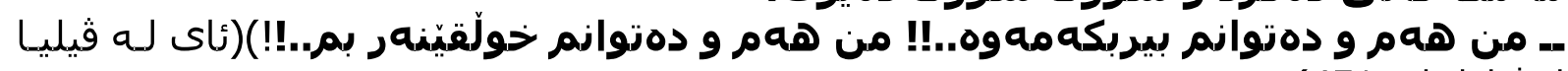
لهقيليا، ل: 451). 


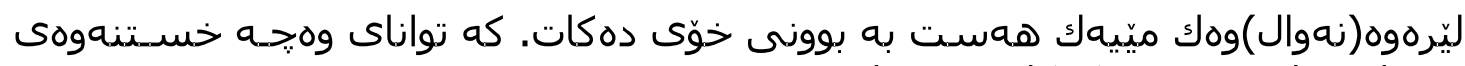

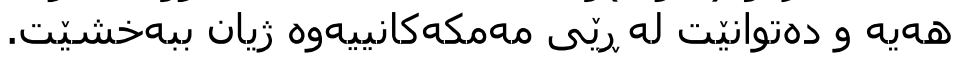

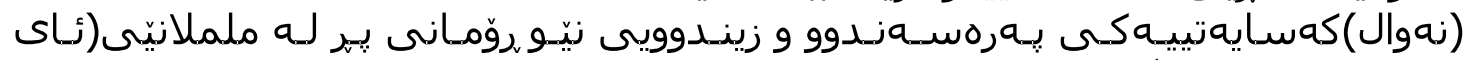

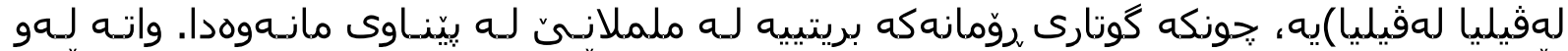

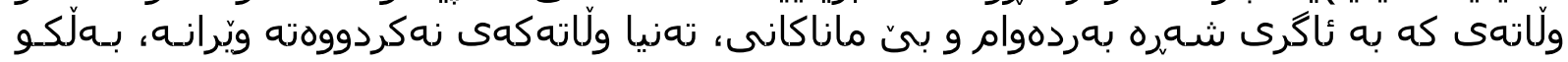

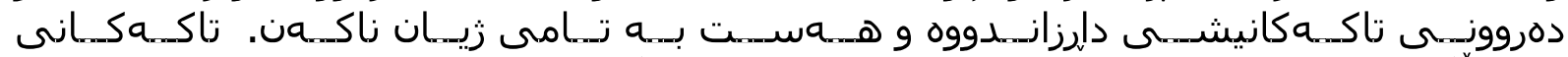

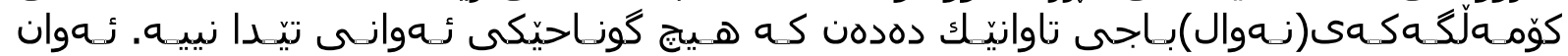

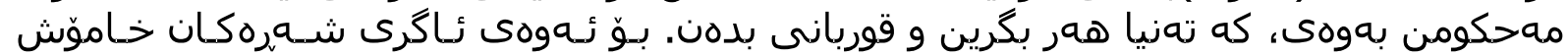

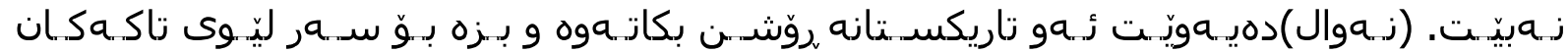

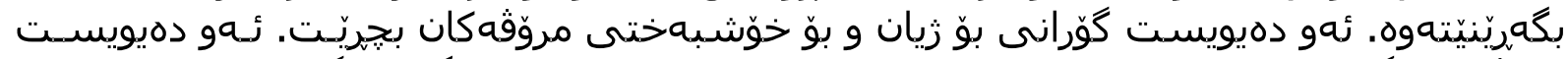

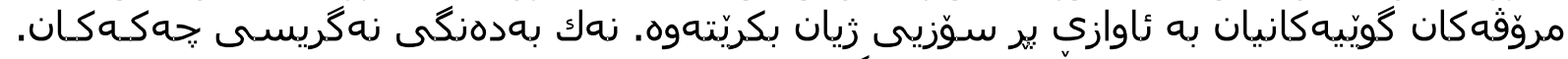

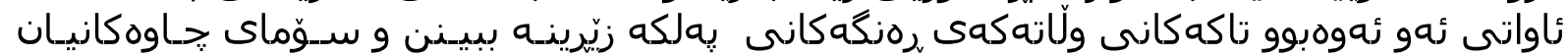

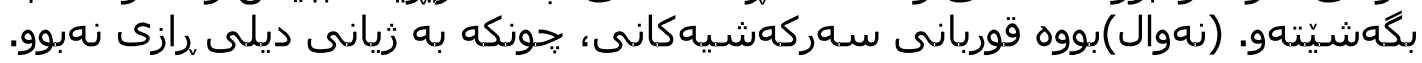

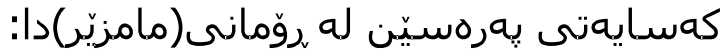

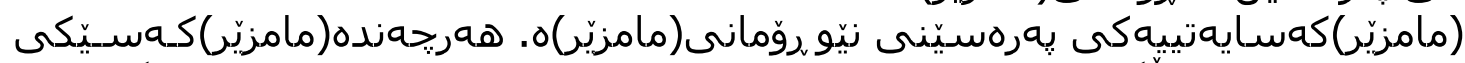

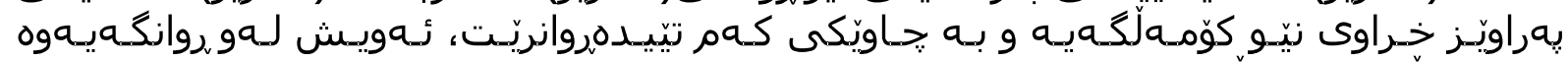

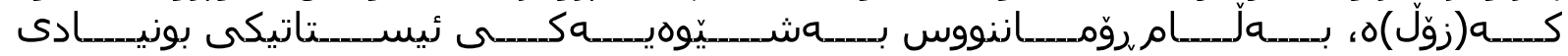

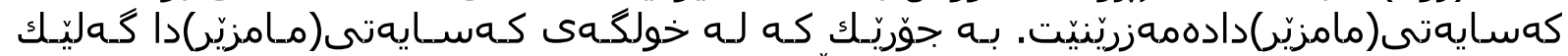

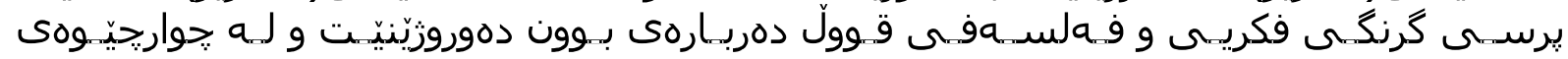

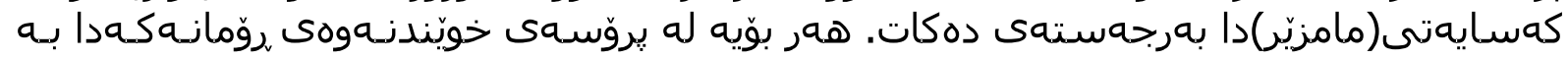

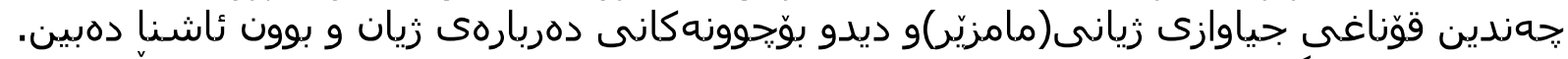

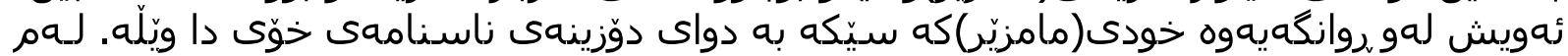

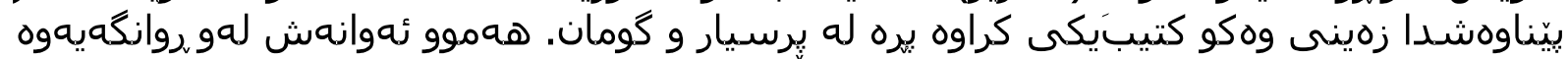

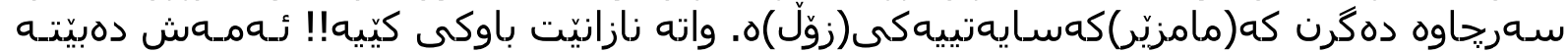

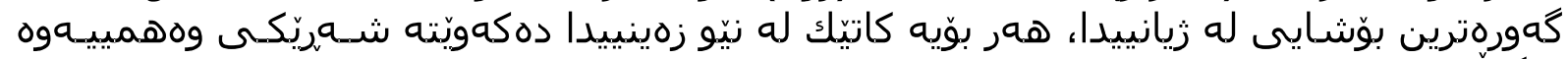

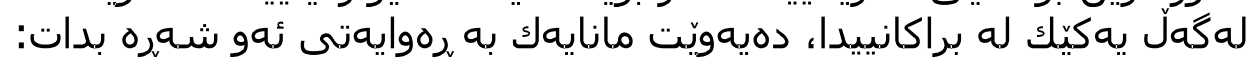

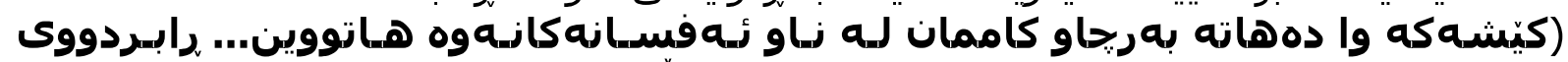

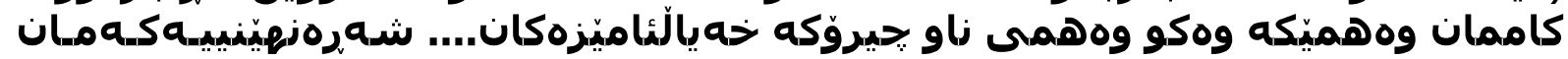

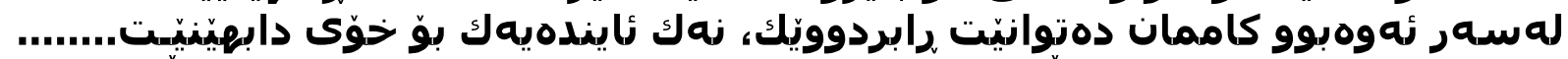

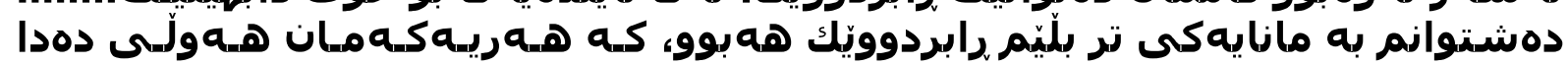

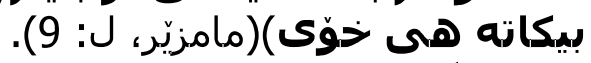

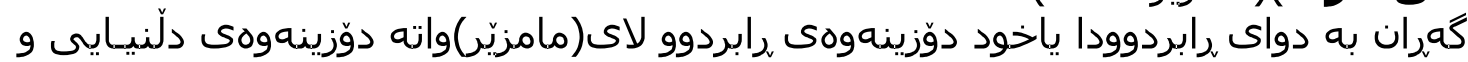

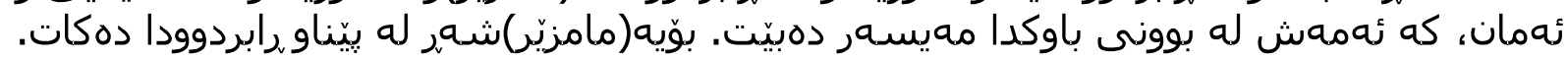

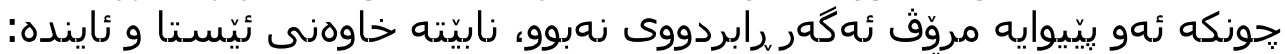

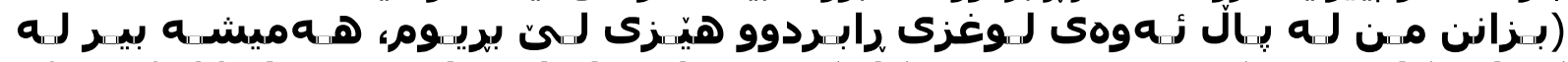

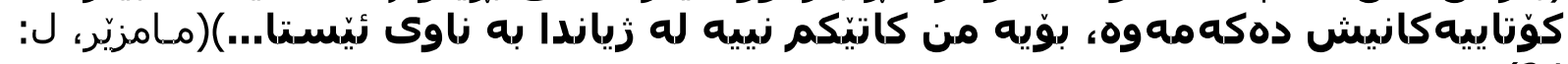

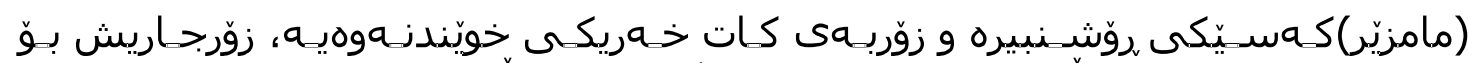

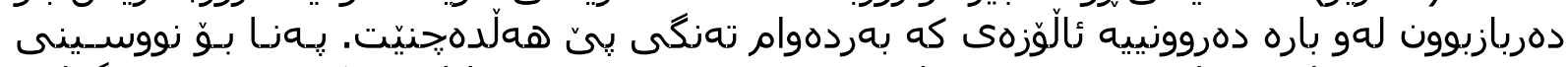

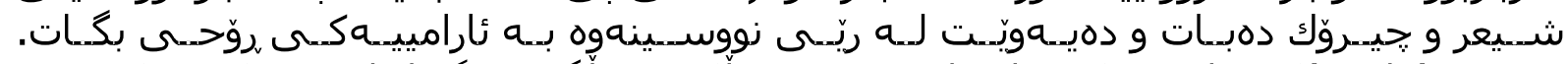

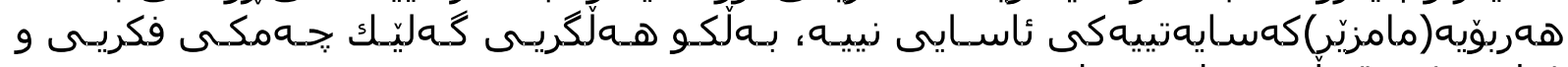

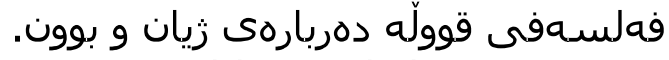

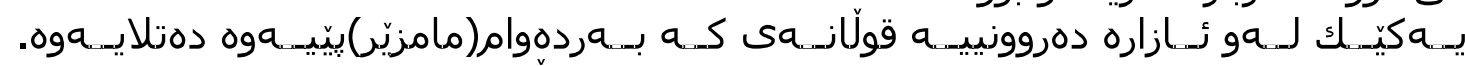

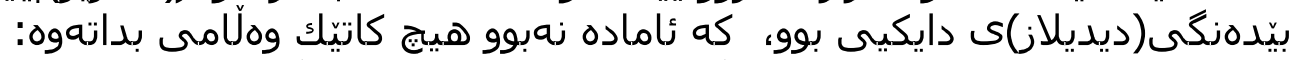

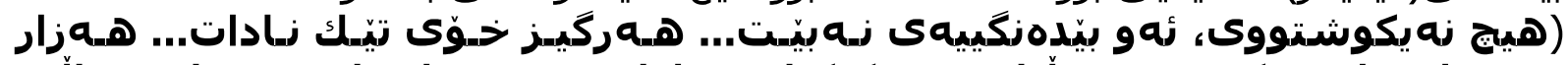

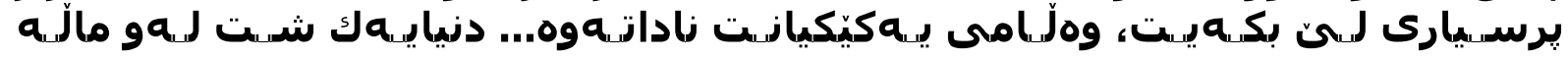

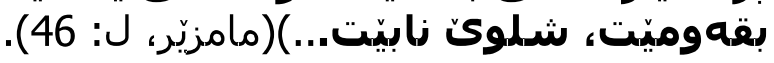




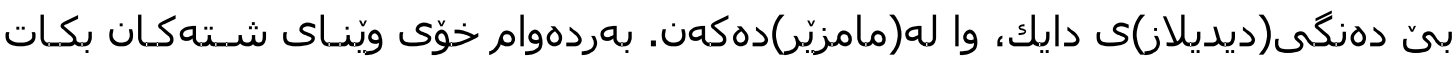

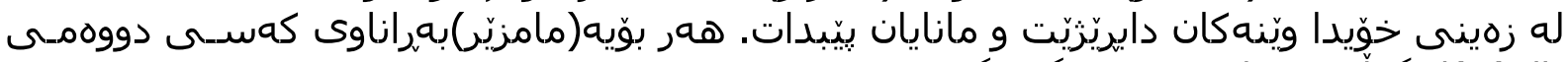

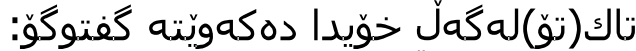

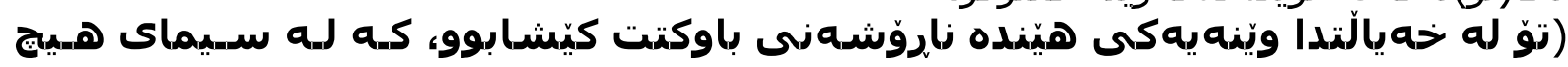

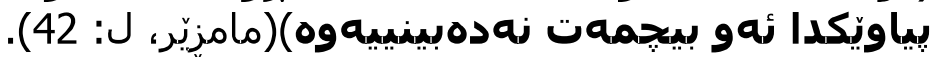

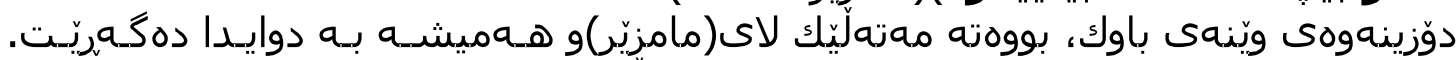

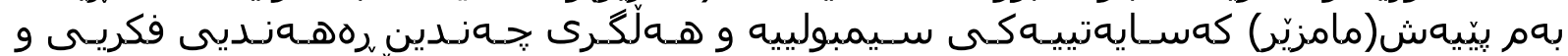

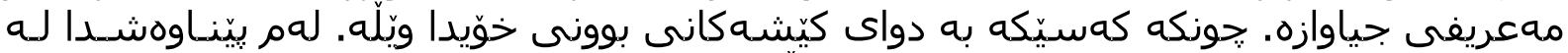

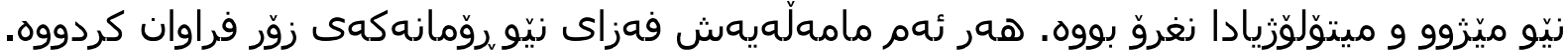

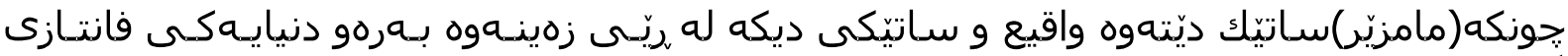

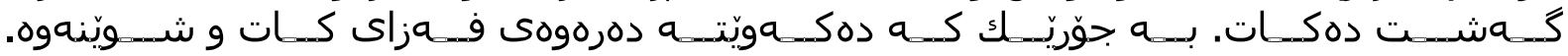

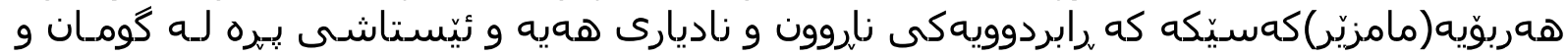

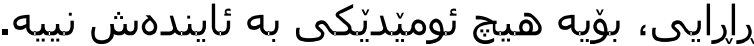

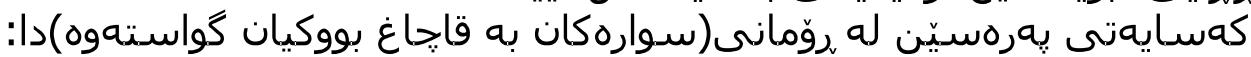

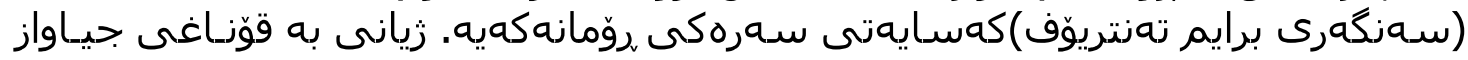

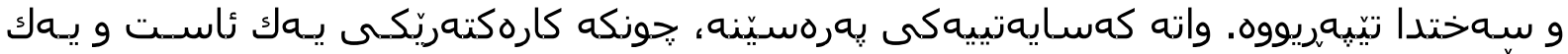

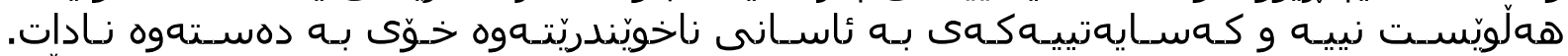

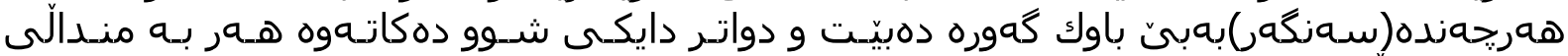

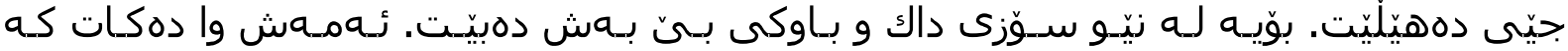

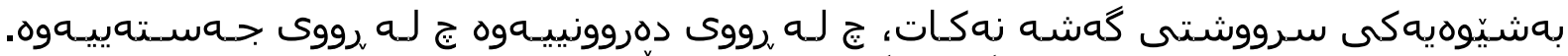

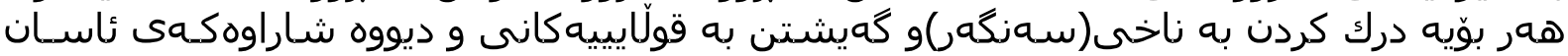

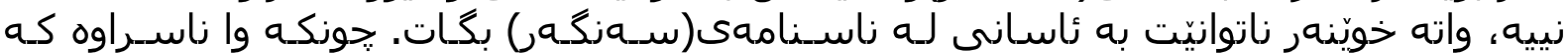

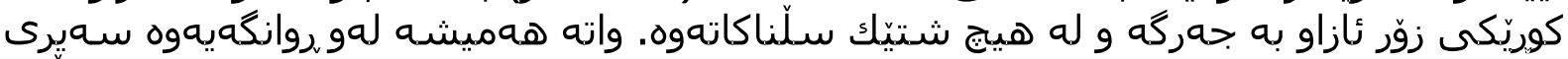

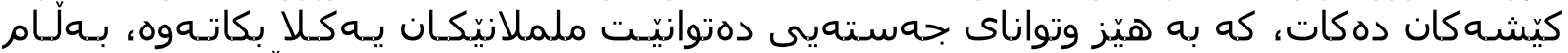

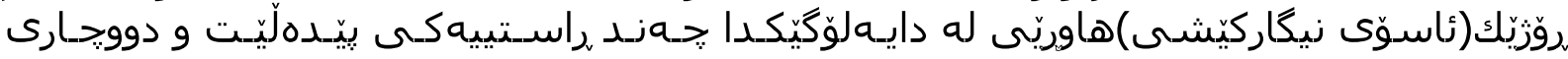
سـوسوورمانى دهوكات:

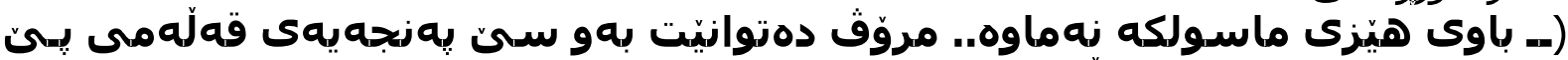

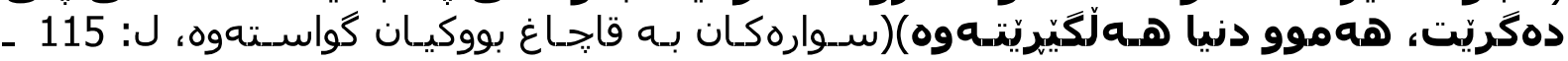

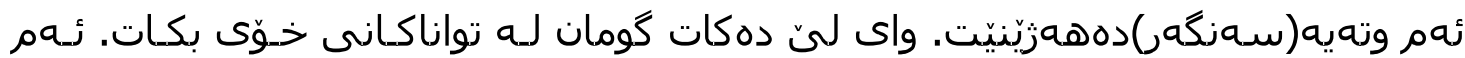

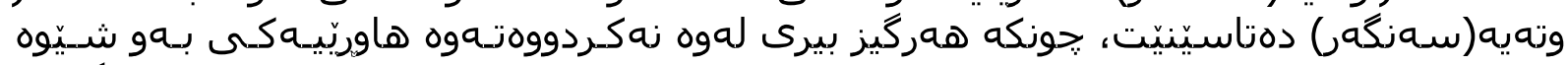

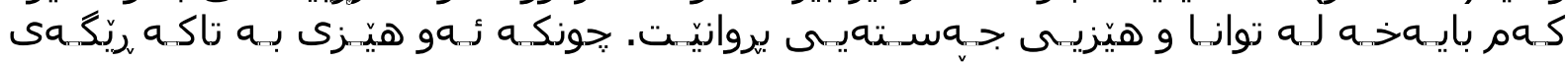

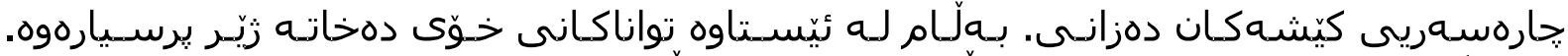

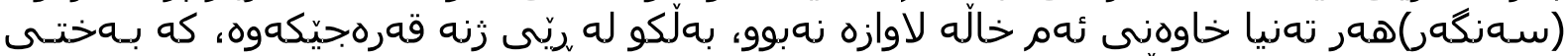

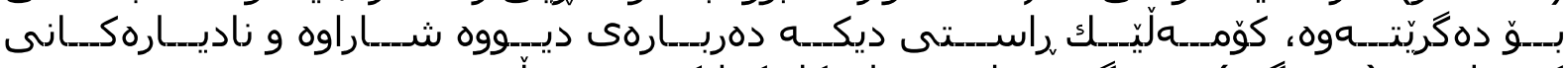

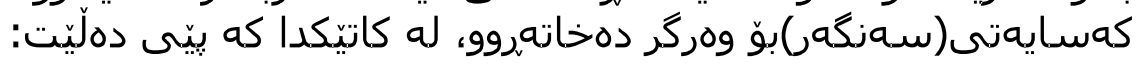

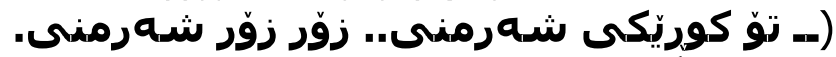

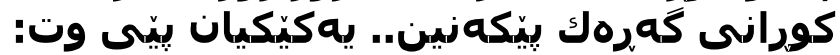

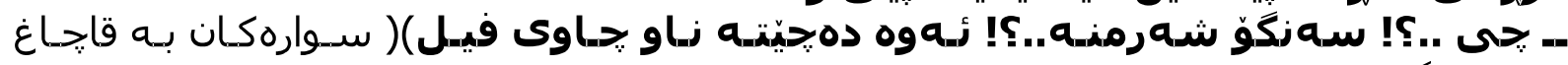

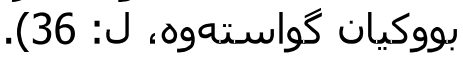

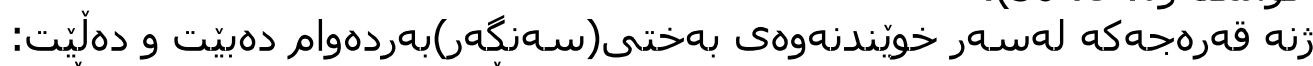

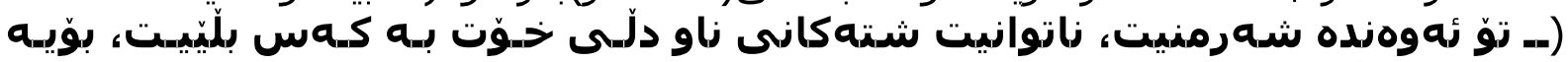

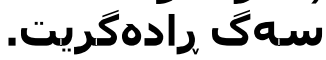

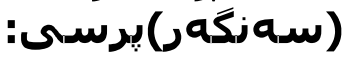

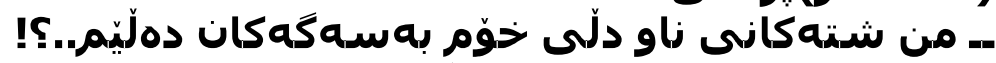

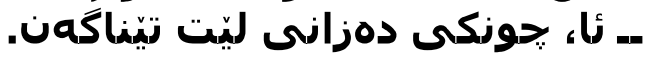

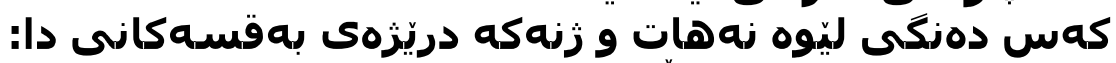

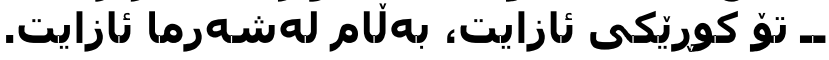




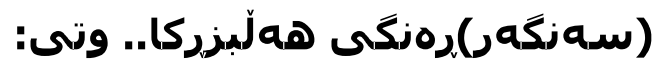

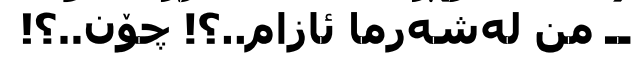

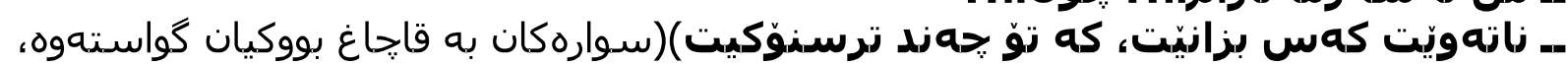

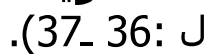

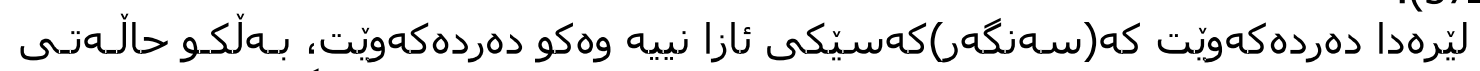

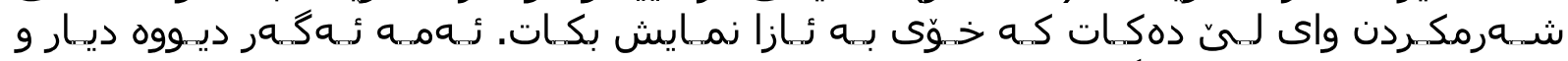

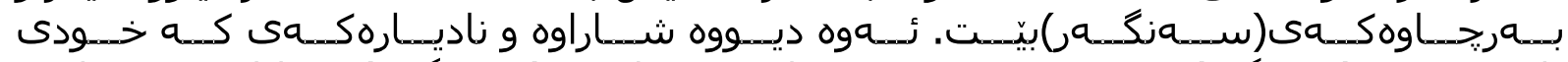

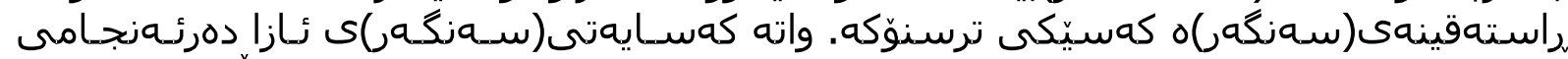

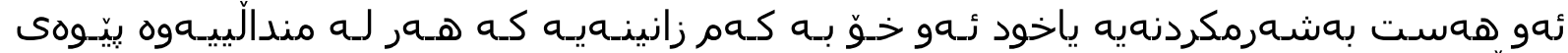

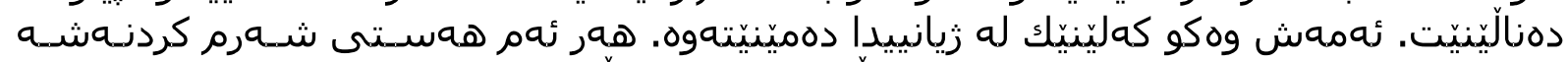

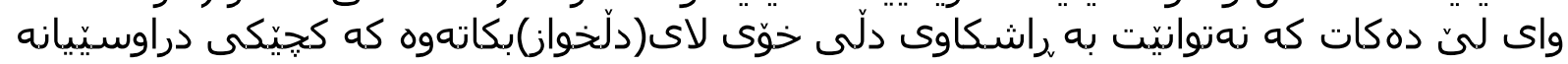

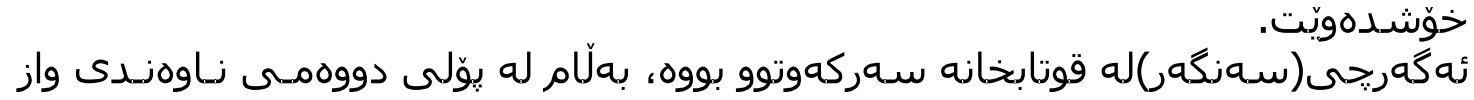

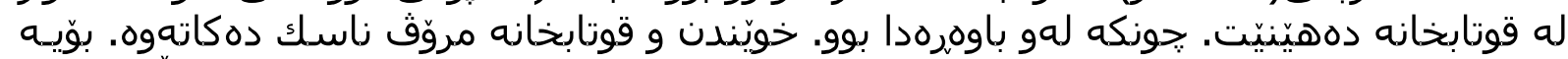

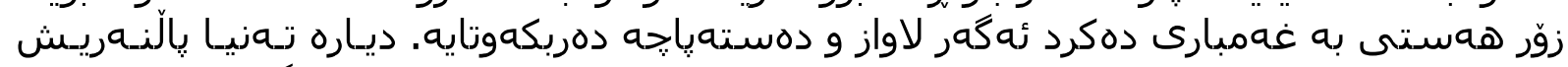

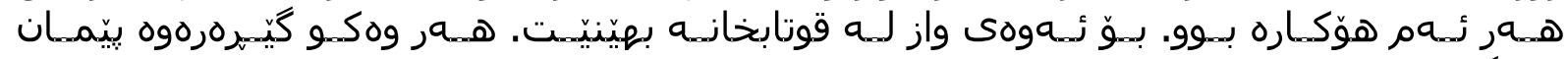

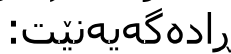

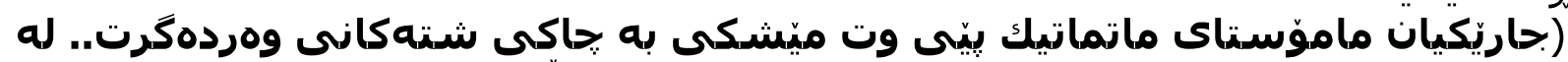

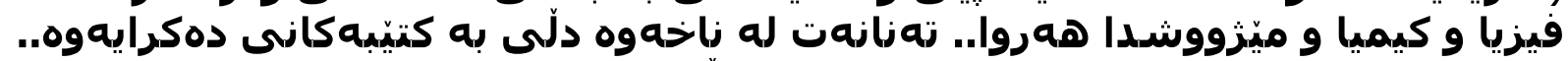

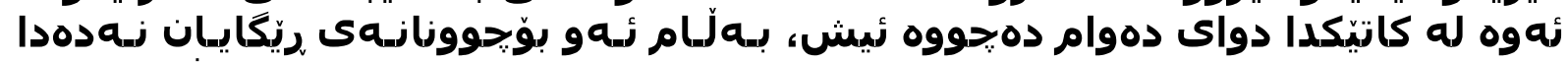

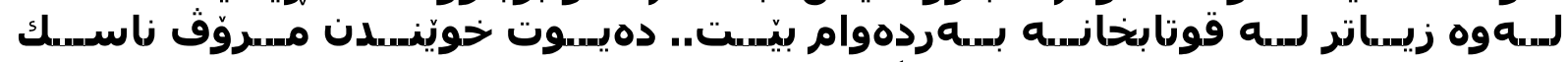

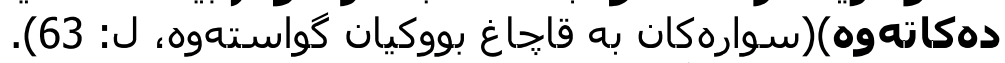

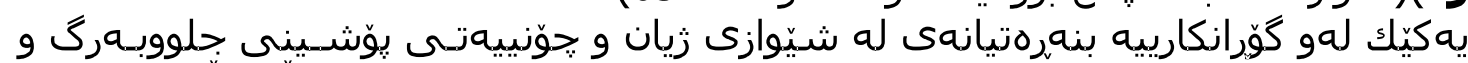

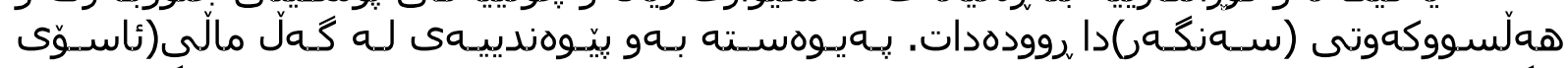

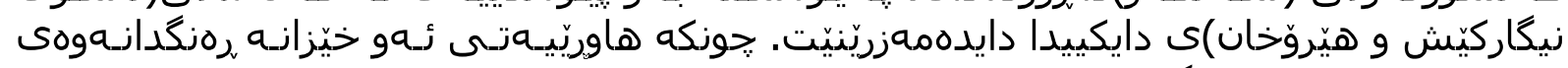

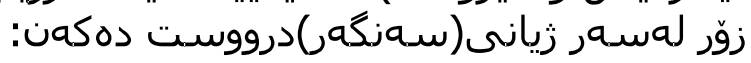

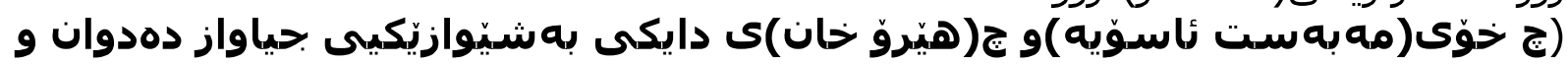

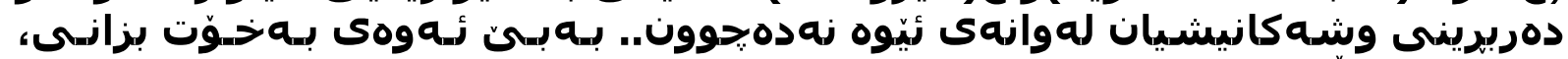

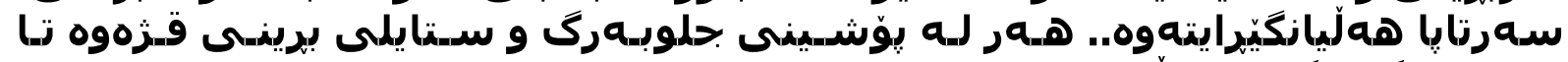

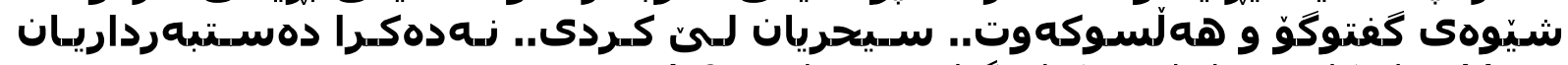

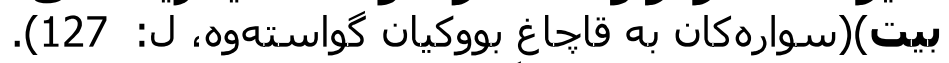

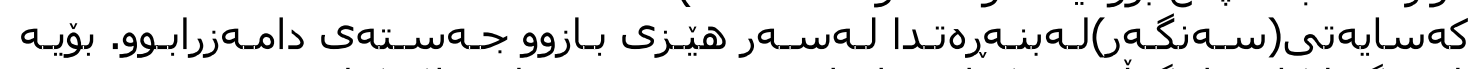

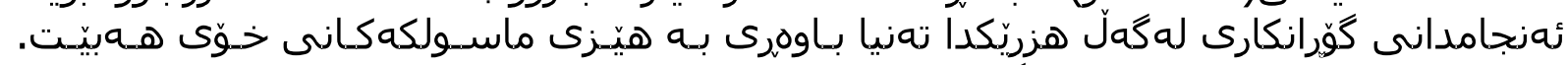

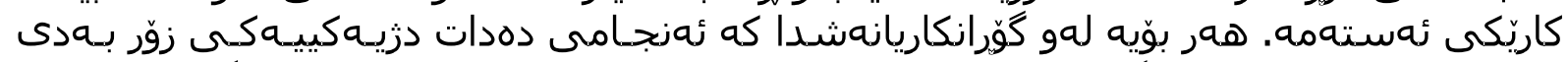

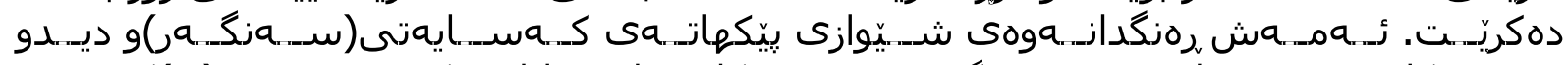

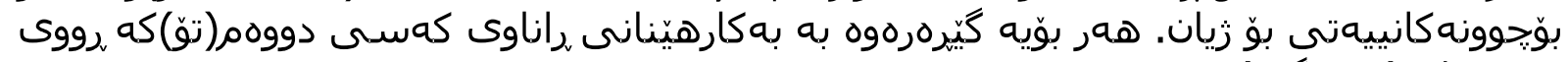

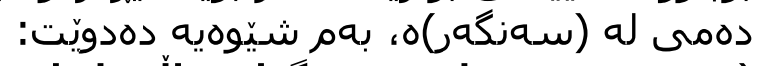

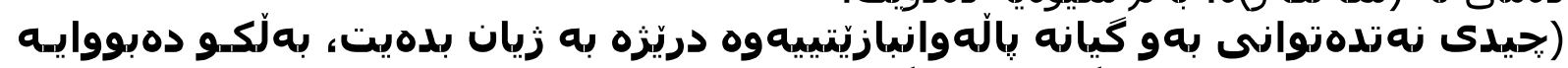

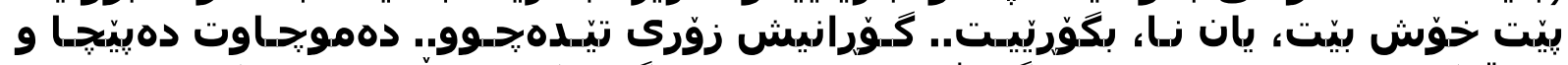

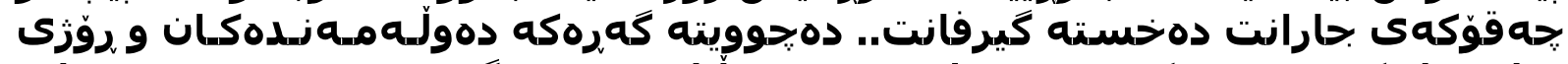

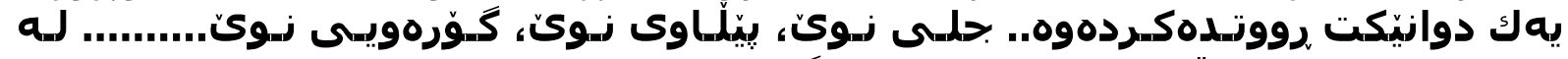

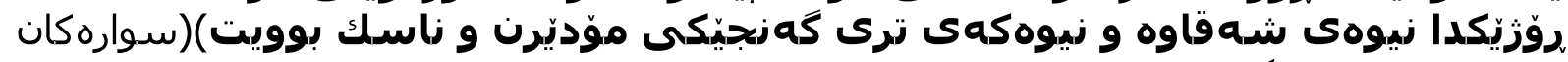

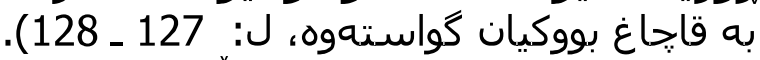

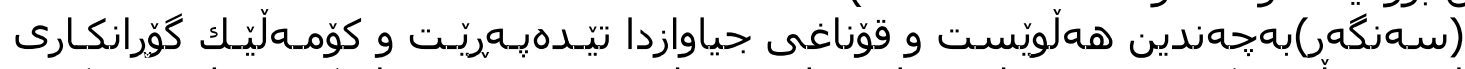

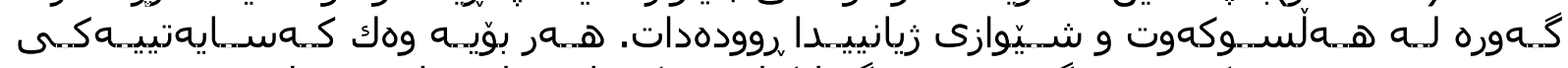

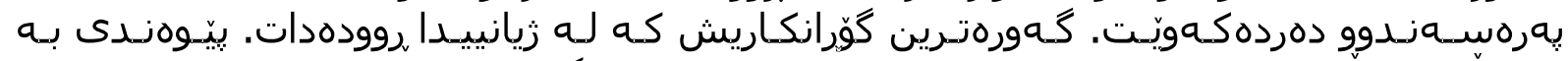

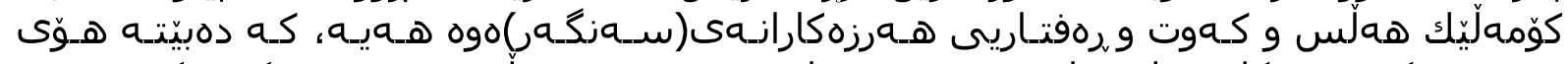

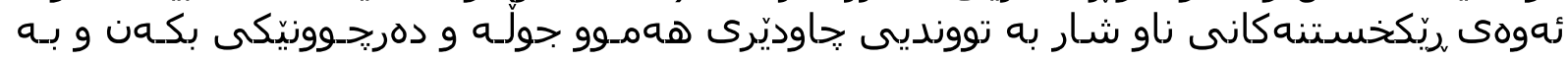




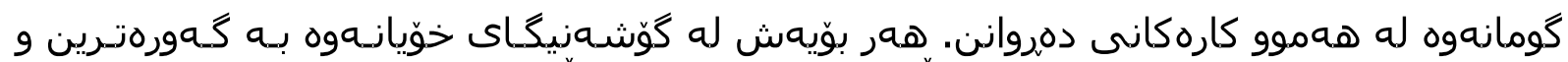

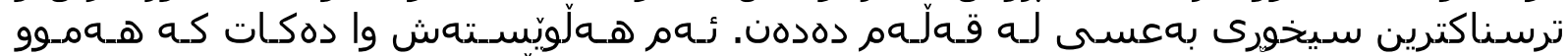

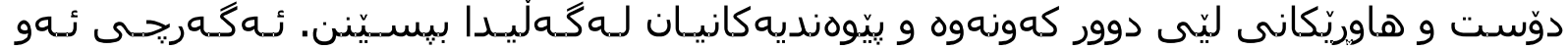

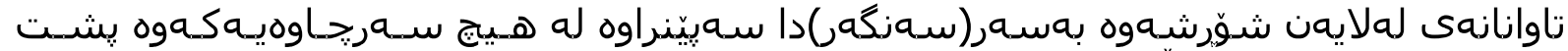

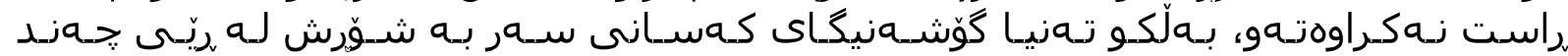

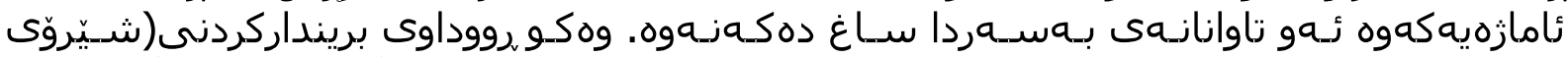
زاز.

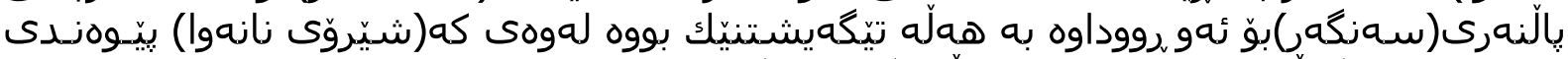

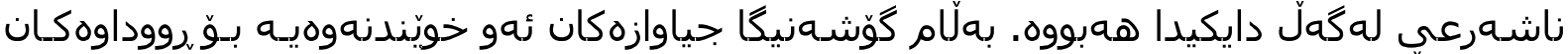

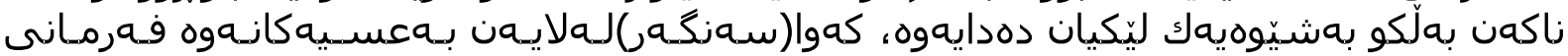

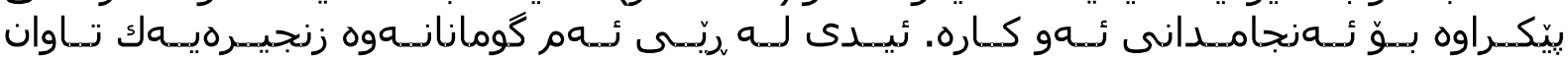

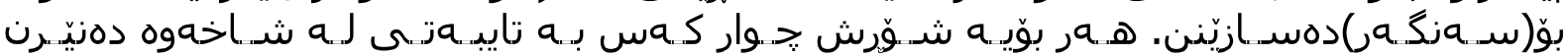

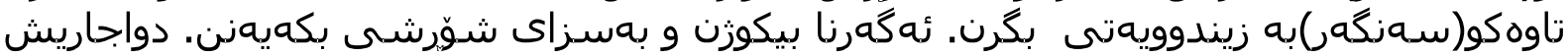

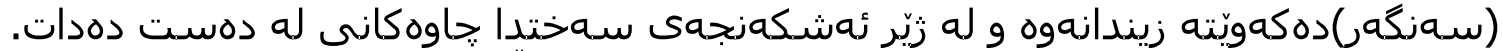

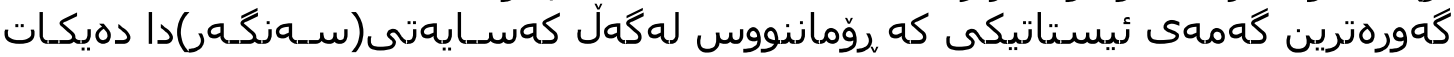

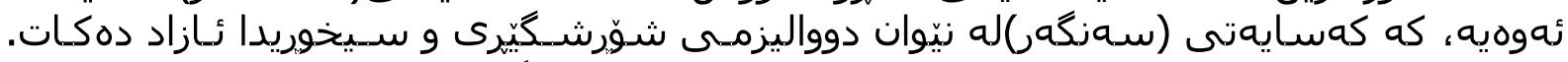

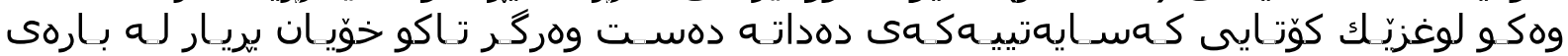

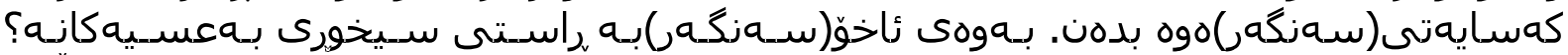

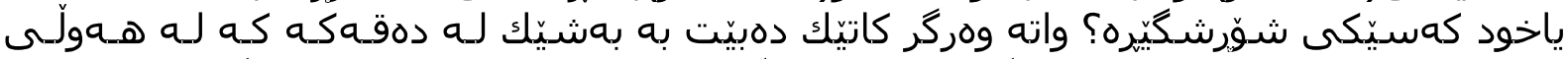

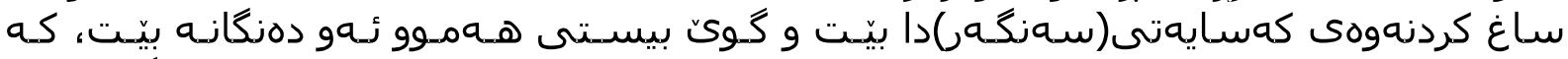

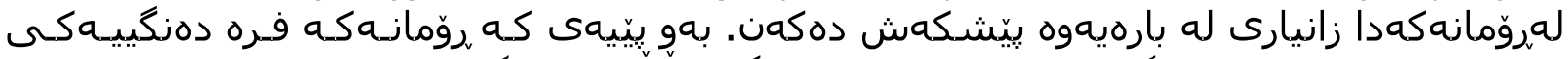

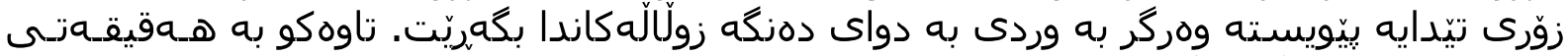

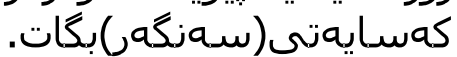

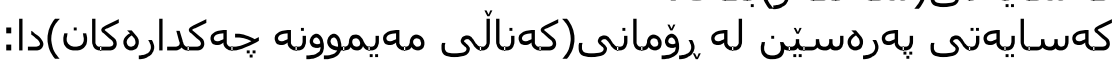

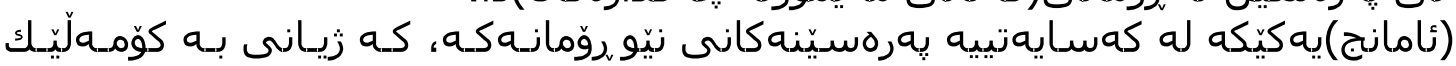

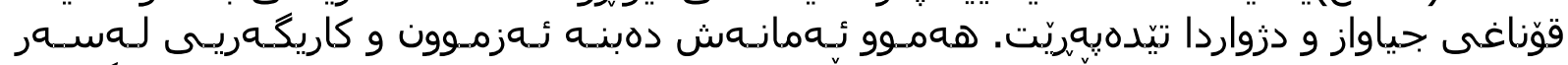

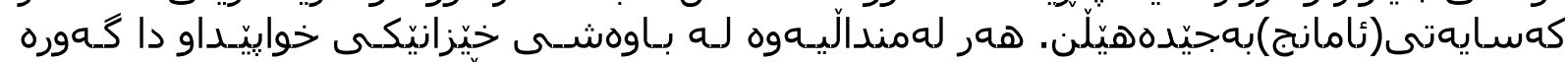

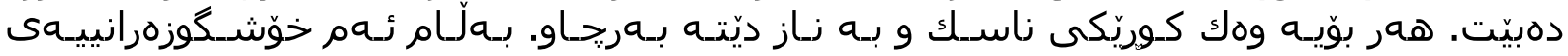

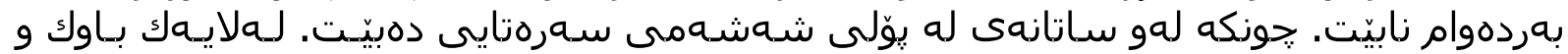

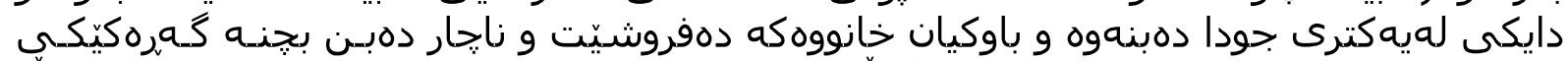

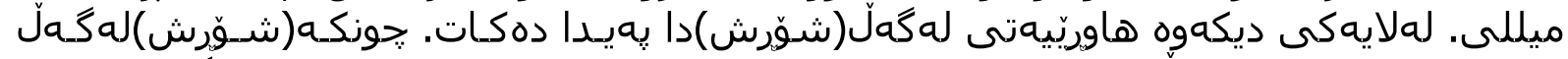

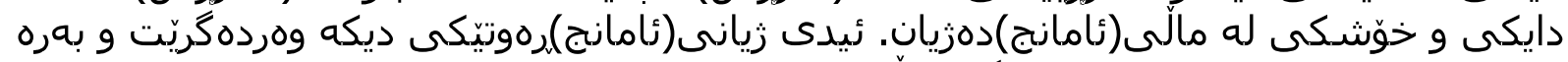

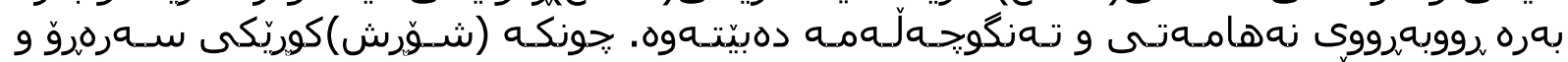

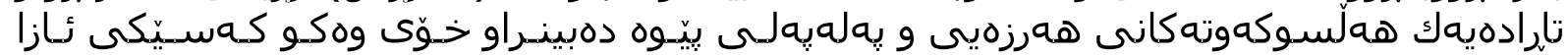

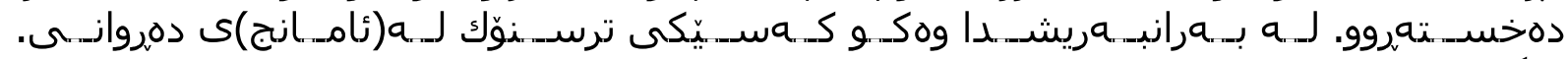

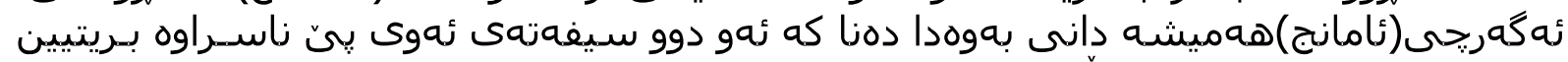

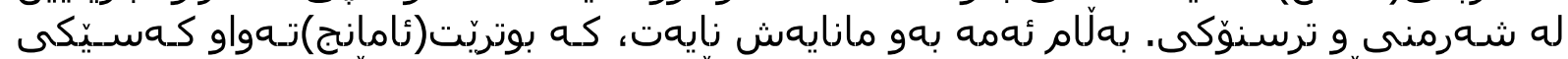

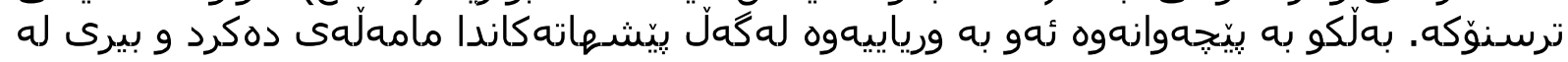

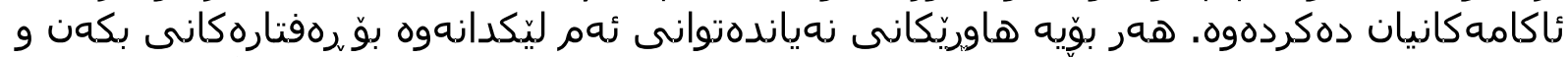

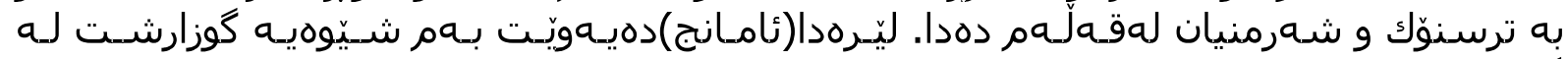

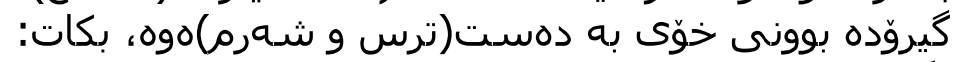

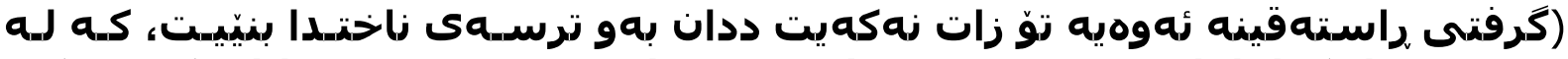

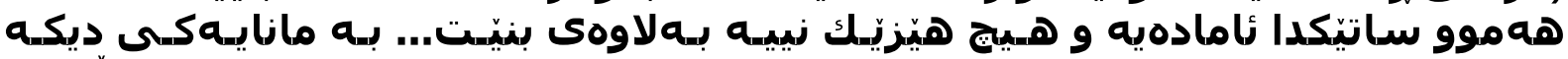

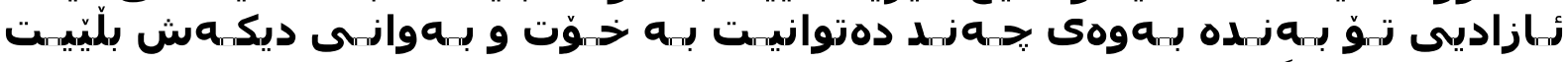

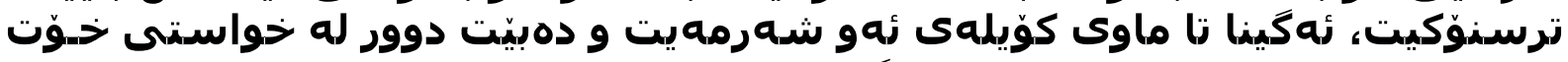

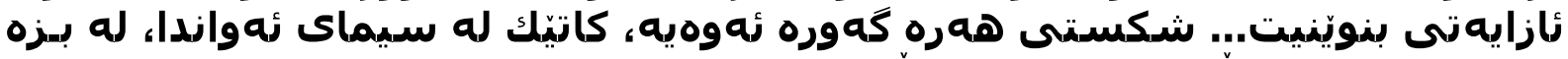

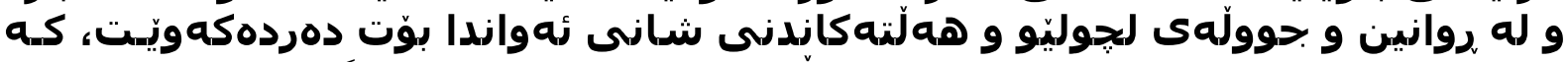

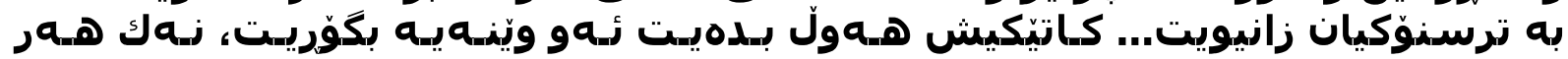

International Journal of Kurdish Studies Vol.5/1 ( January 2019) 


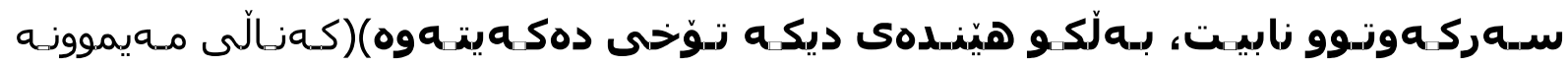

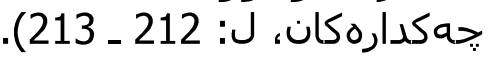

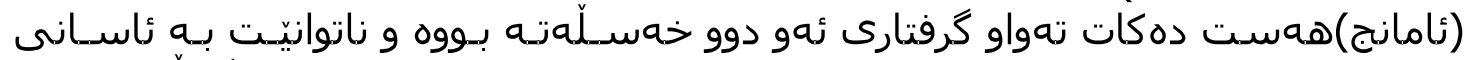

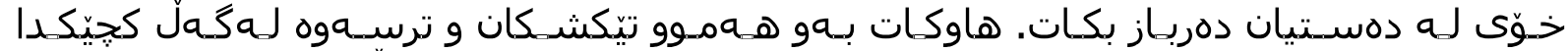

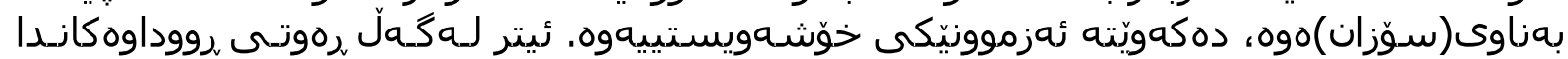

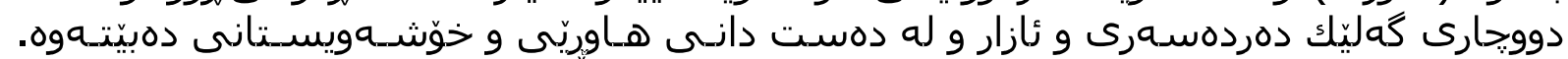

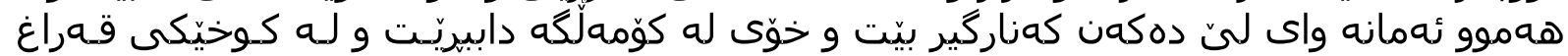

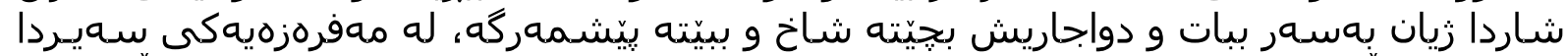

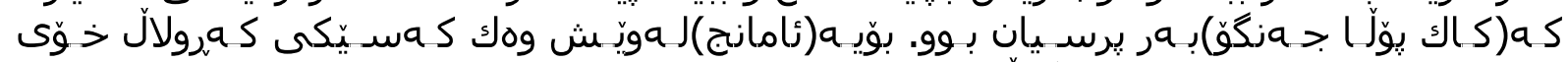

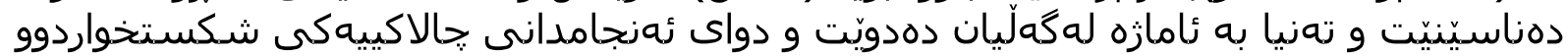

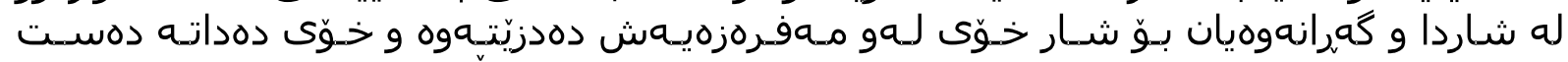

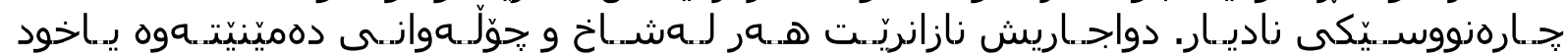

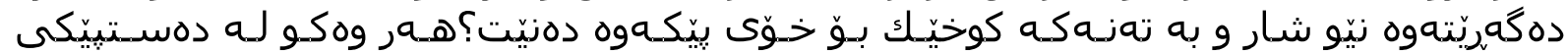

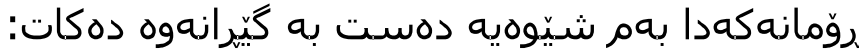

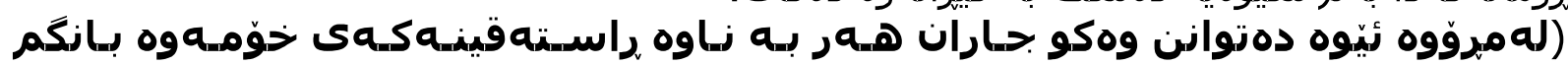

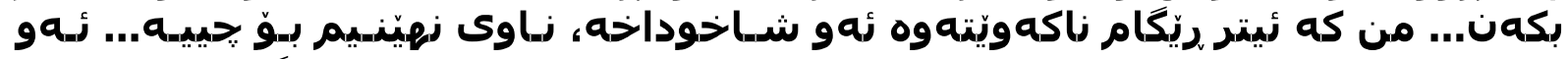

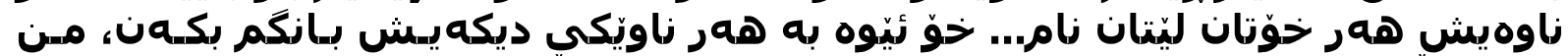

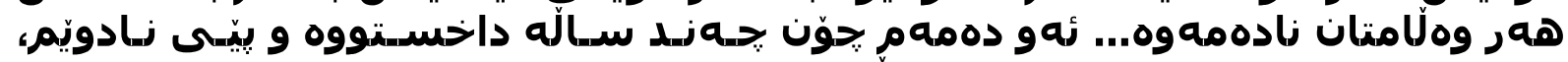

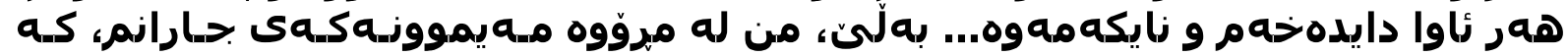

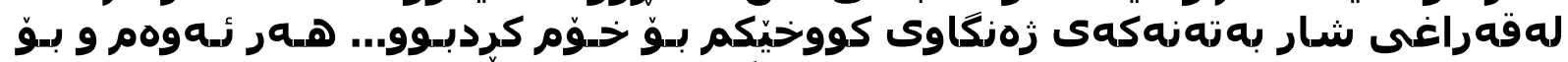

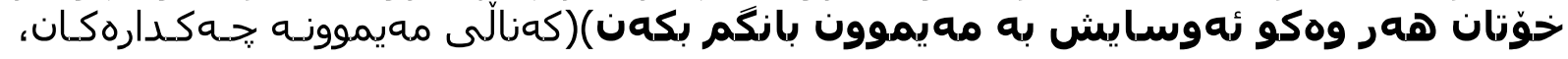

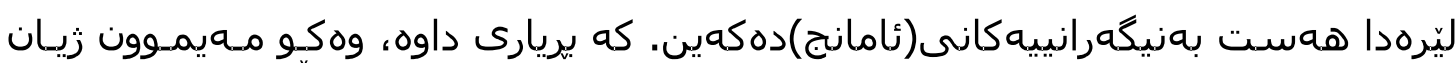

ل: (7) ( )

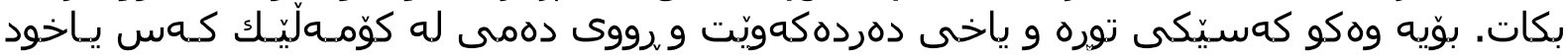

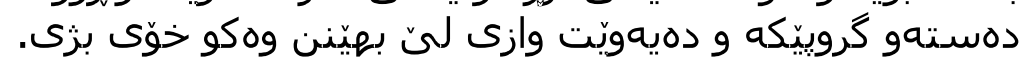

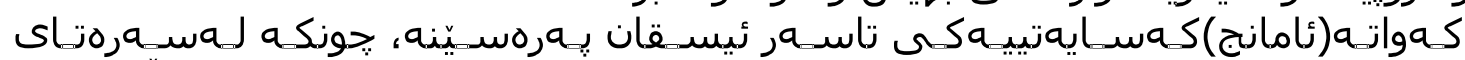

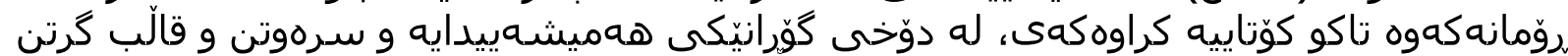

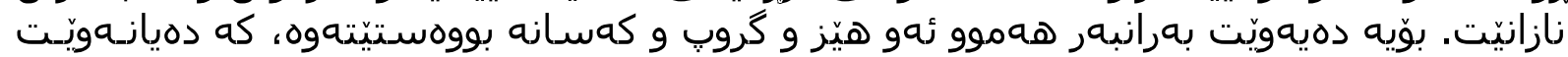

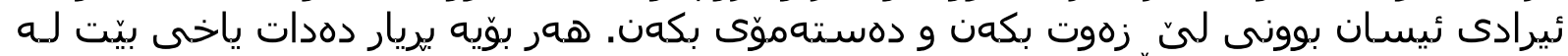

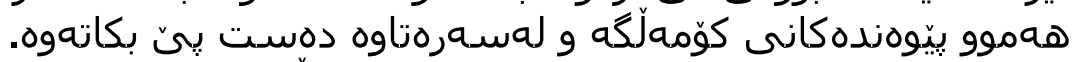

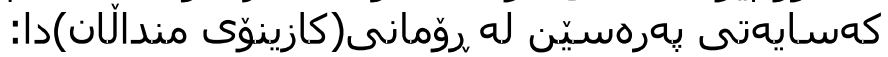

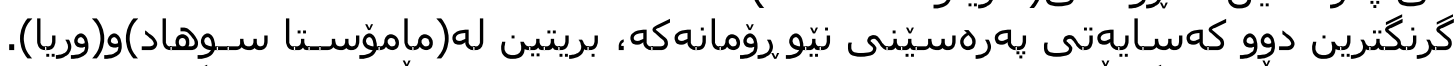

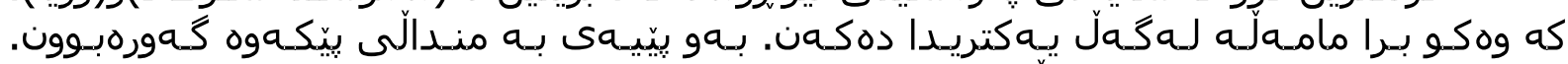

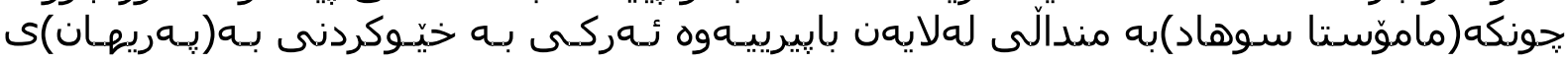

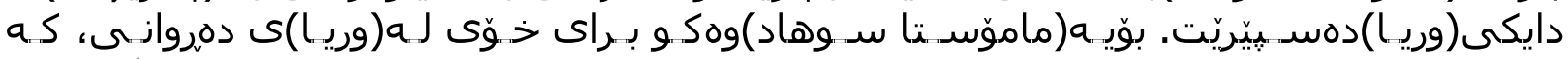

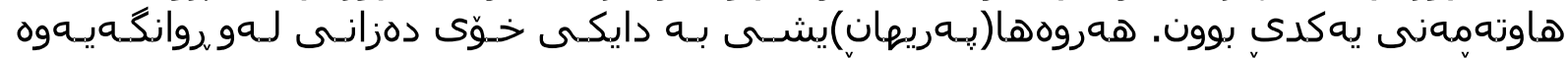

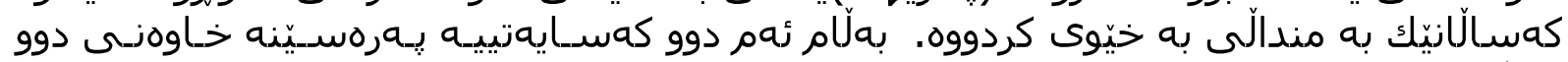

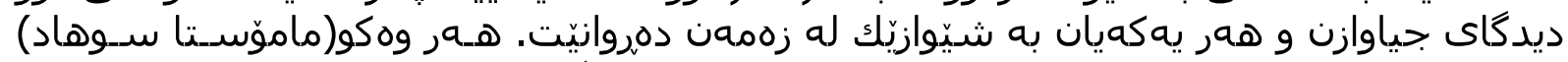

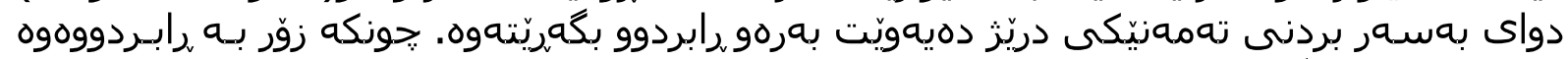

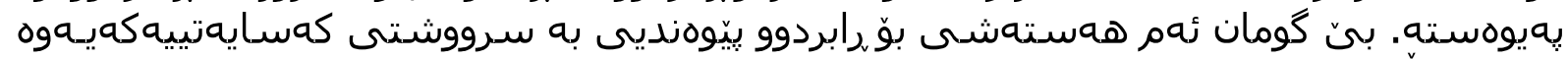

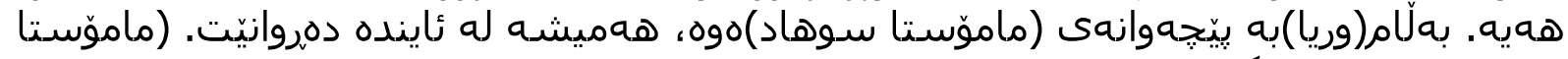

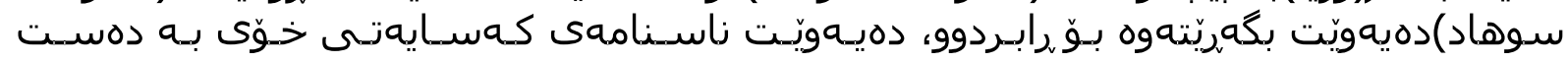

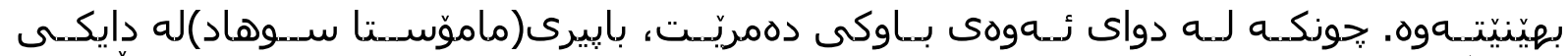

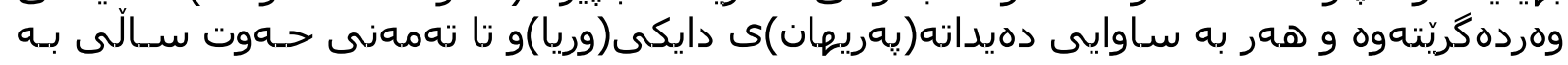

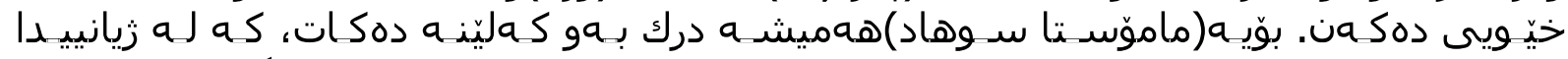

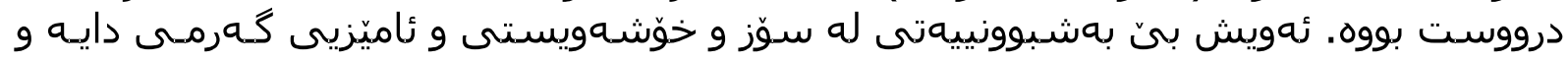

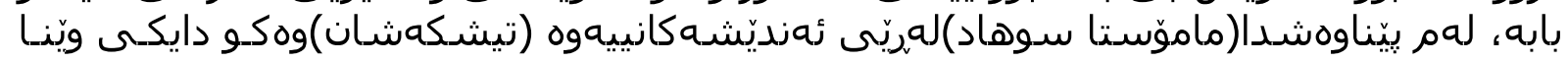

International Journal of Kurdish Studies Vol.5/1 ( January 2019) 


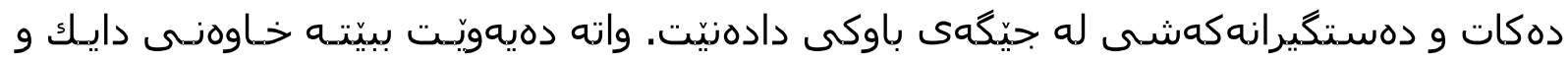

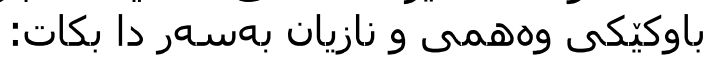

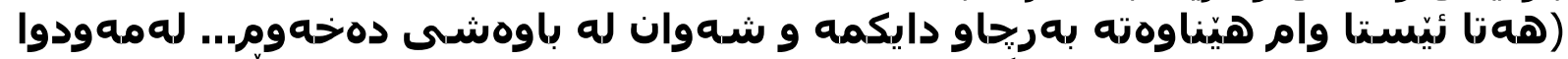

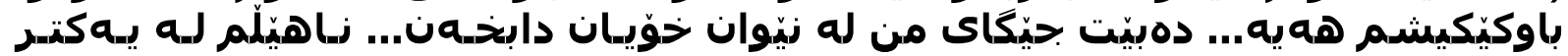

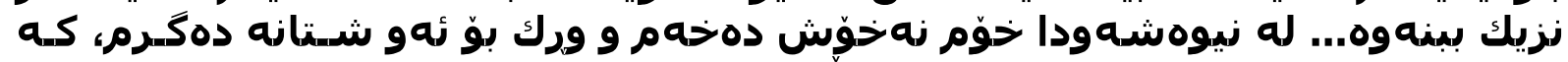

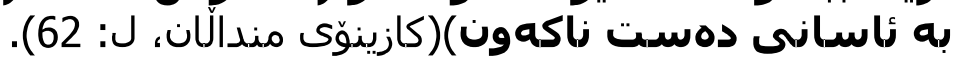

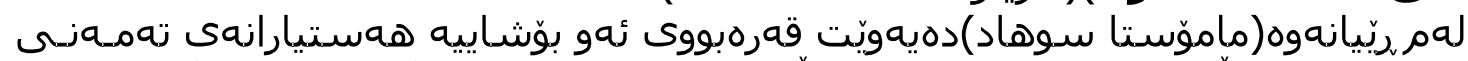

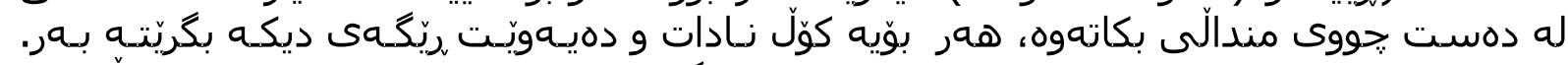

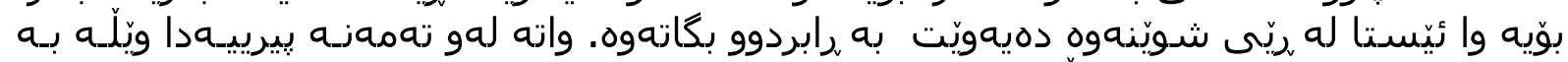

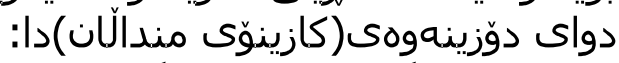

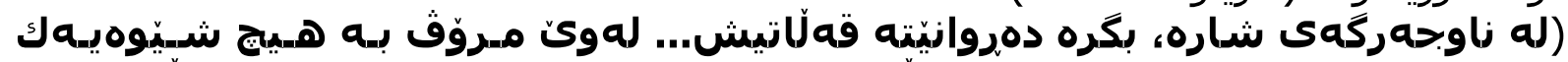

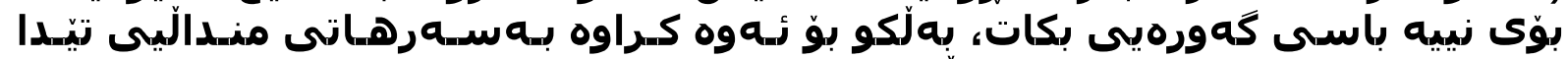

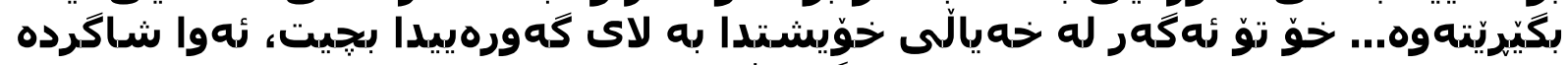

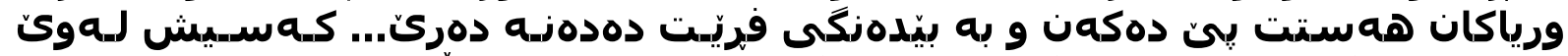

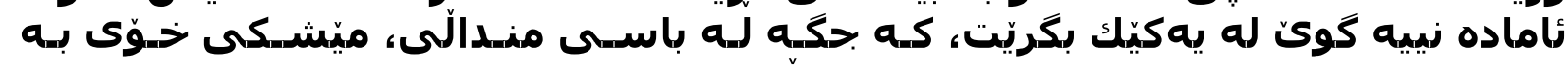

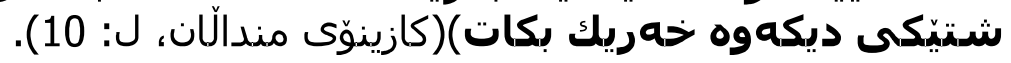

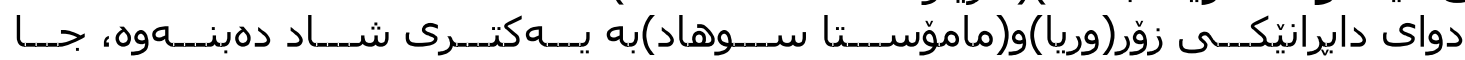

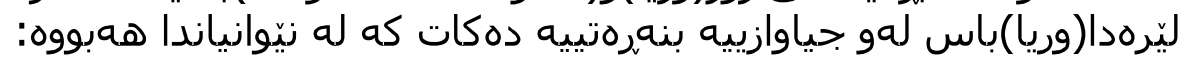

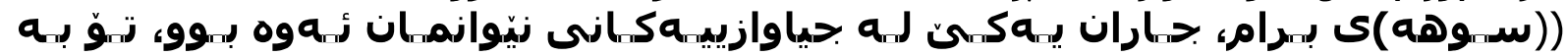

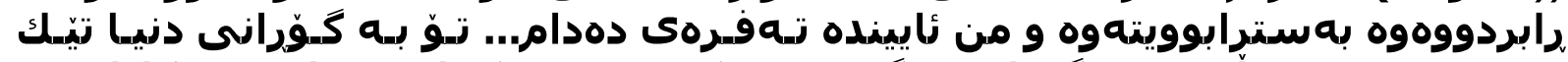

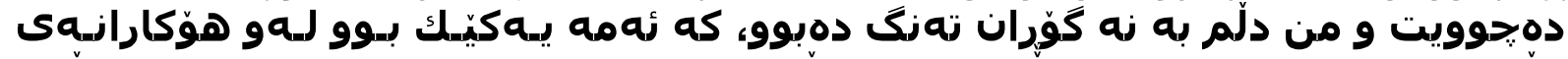

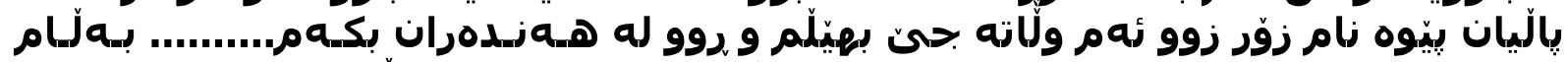

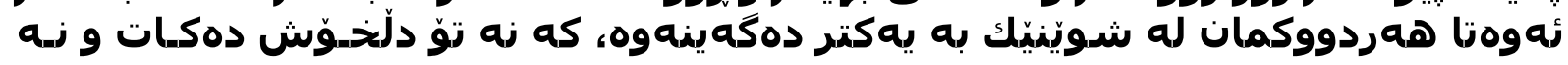

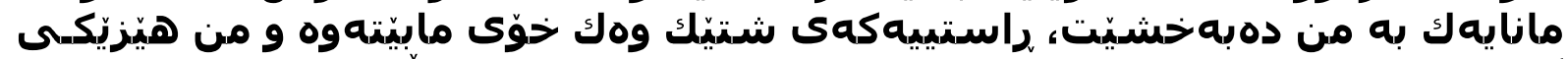

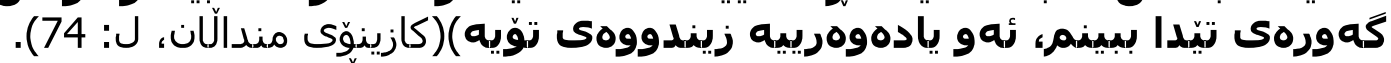

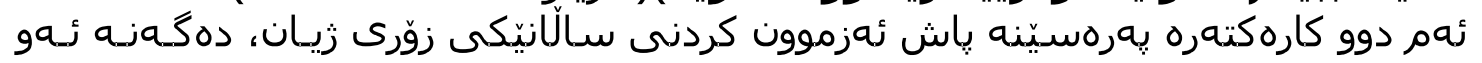

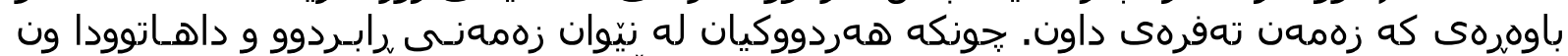

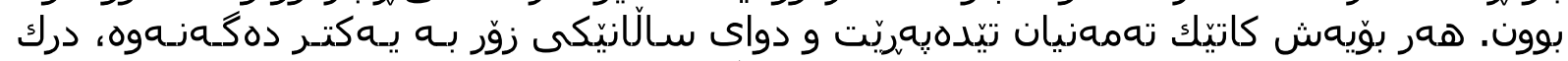

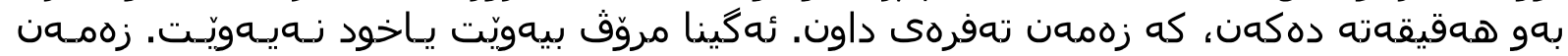

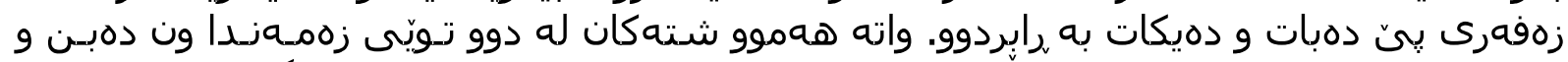

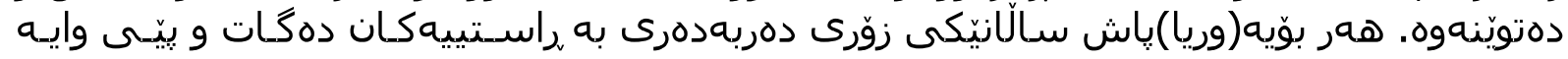

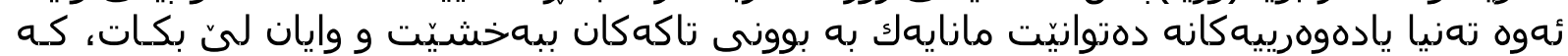

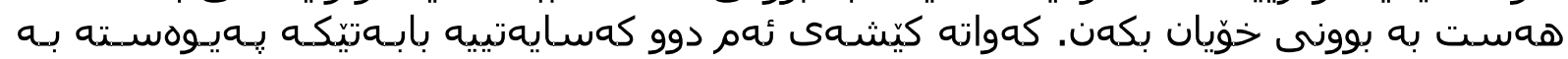

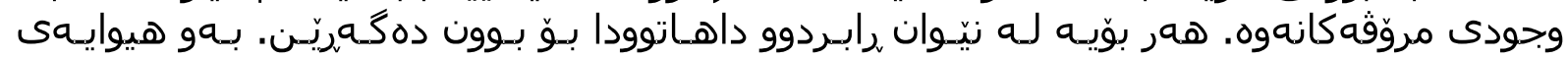

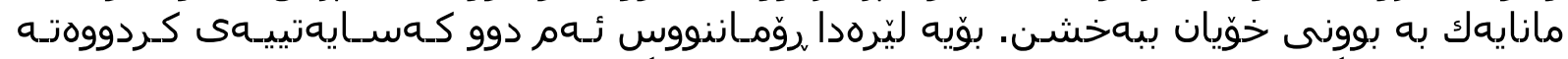

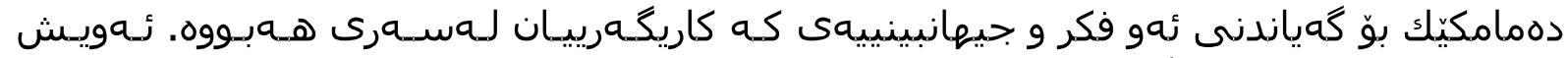

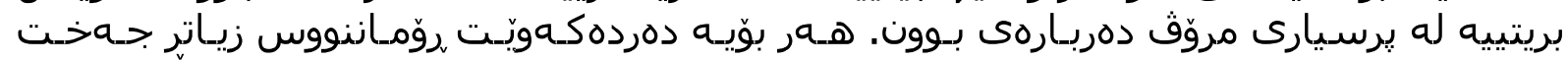

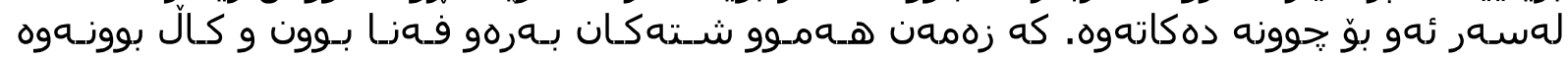

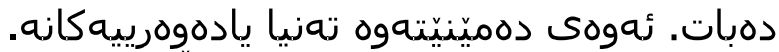

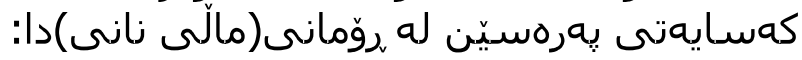

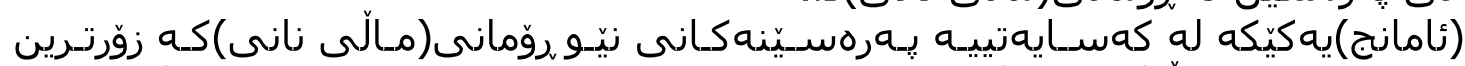

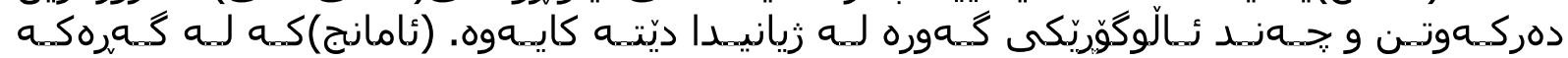

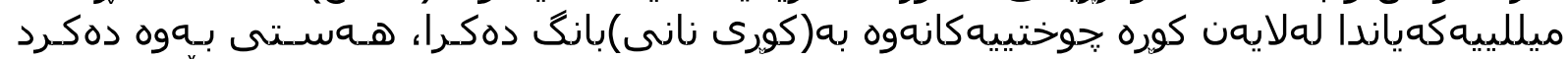

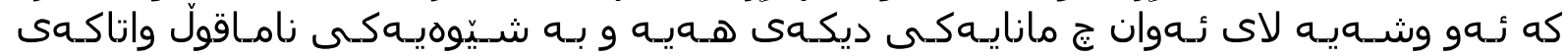

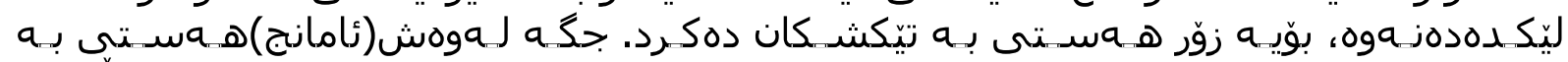

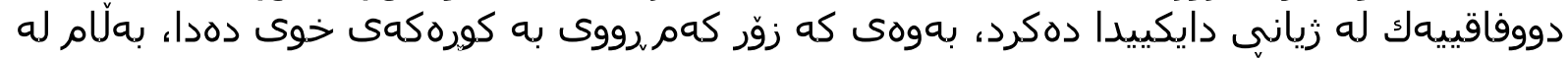

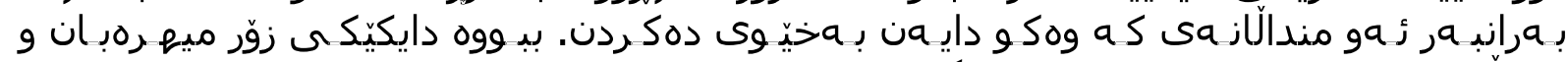

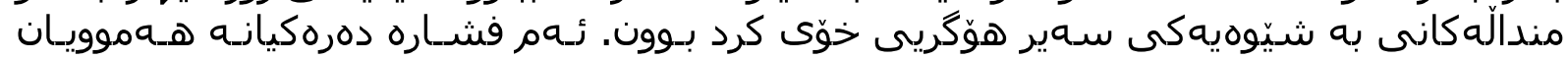




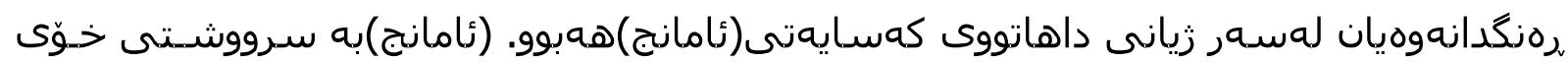

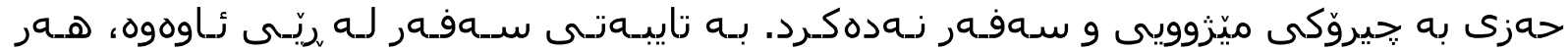

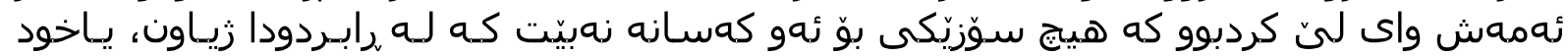

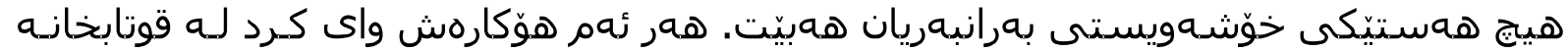

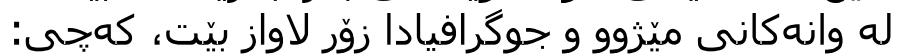

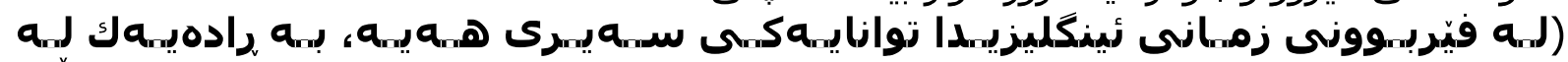

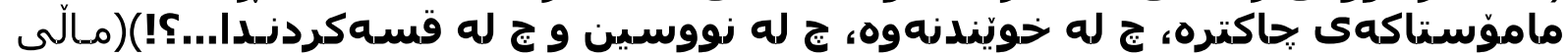

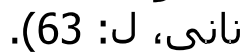

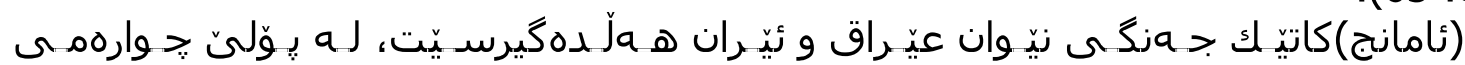

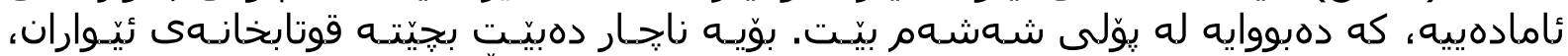

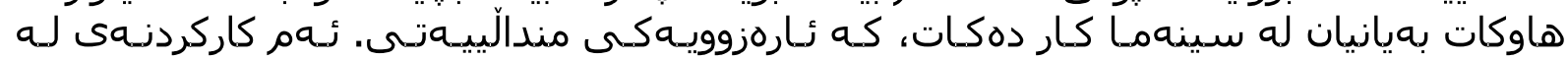

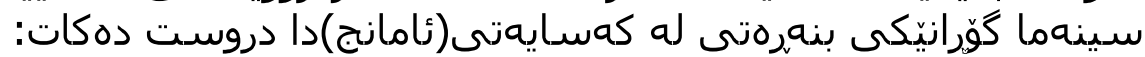

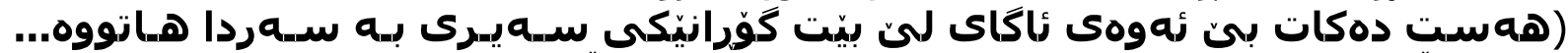

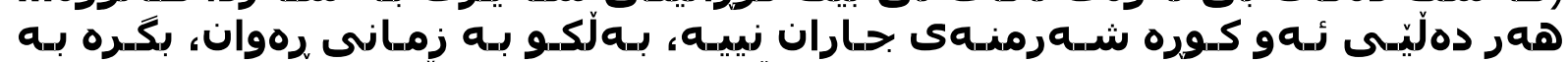

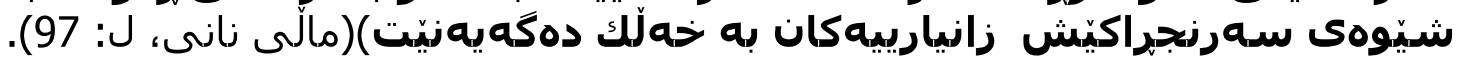

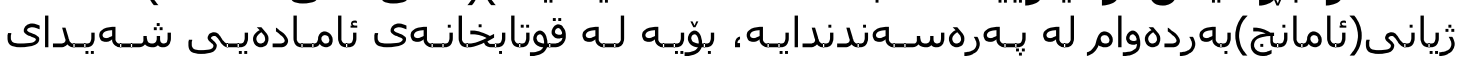

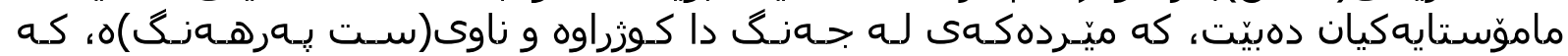

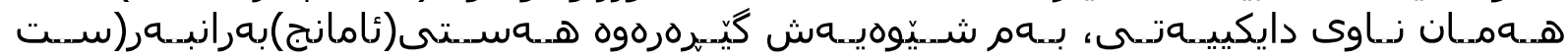

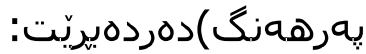

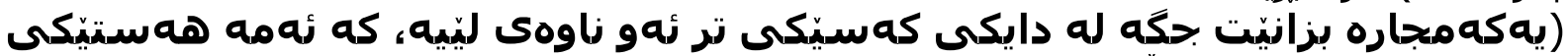

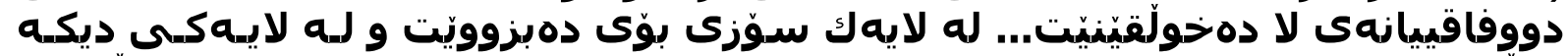

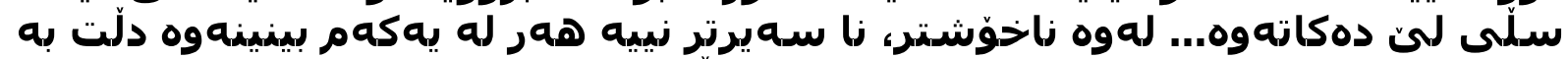

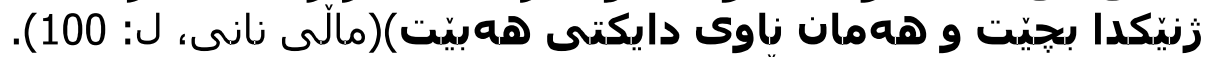

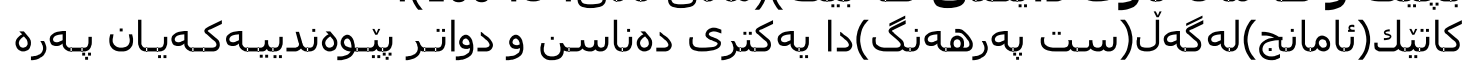

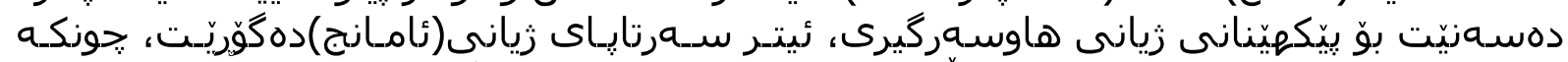

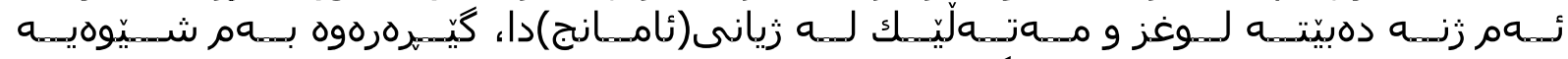

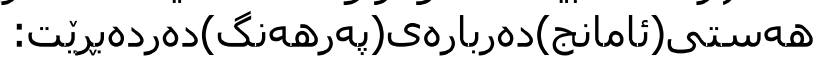

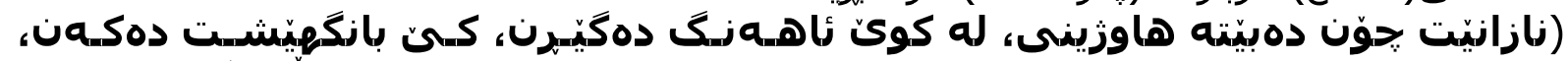

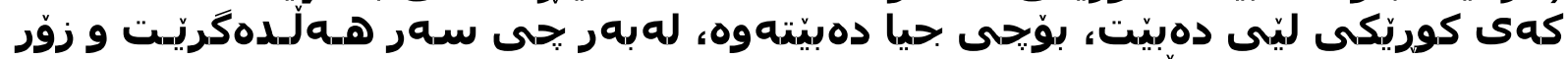

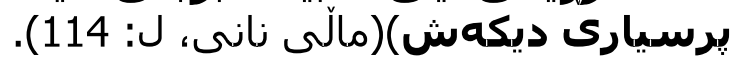

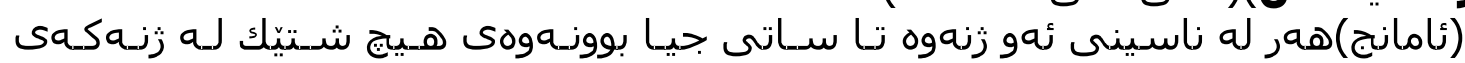

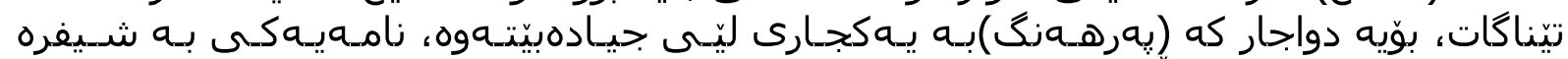

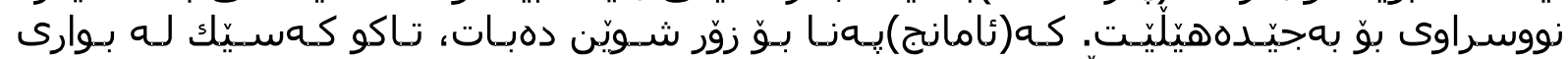

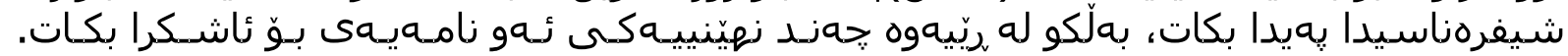

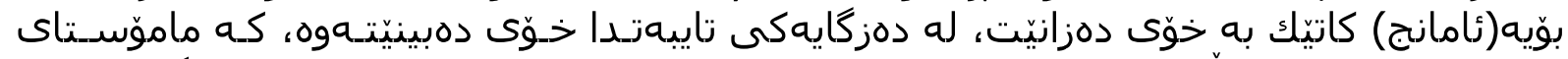

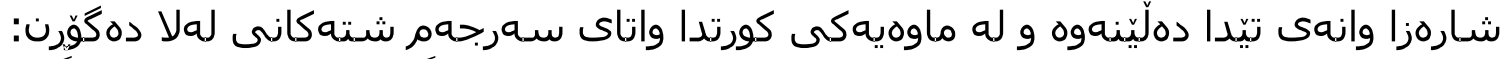

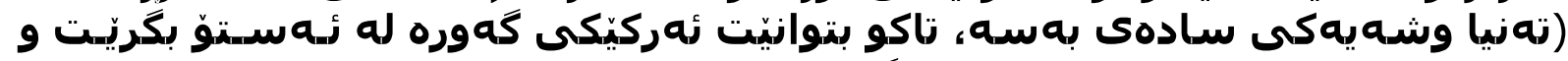

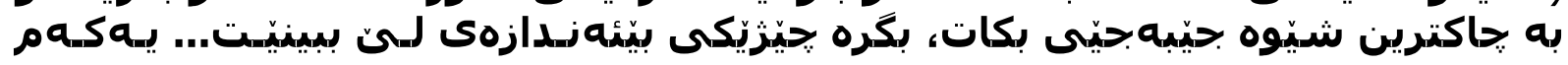

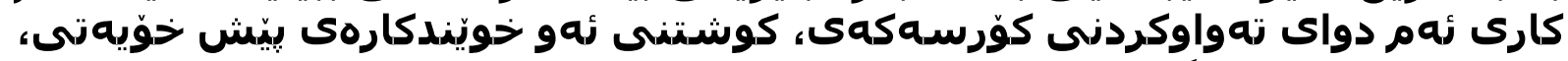

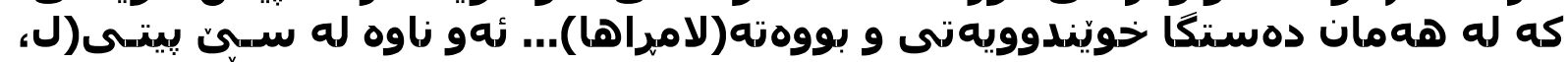

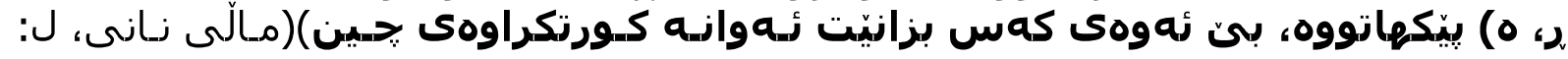

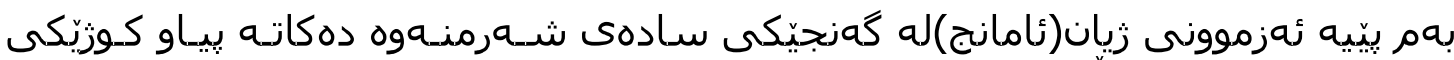

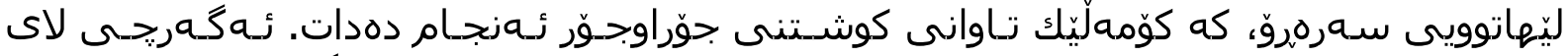

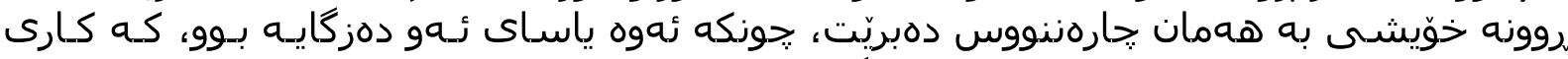

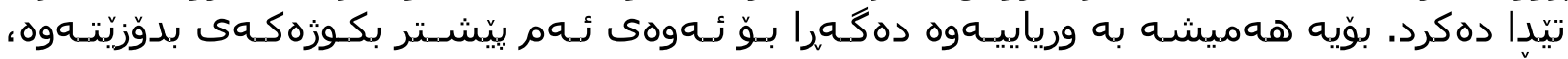

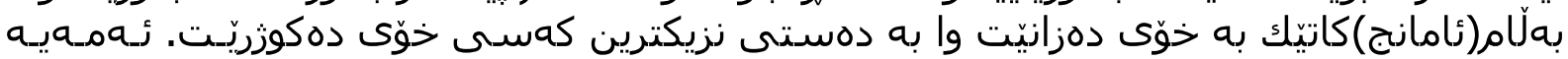

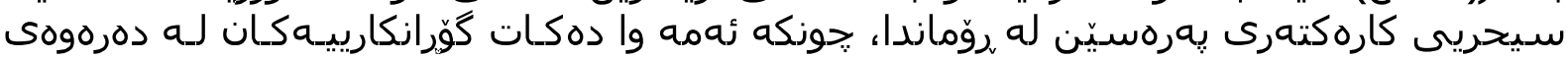




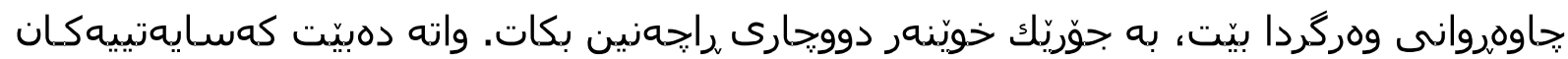

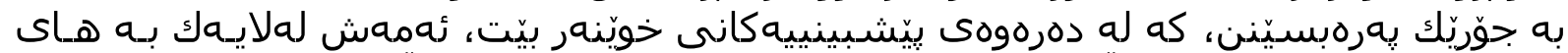

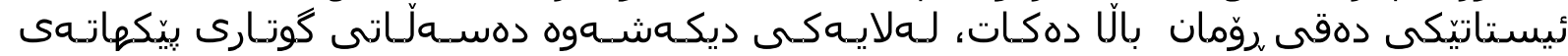

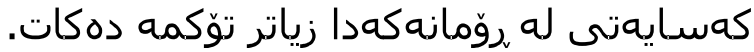

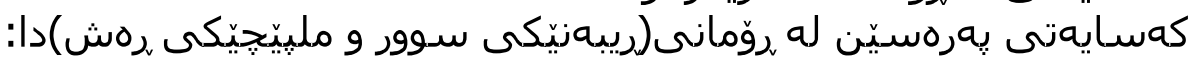

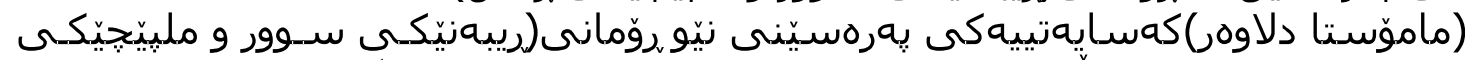

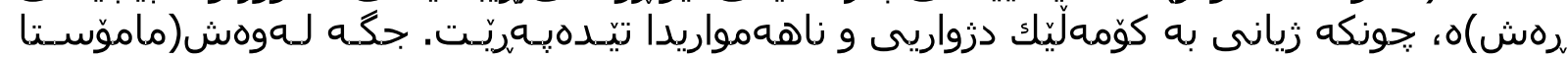

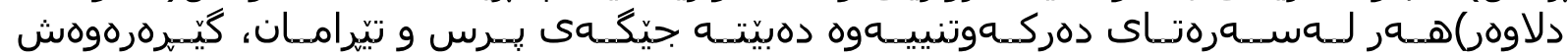

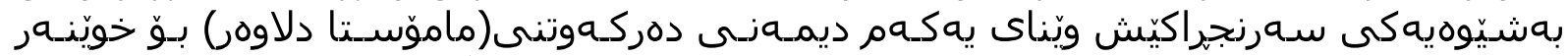

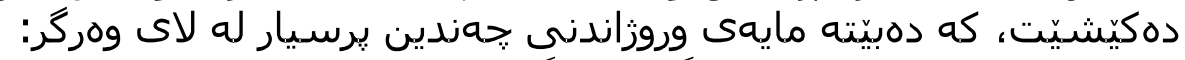

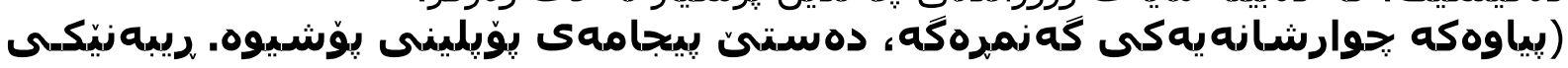

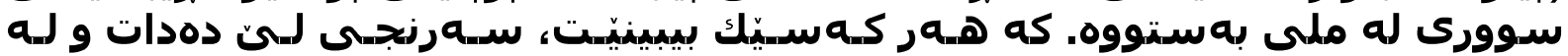

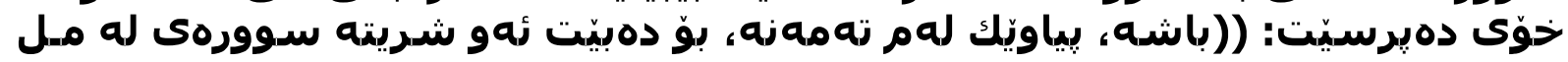

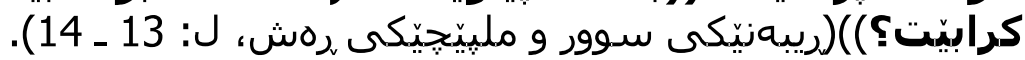

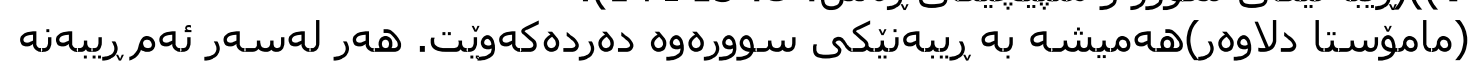

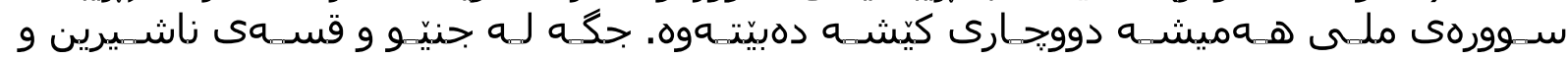

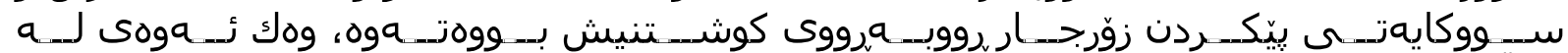

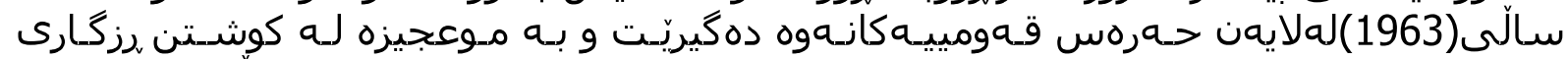

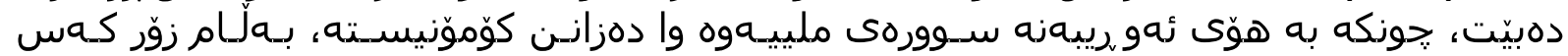

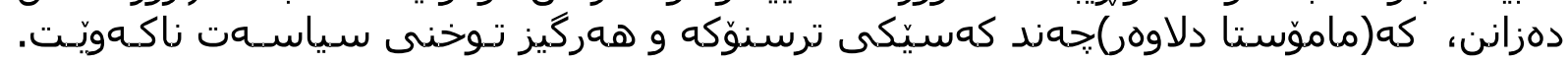

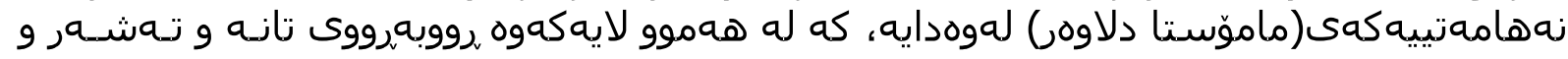

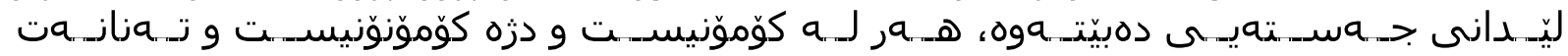

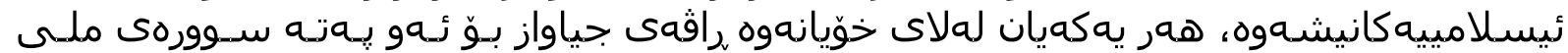

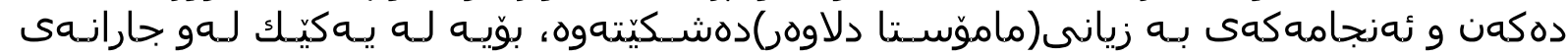

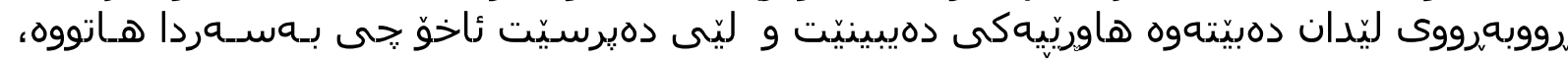

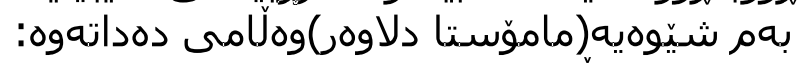

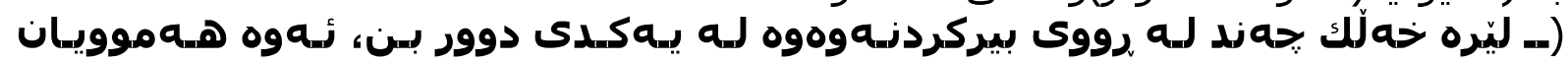

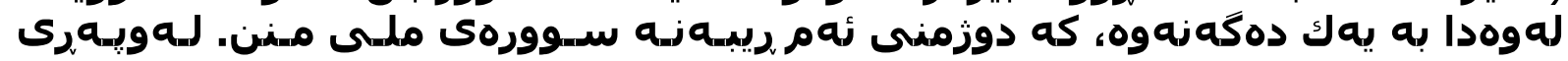

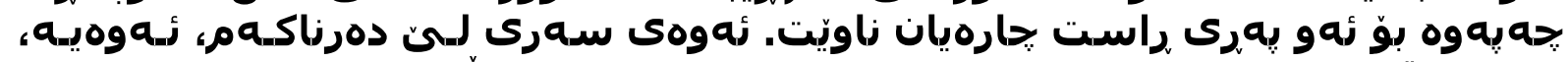

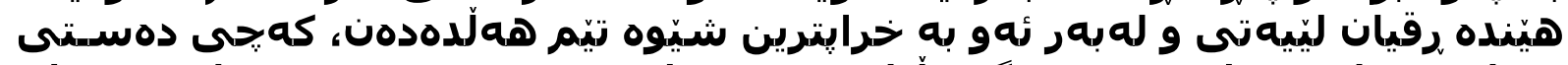

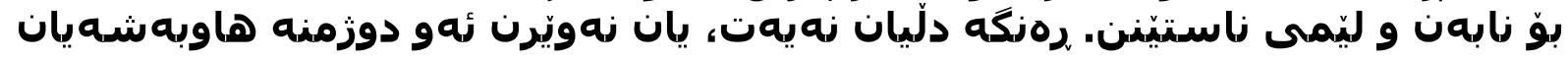

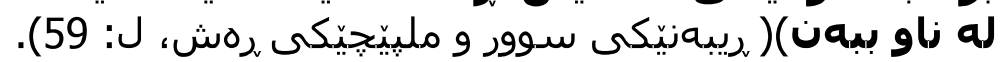

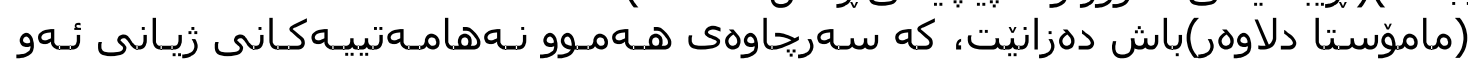

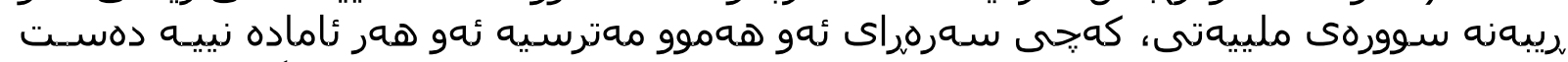

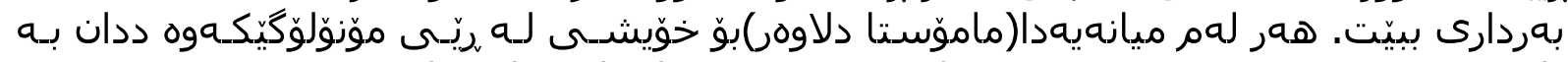

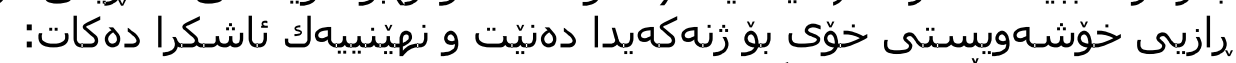

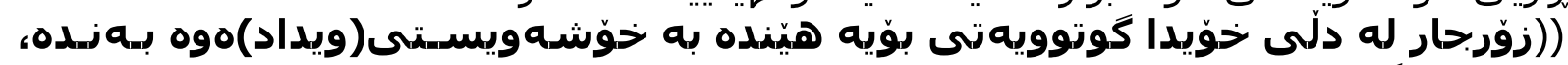

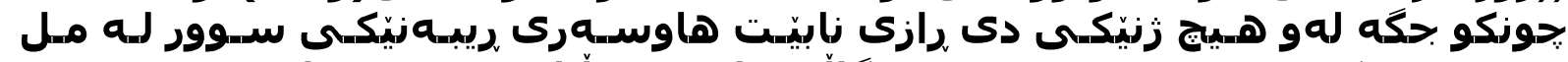

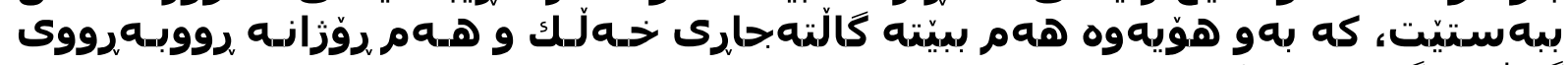

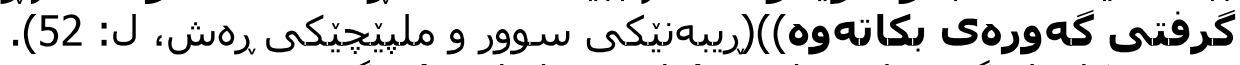

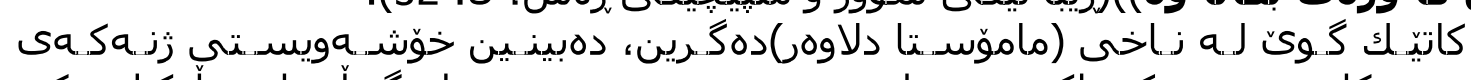

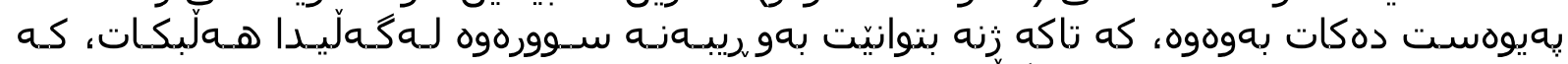

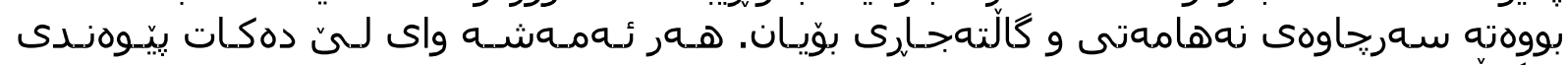

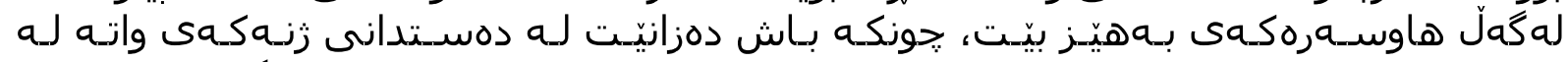

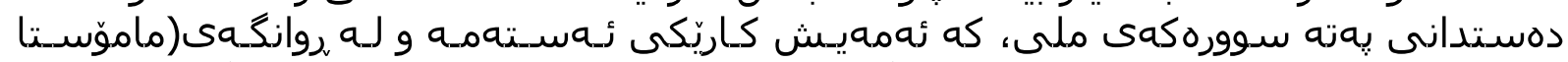

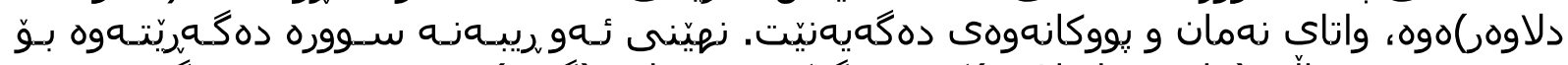

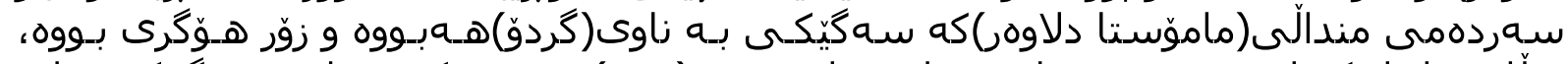

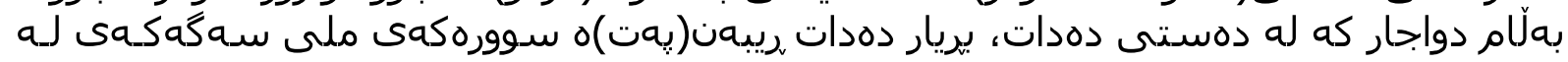




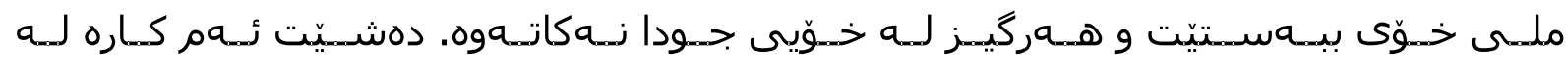

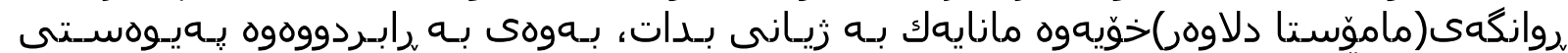

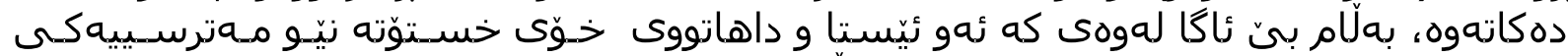

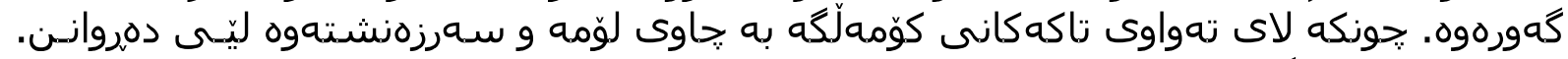

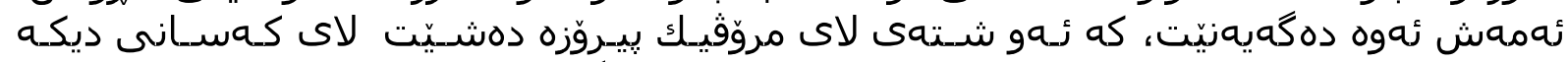

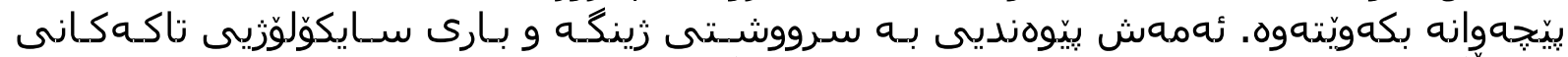

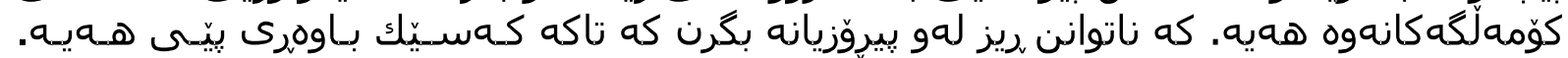

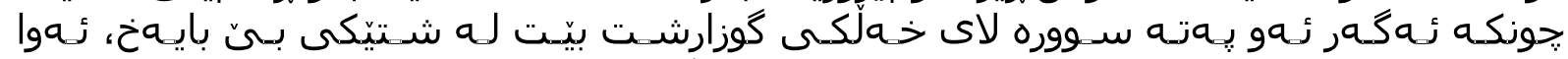

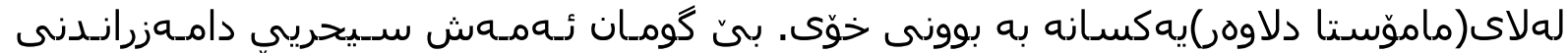

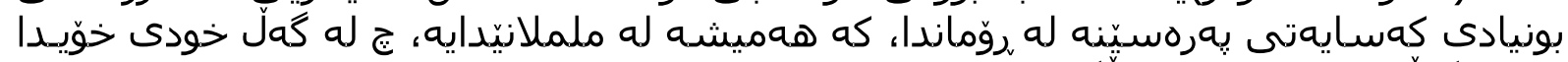

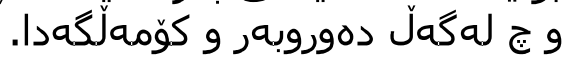
2. 2

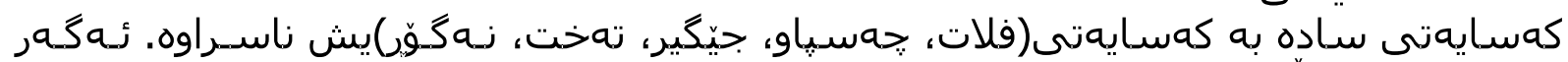

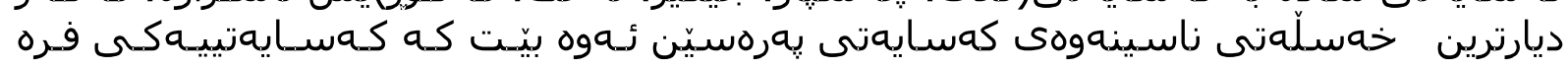

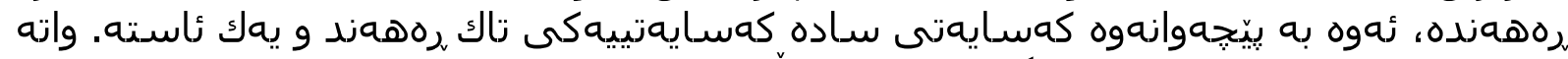

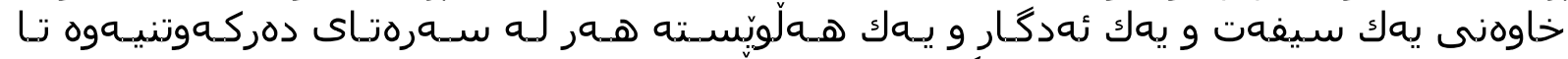

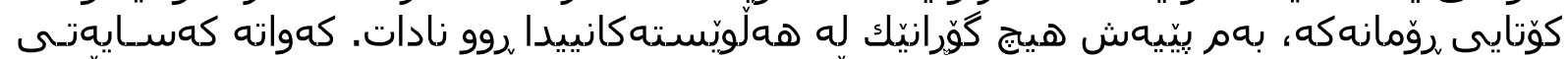

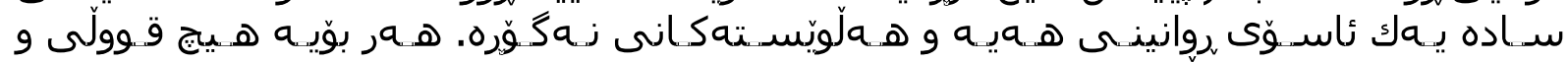

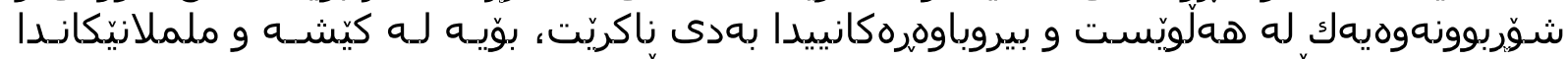

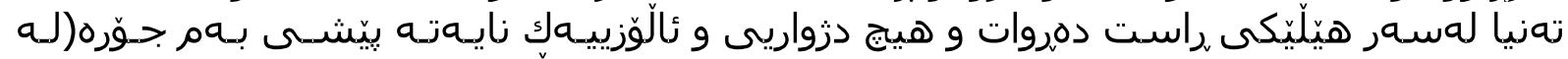

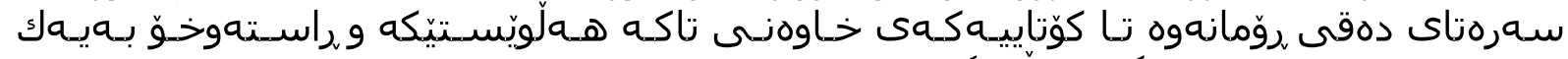

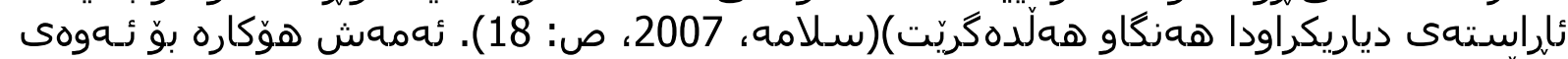

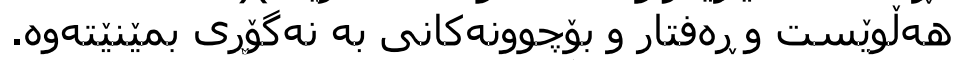

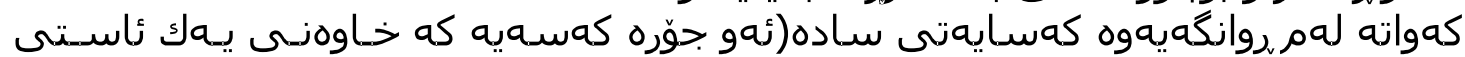

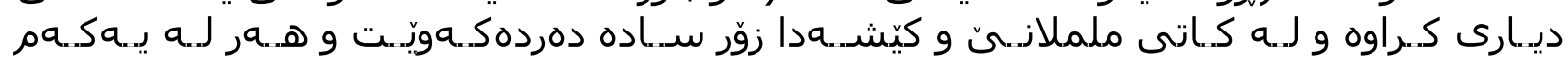

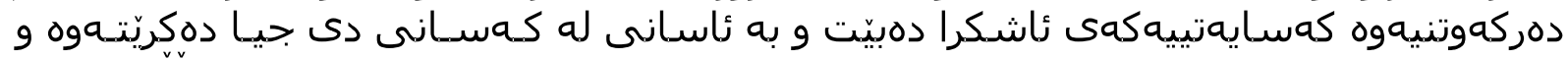

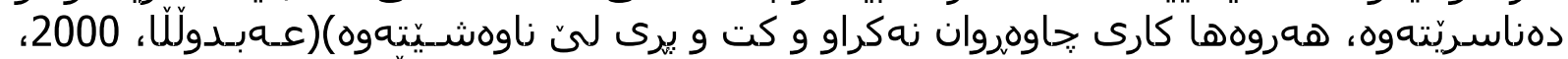

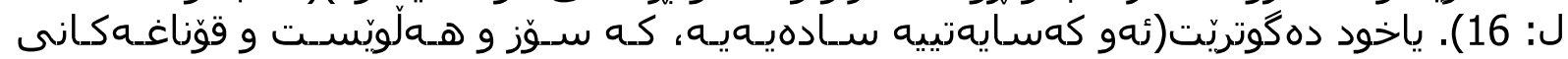

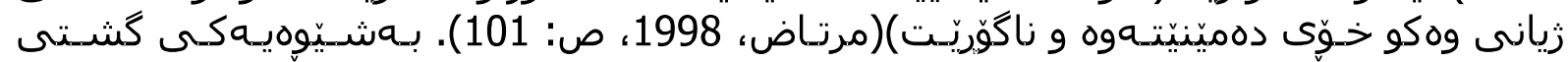

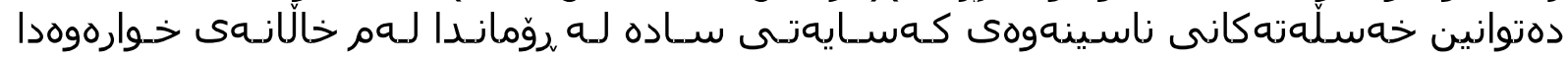

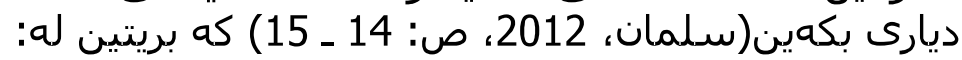
1.

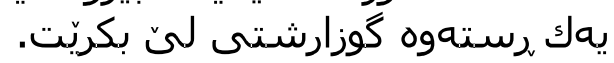

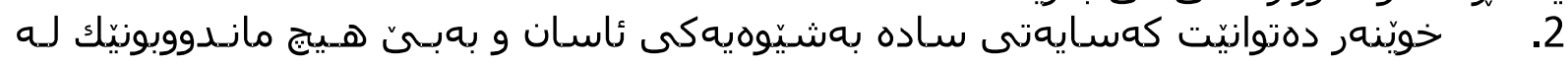

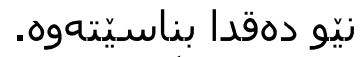
3.

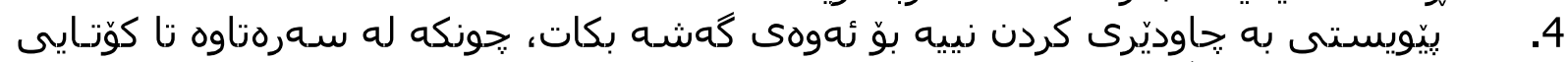

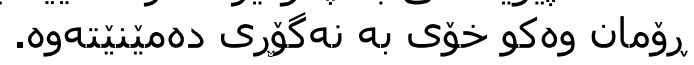

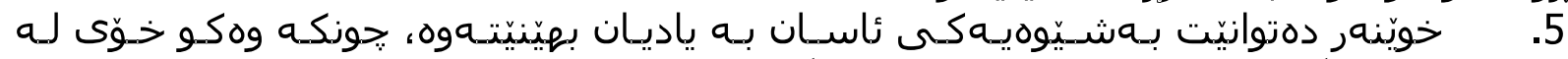

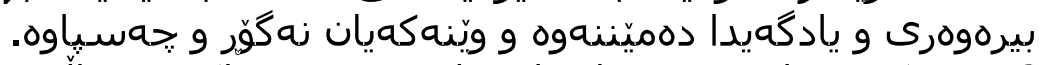
6.

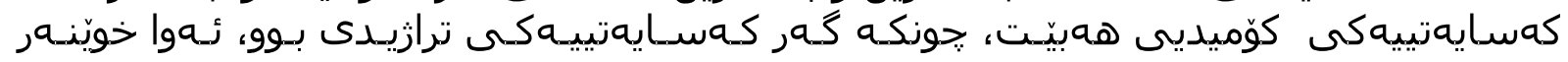

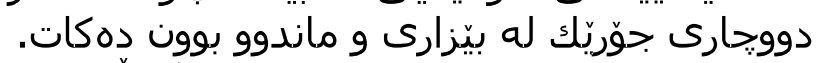

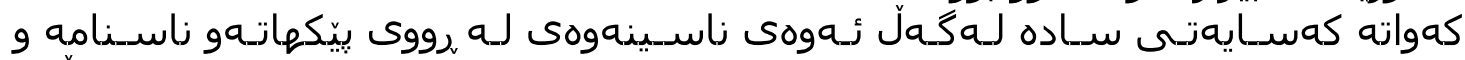

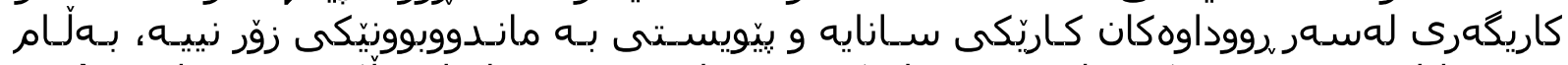

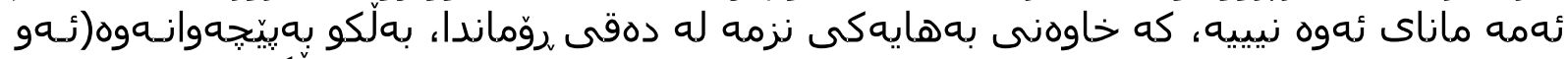

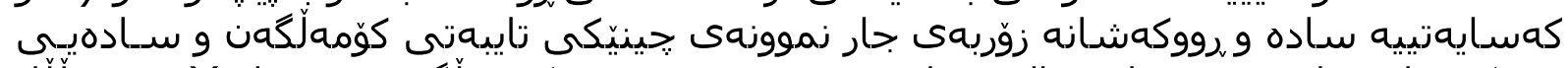

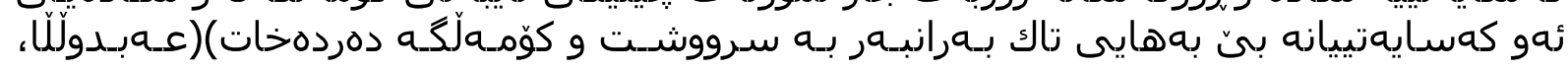




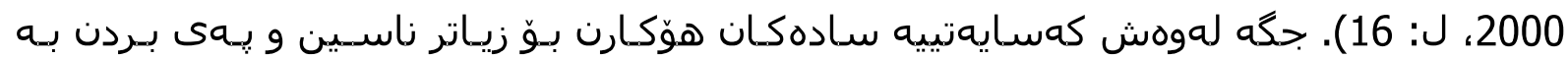

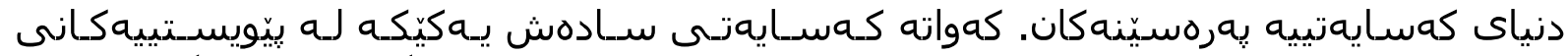

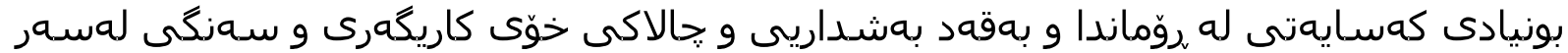

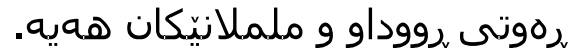

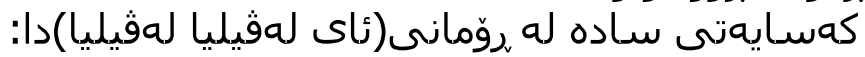

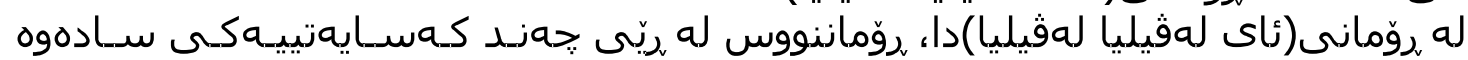

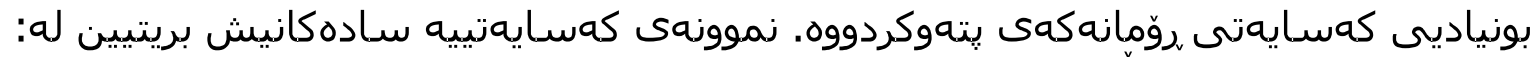

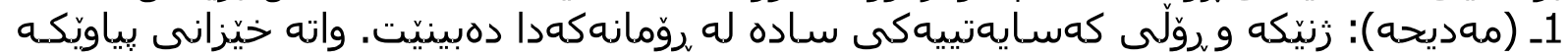

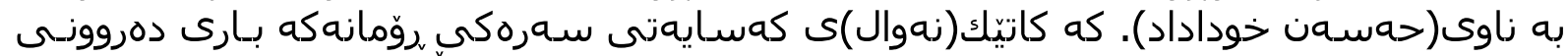

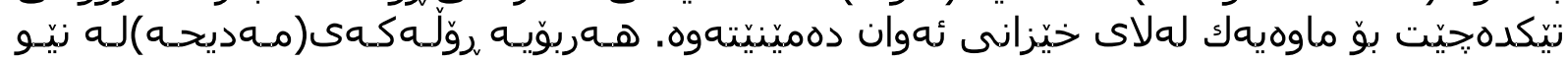

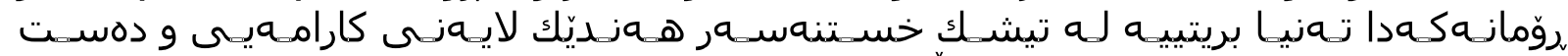

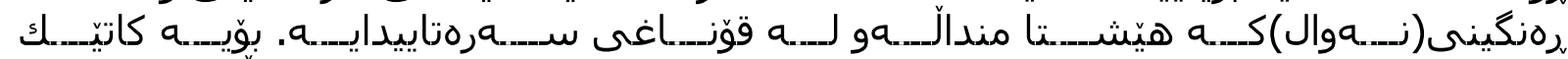

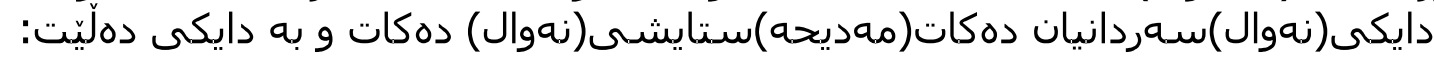

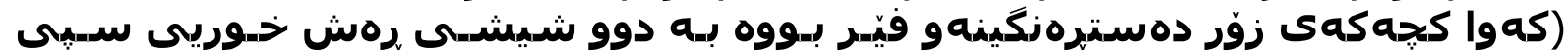

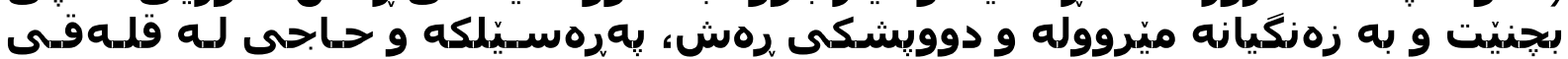

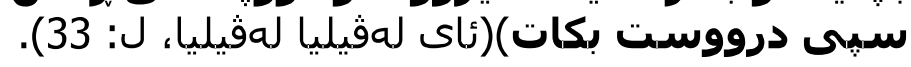

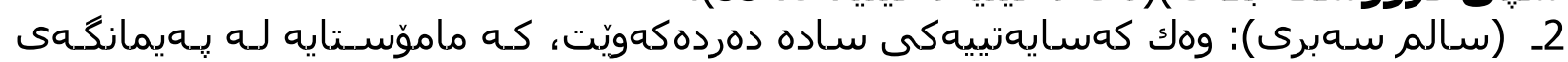

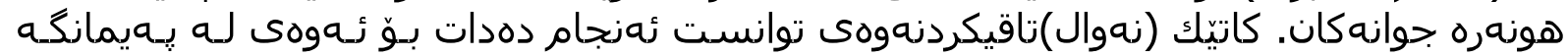

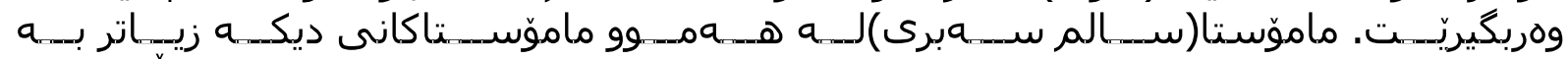

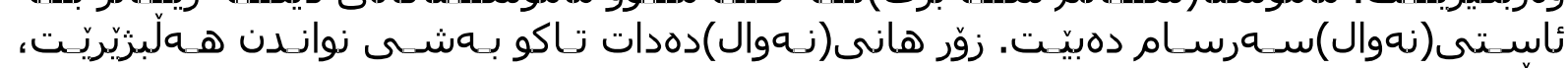

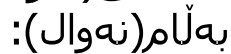

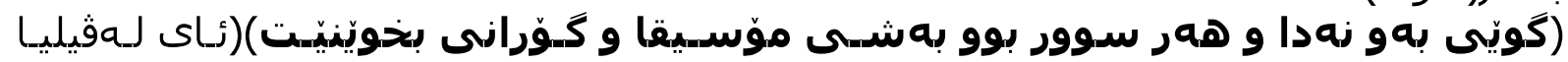

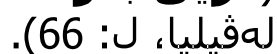

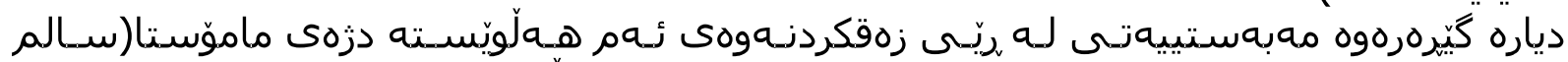

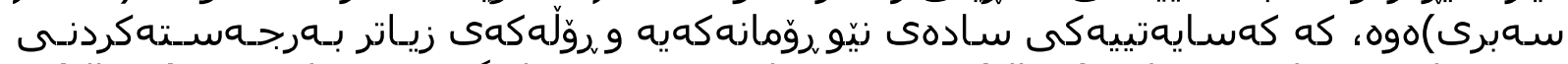

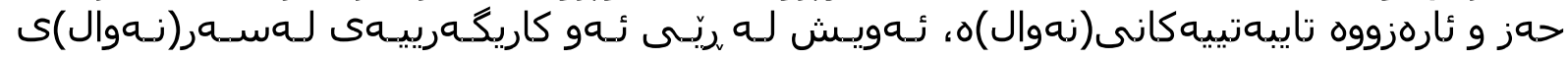

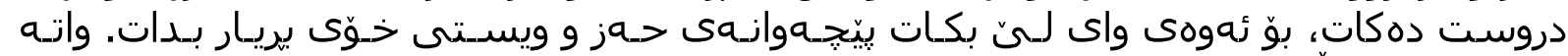

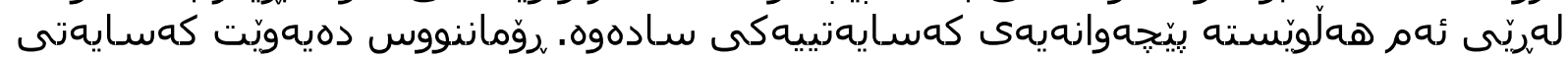

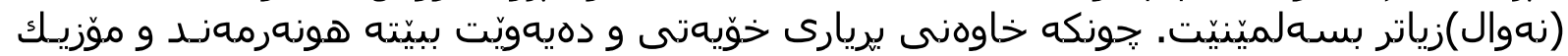

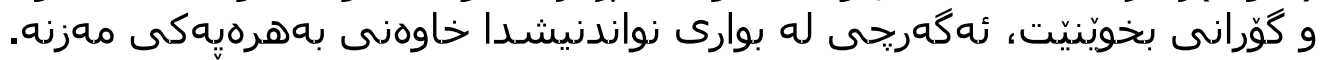

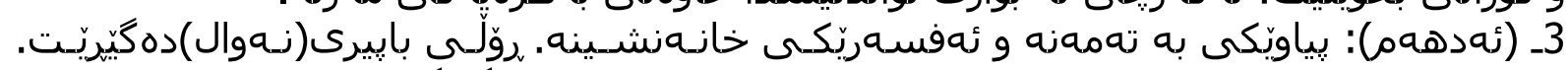

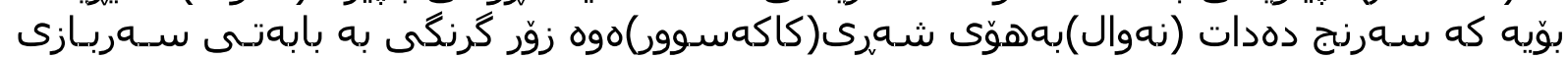

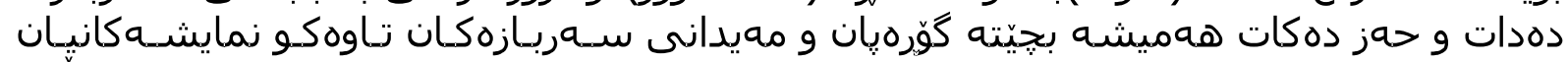

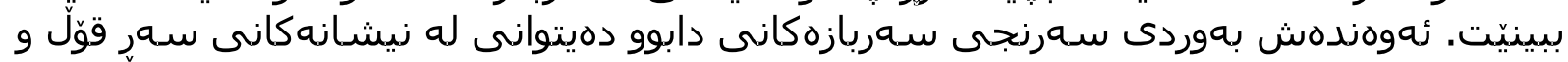

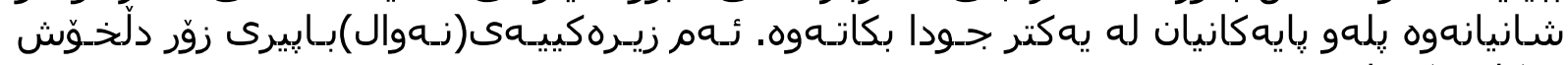
دمكات. كaوا:

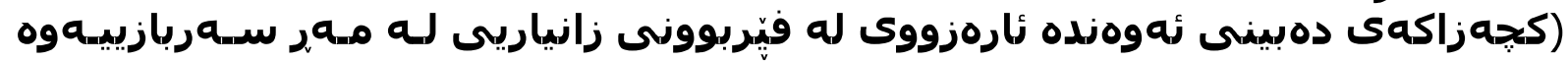

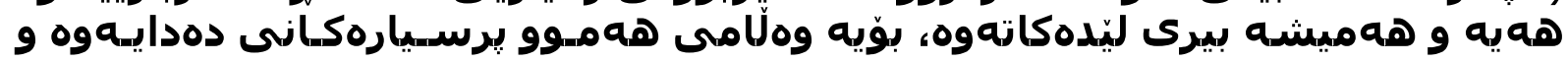

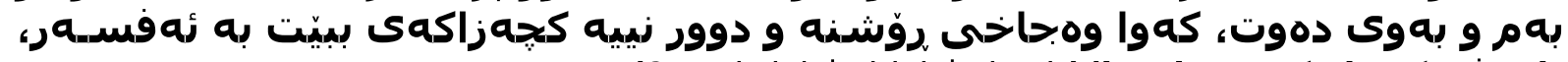

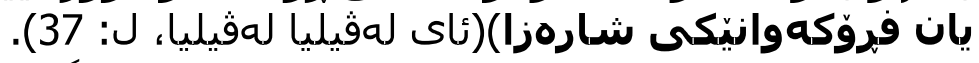

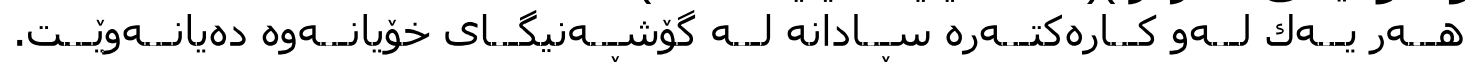

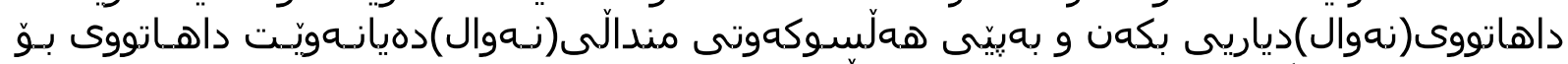

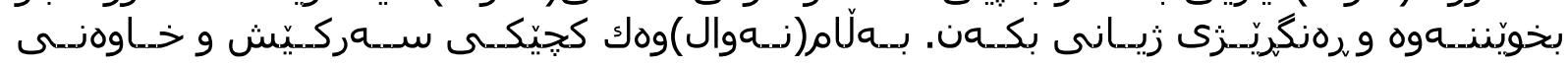

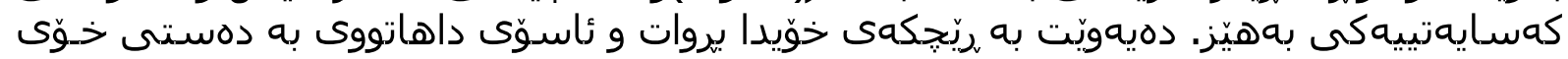

بنهوخشِيَنيِت.

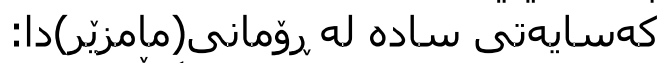

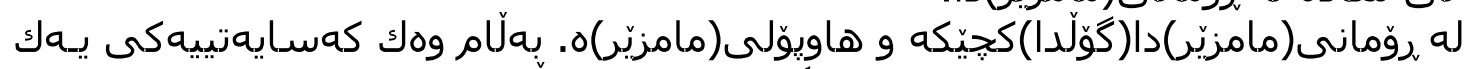

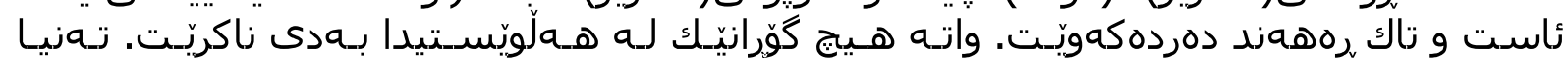




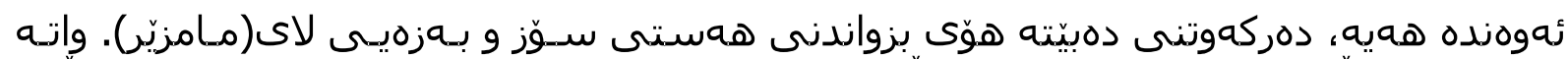

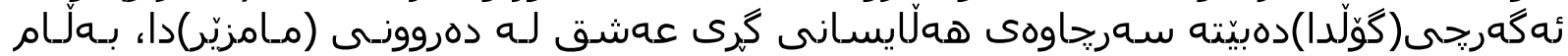

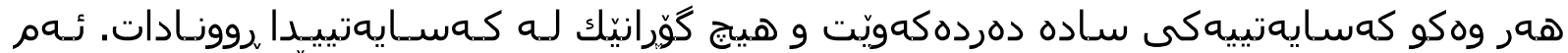

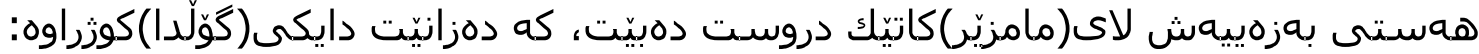

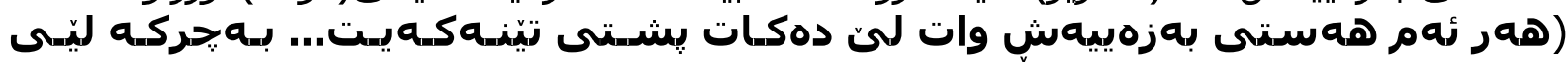

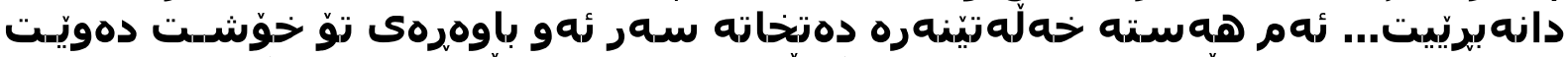

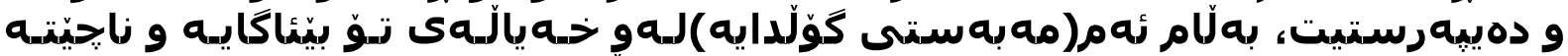

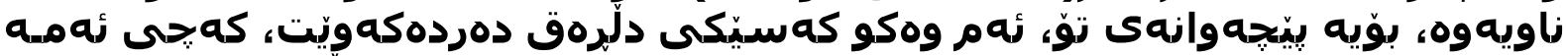

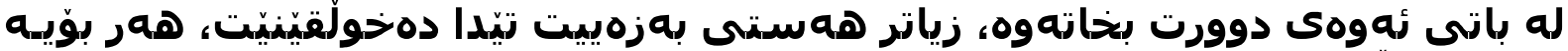

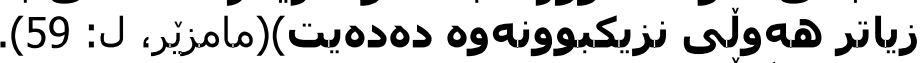

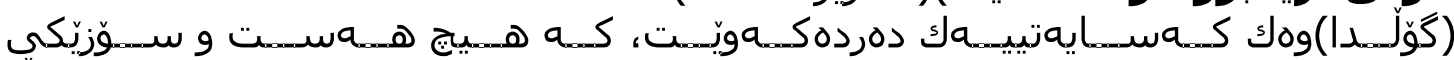

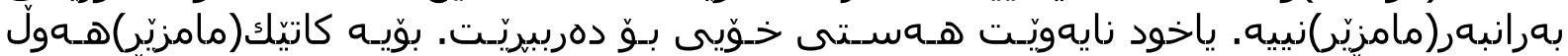

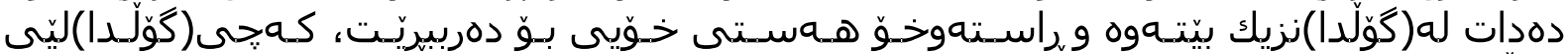

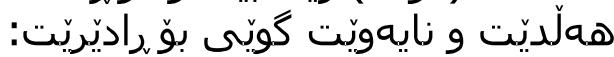

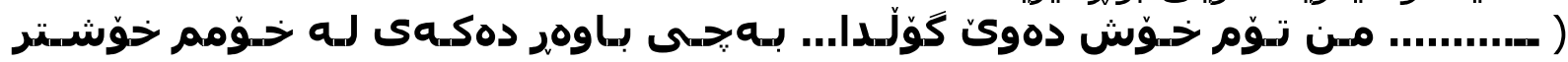

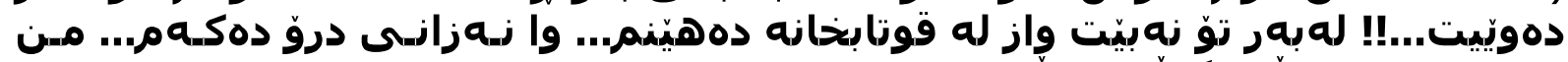

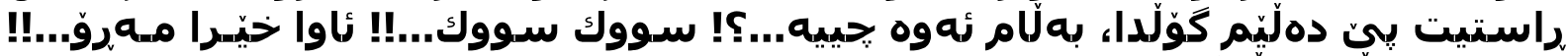

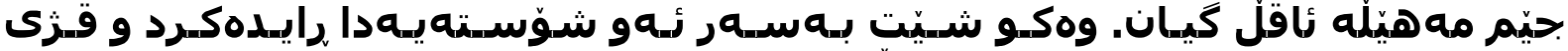

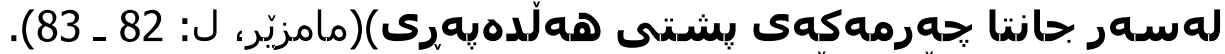

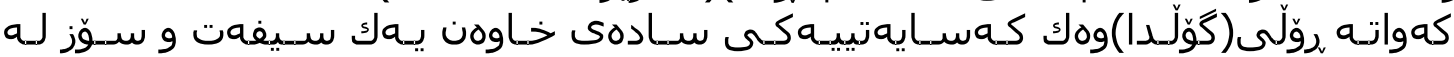

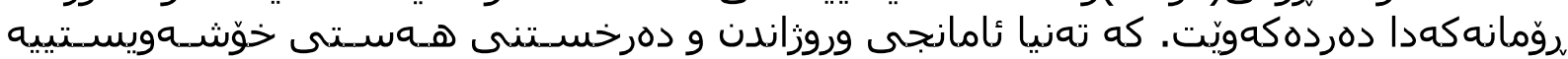

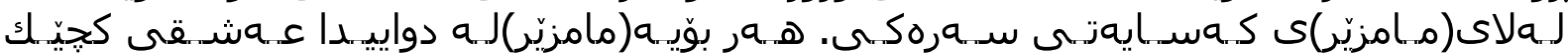

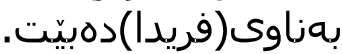

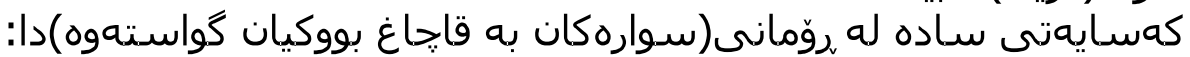

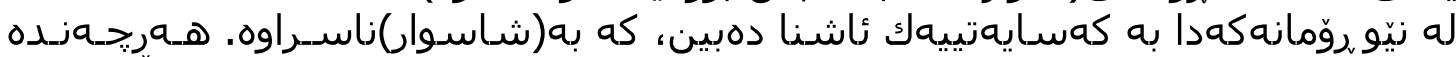

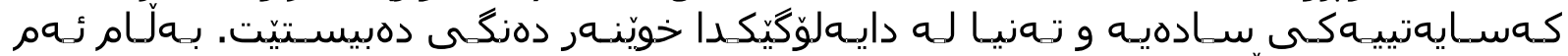

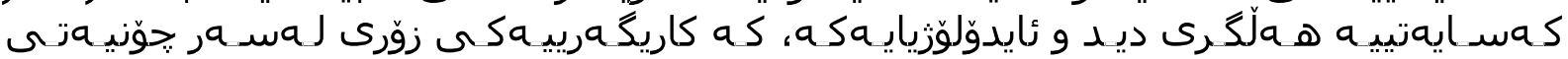

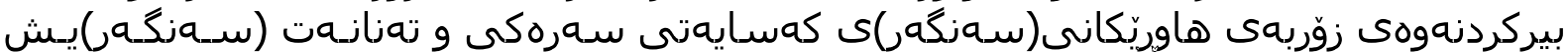

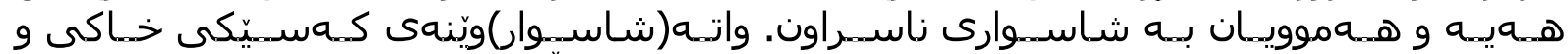

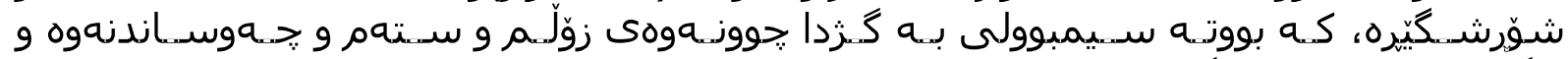

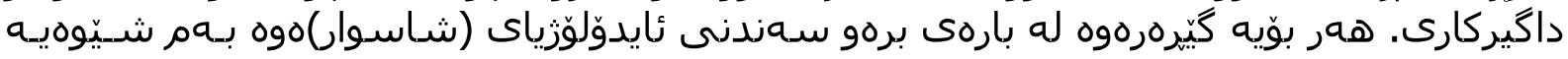

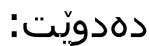

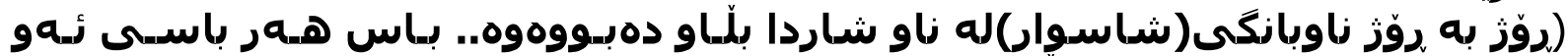

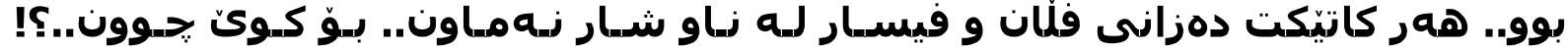

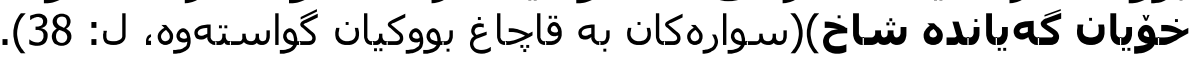

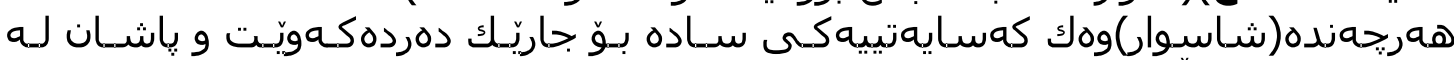

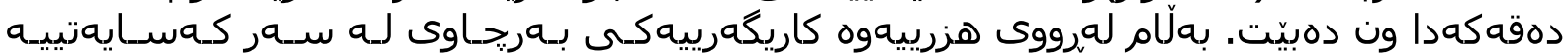

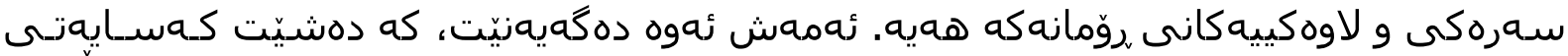

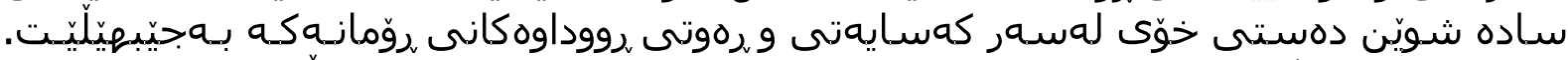

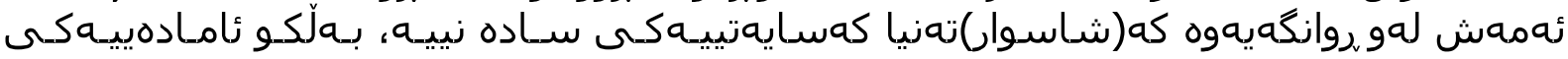

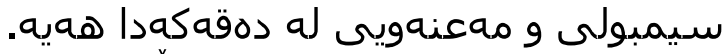

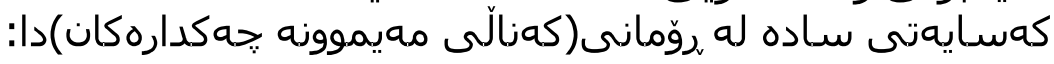

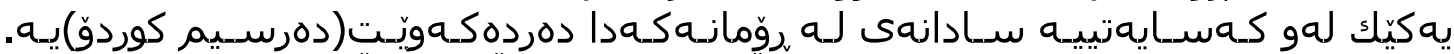

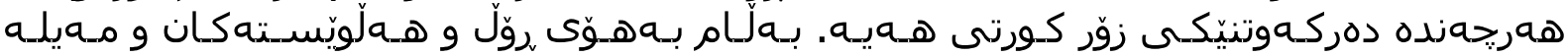

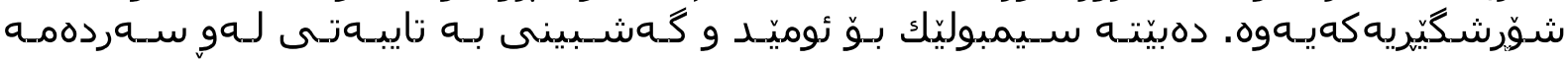

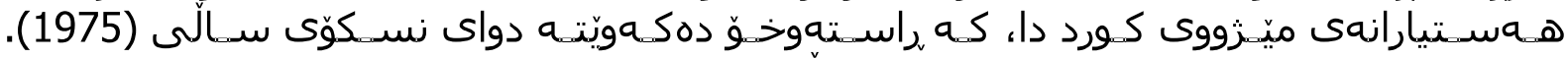

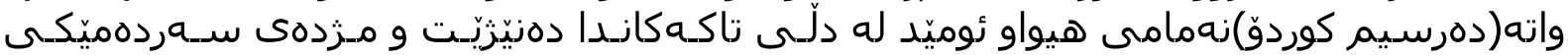

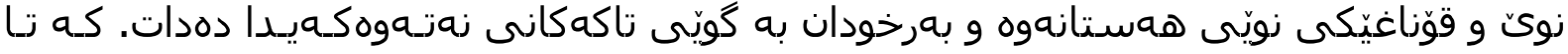

International Journal of Kurdish Studies Vol.5/1 ( January 2019) 


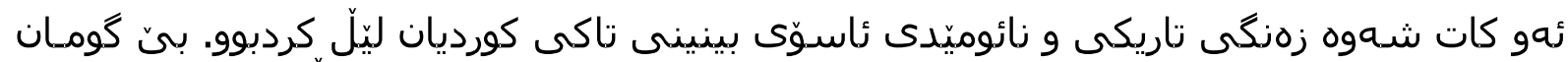

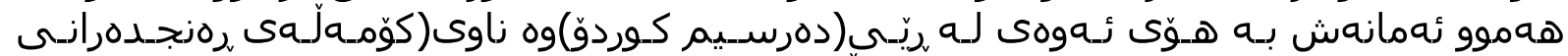

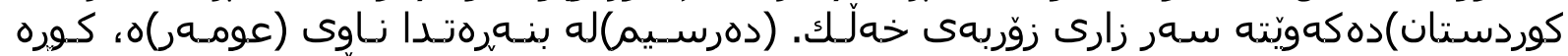

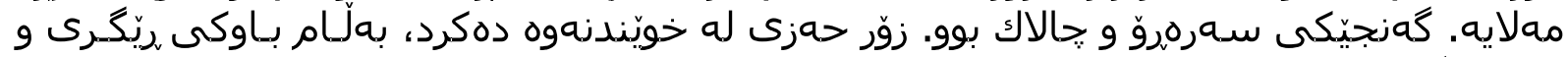

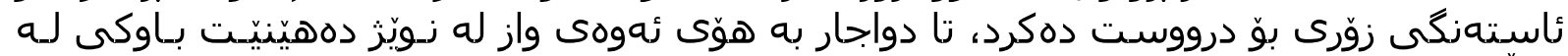

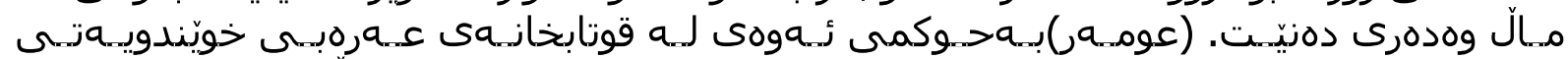

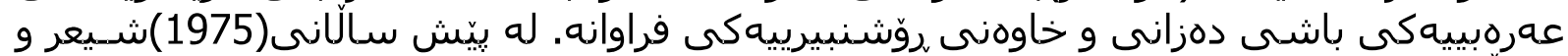

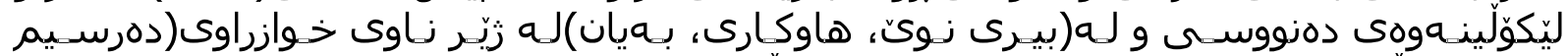

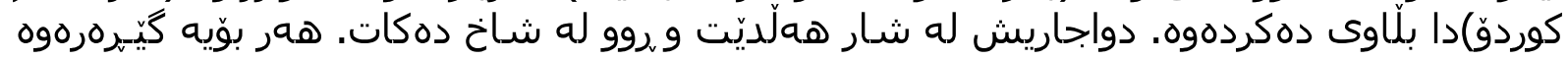

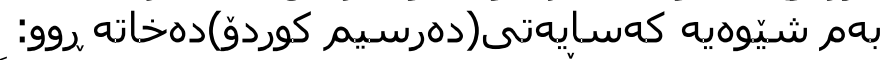

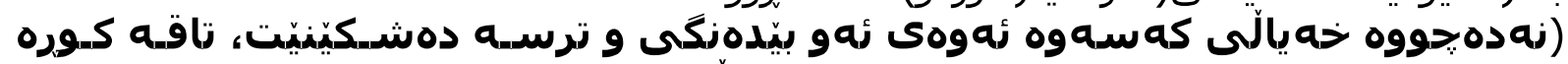

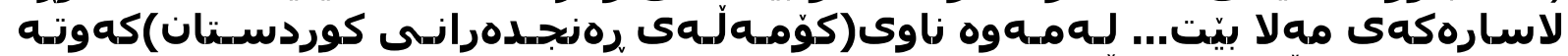

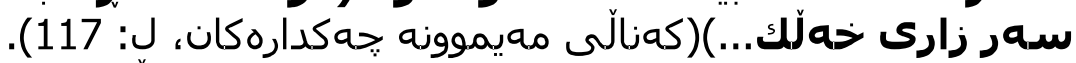

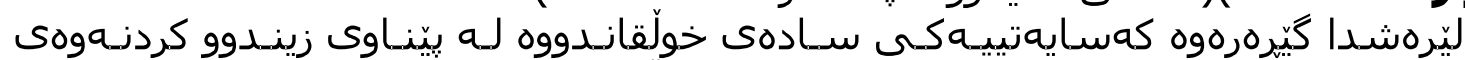

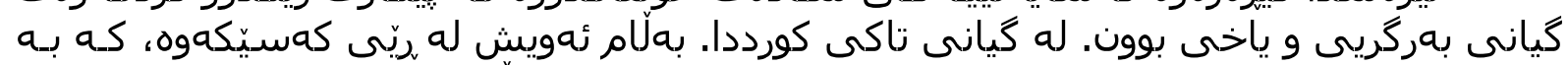

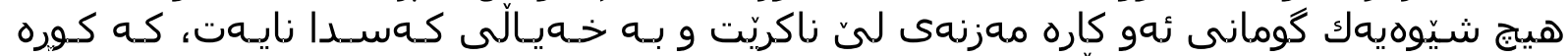

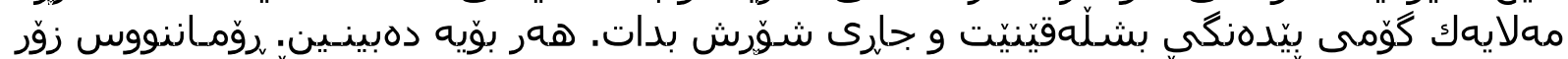

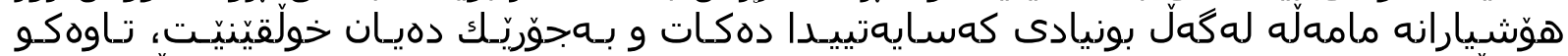

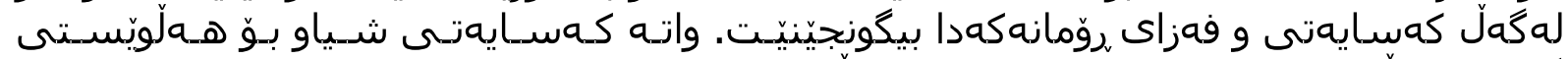

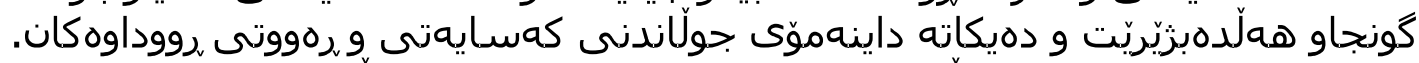

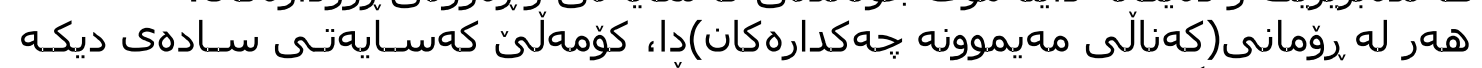

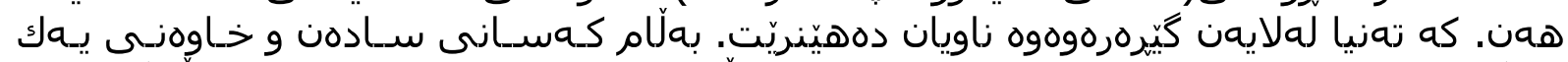

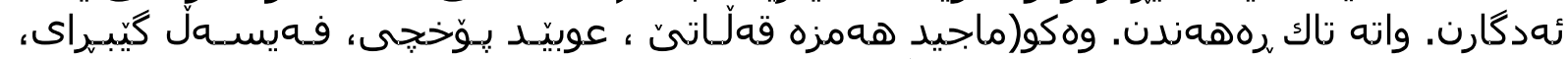

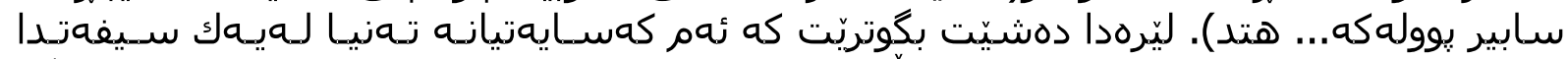

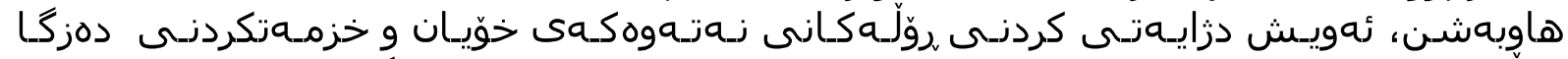

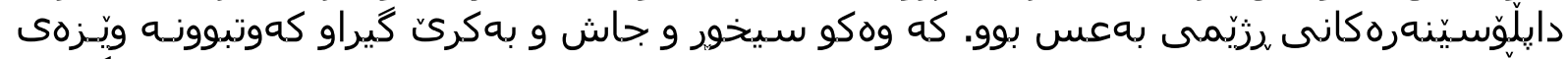

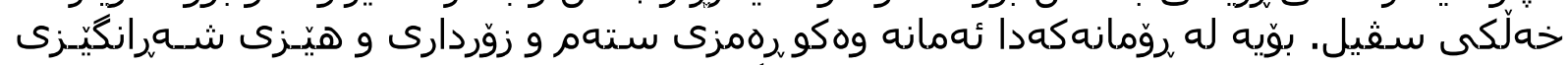

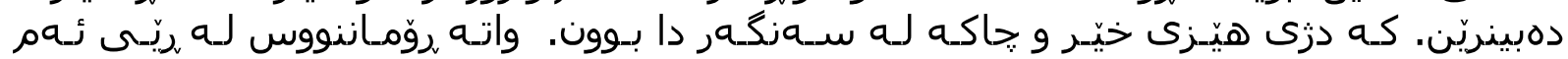

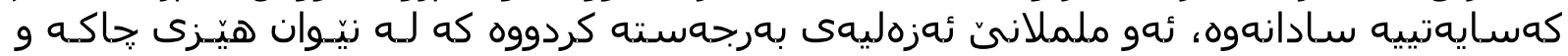

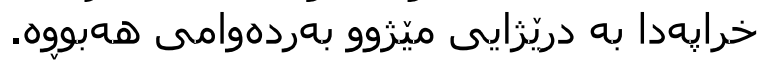

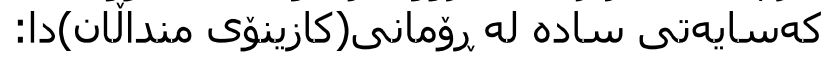

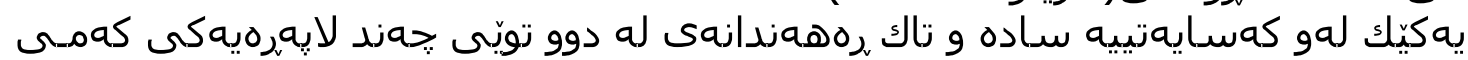

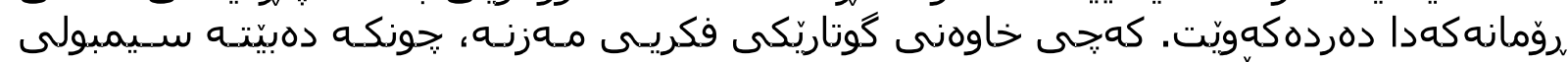

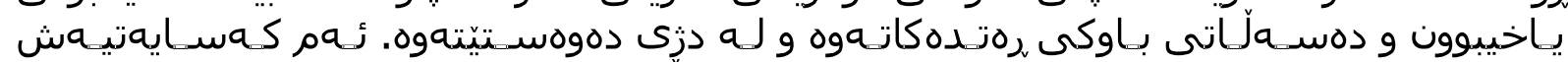

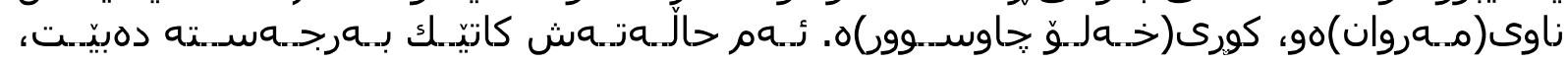

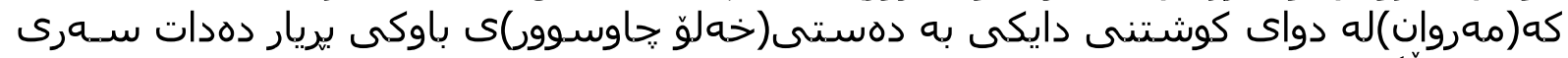

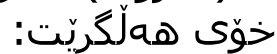

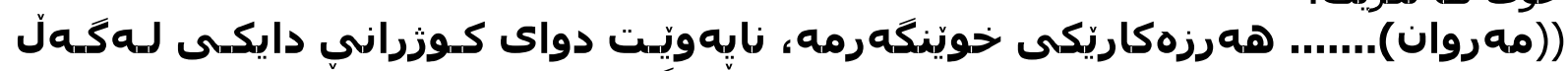

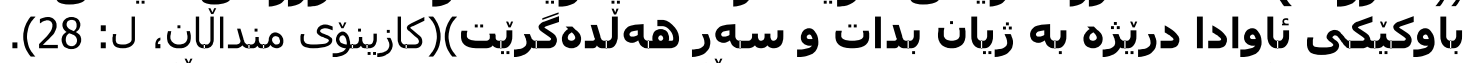

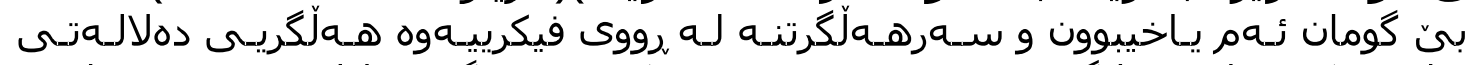

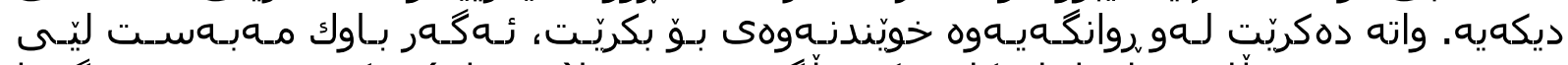

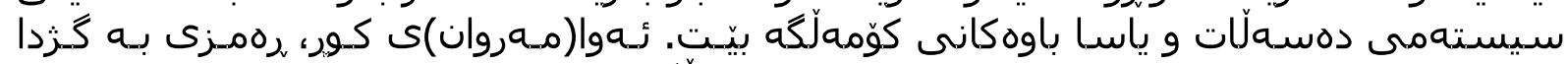

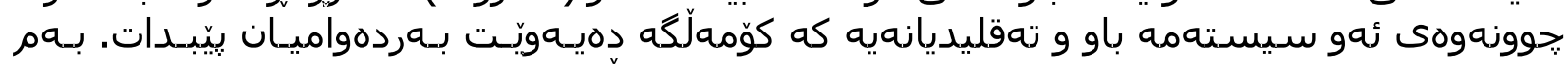

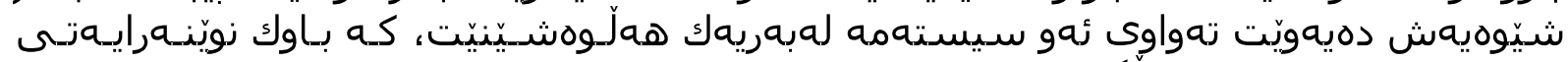

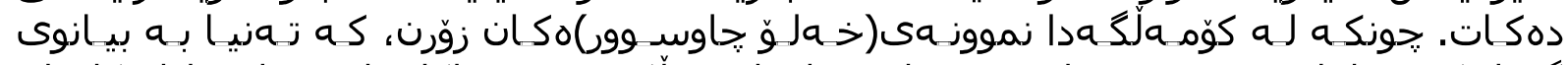

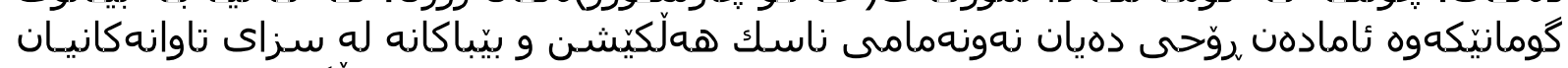

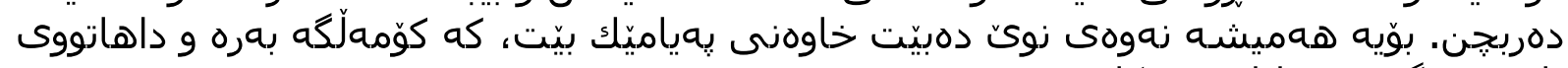

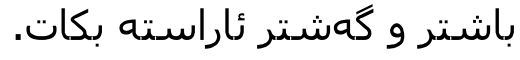




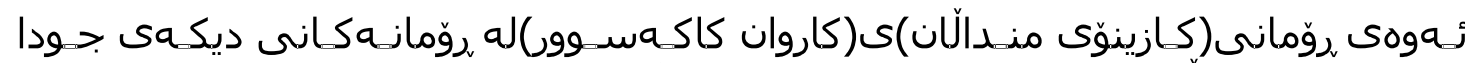

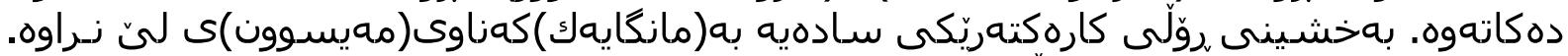

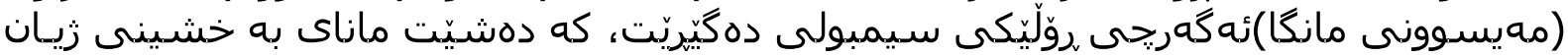

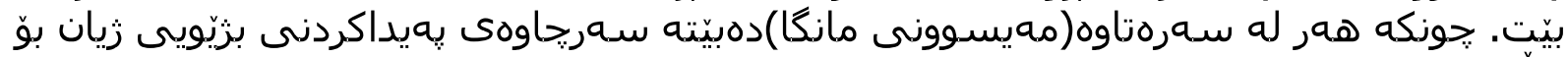

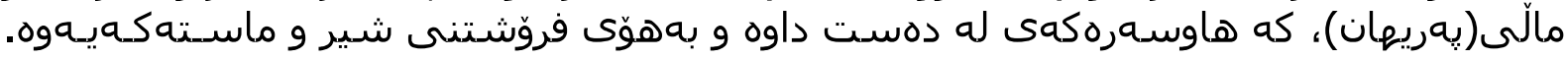

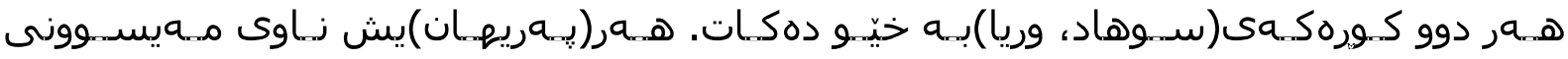

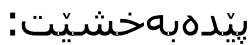

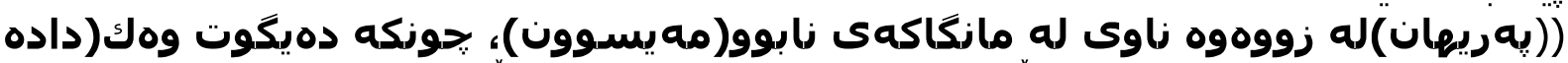

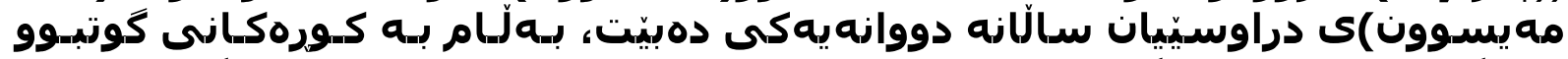

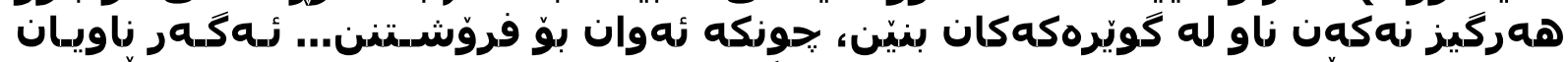

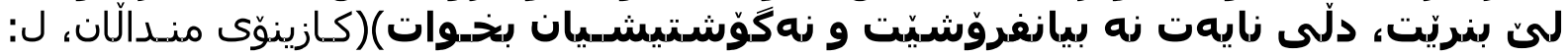

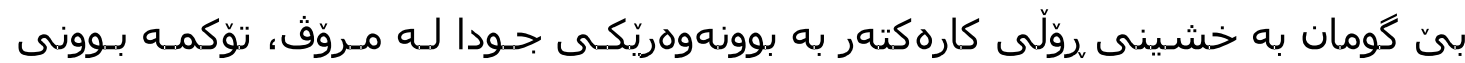

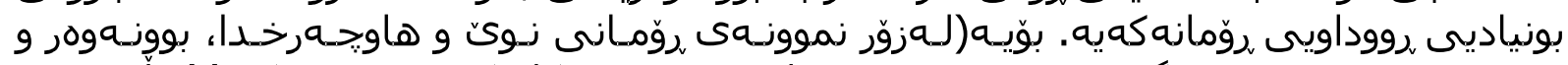

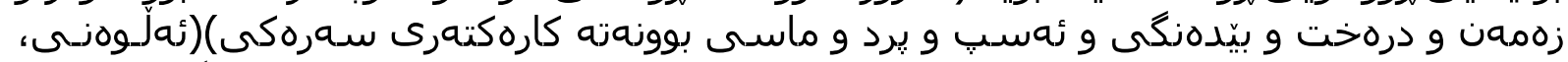

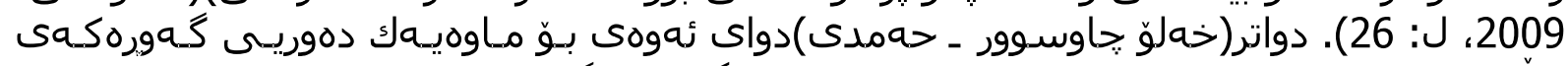

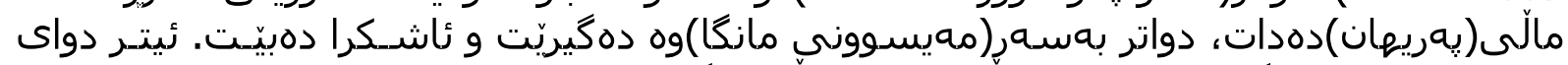

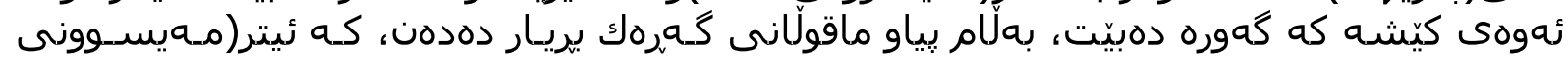

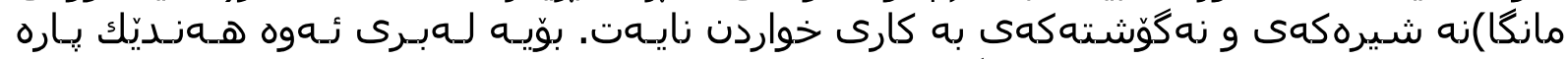

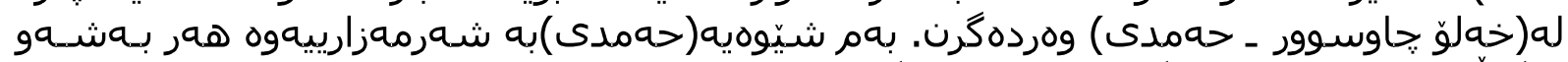

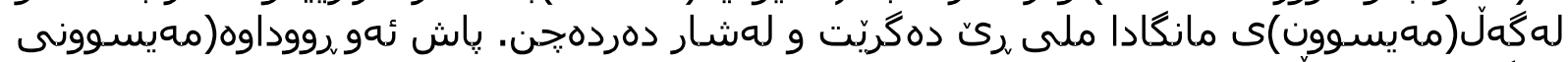

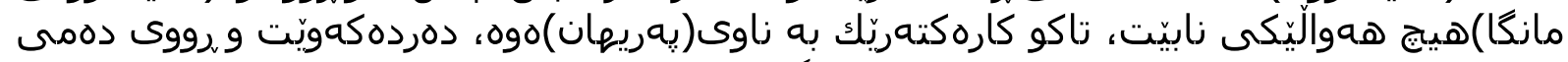

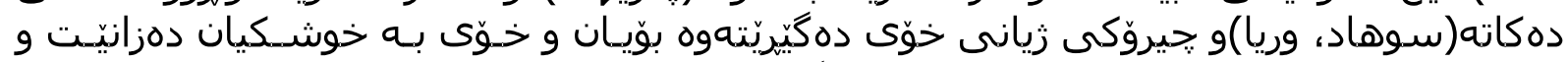

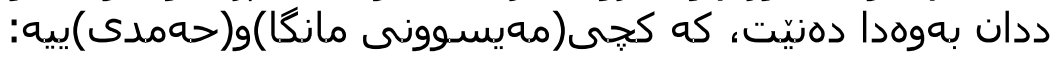

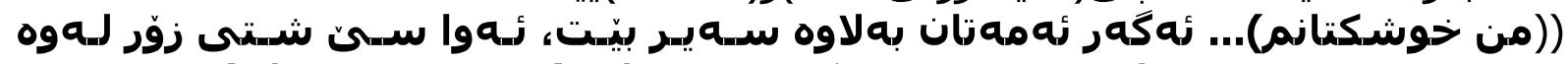

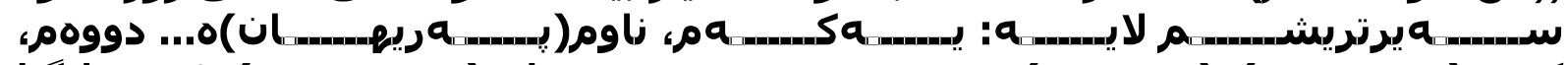

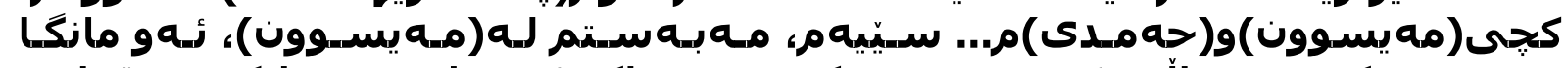

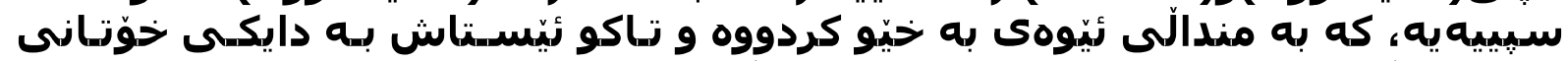

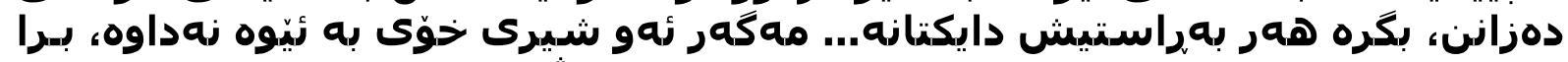

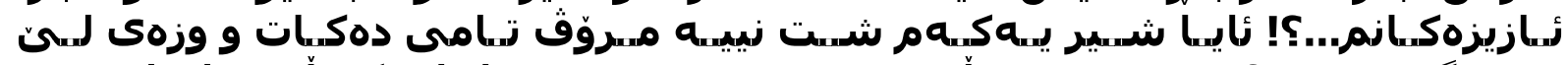

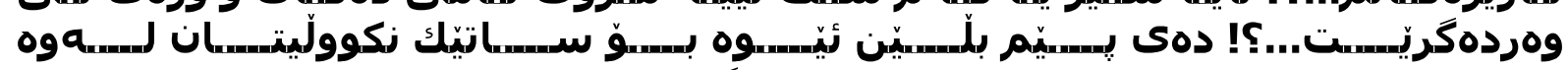

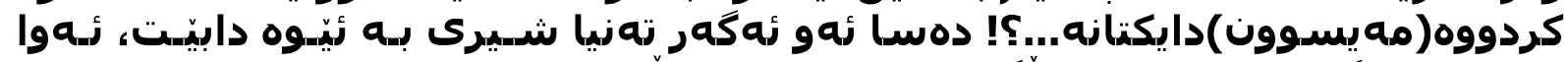

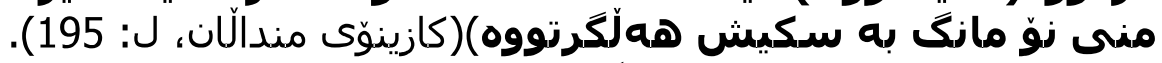

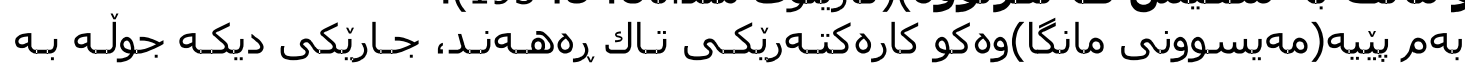

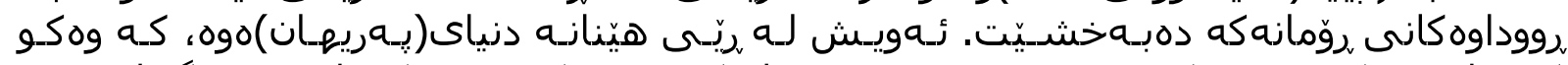

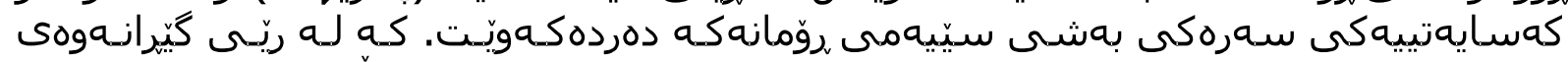

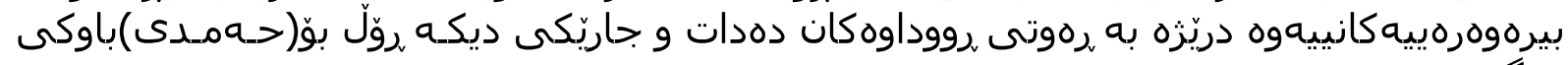

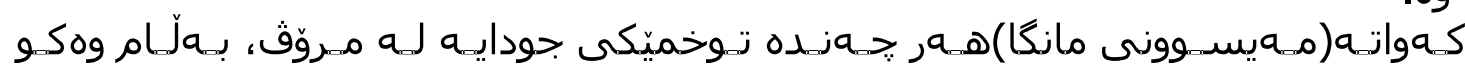
ده كيّرِيّتوهوه.

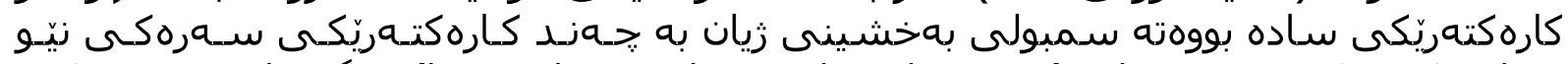

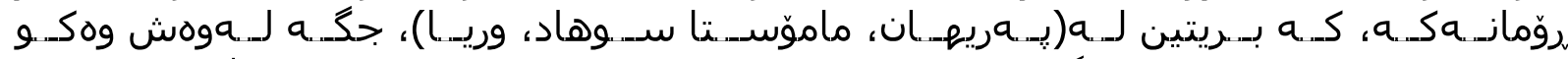

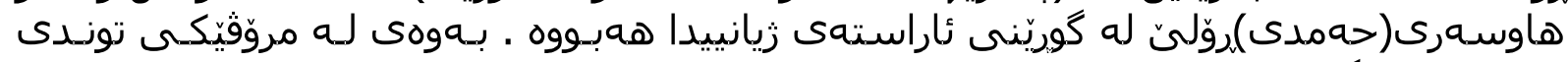

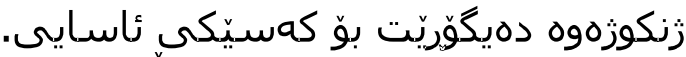

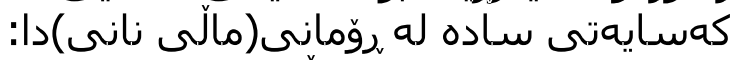

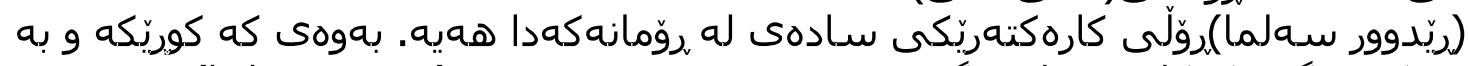

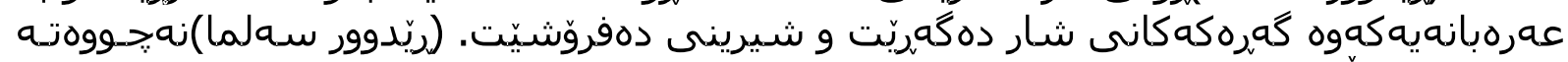

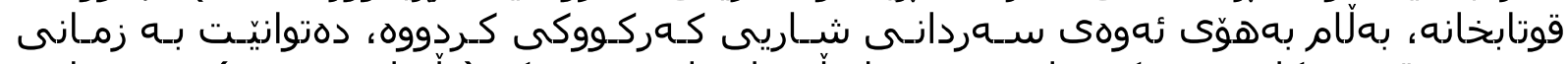

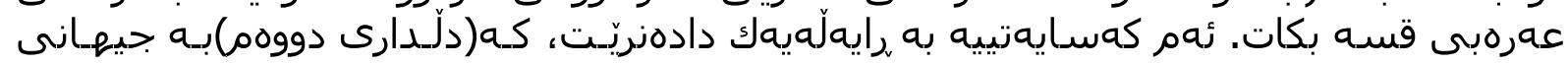




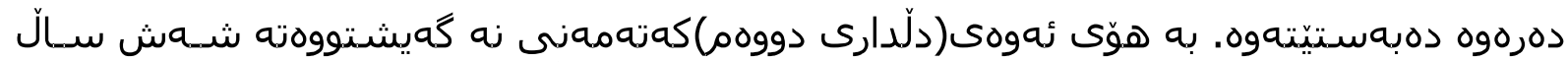

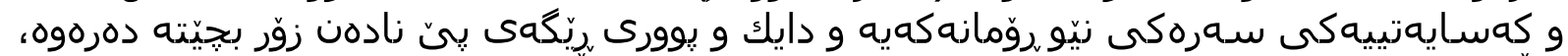

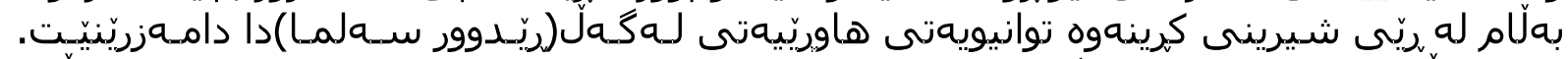

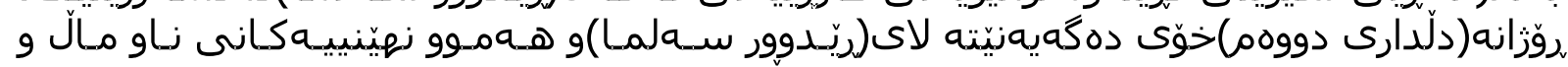

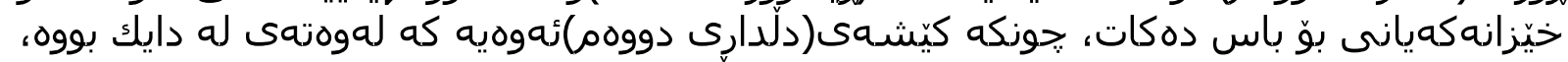

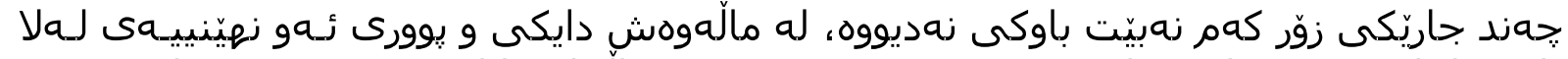

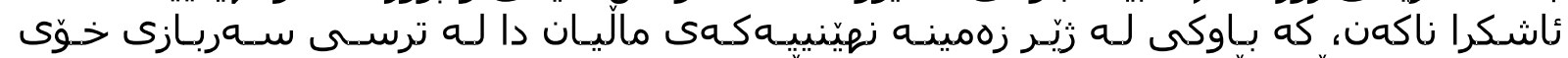

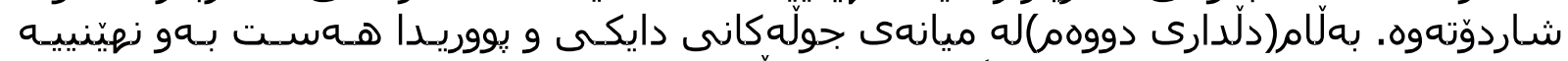

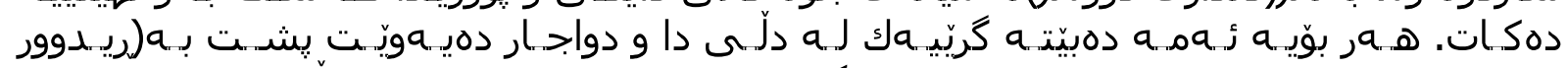

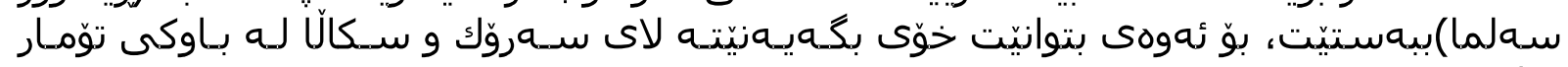

بكات:

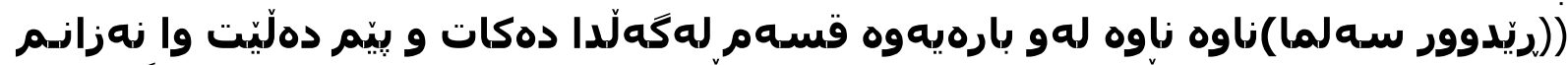

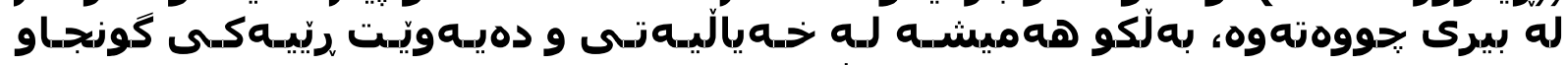

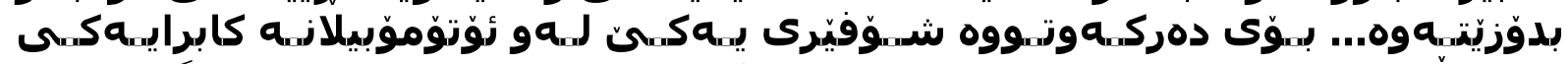

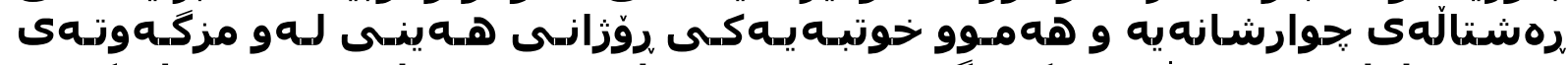

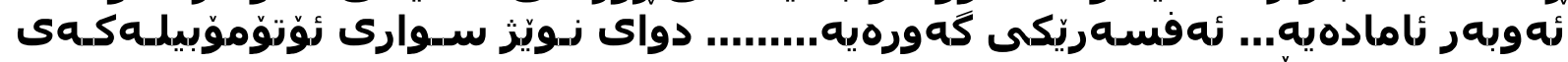

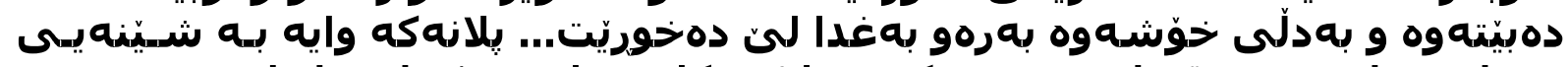

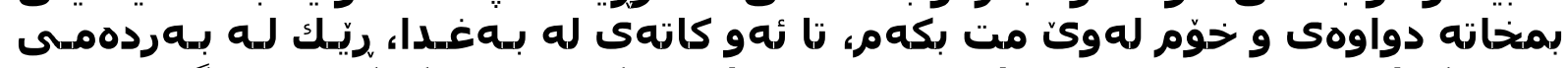

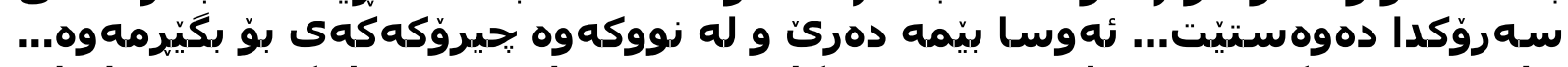

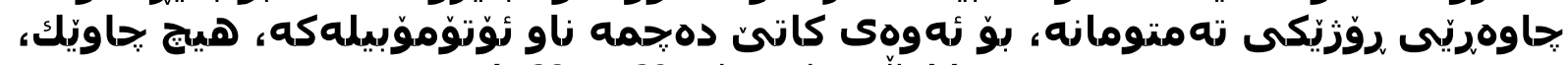

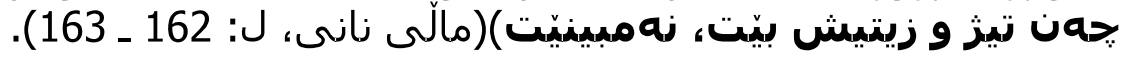

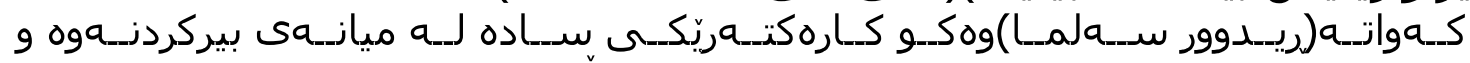

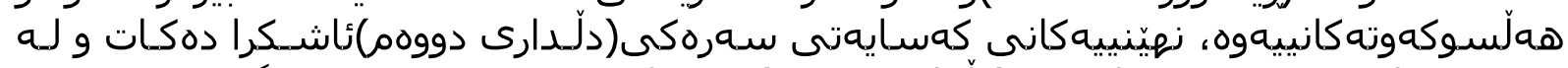

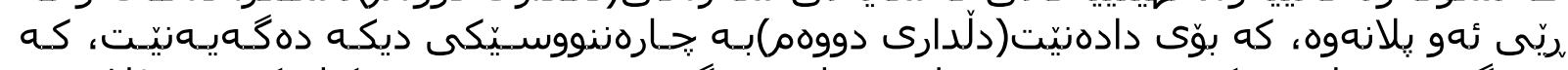

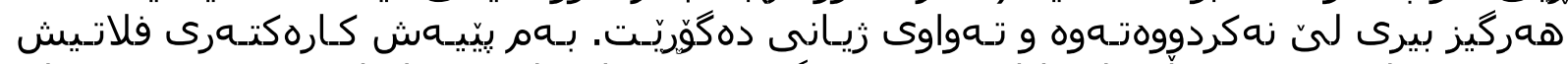

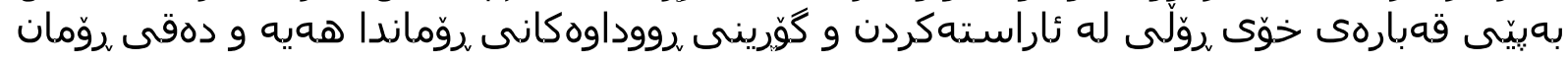

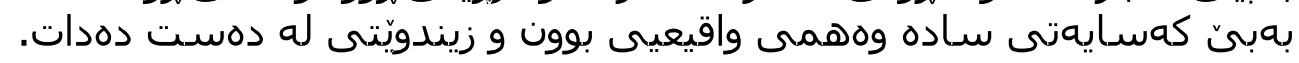

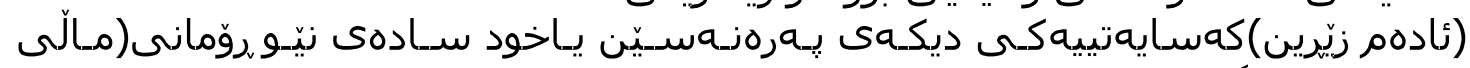

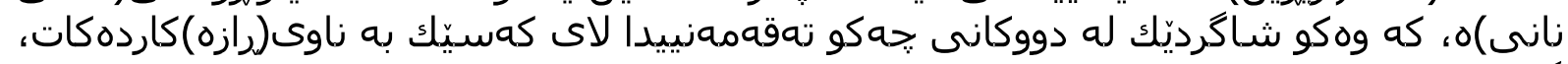

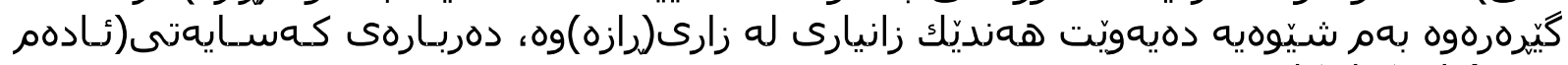

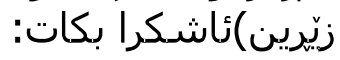

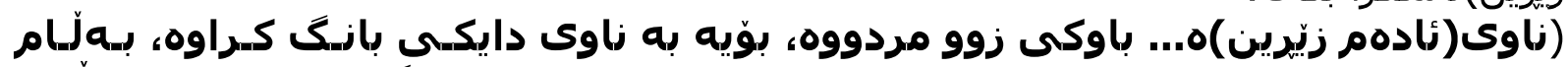

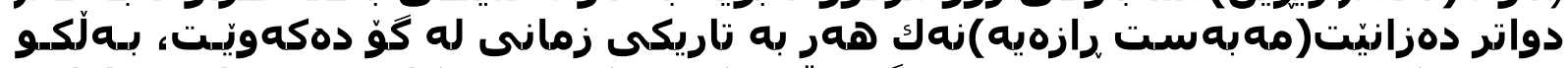

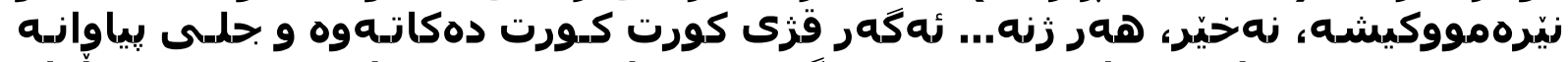

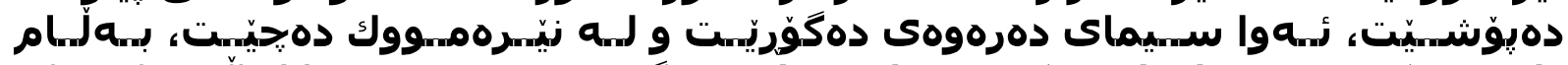

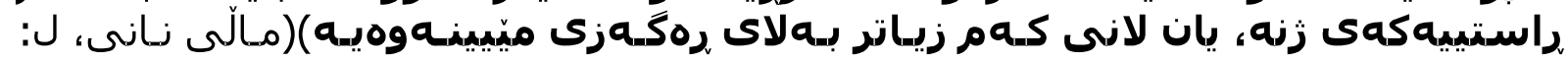

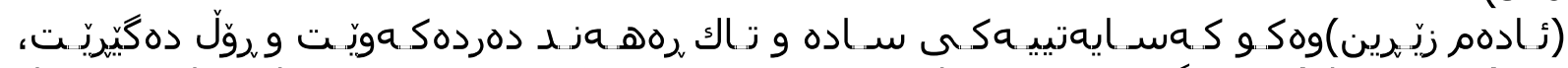

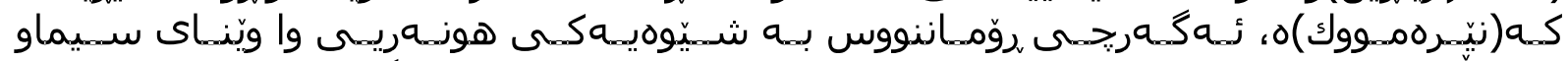

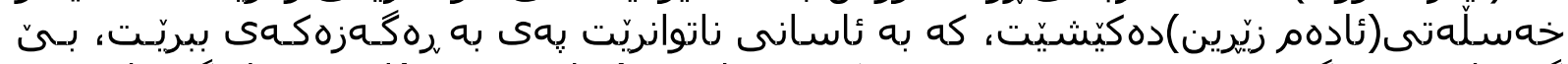

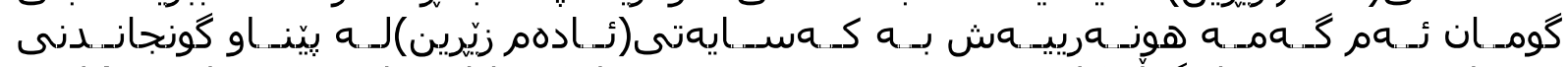

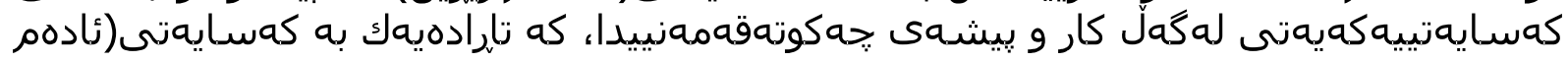

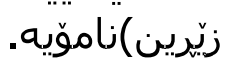

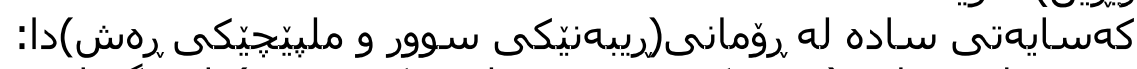

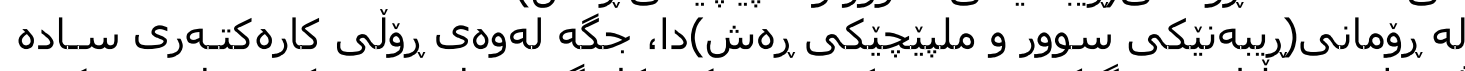

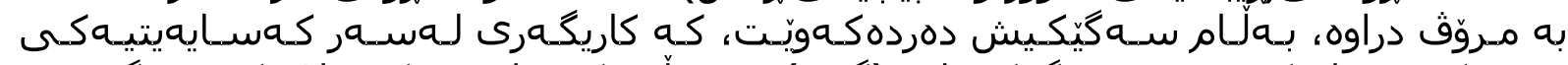

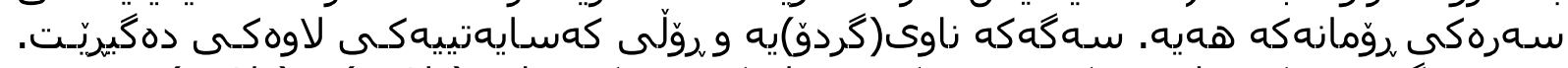

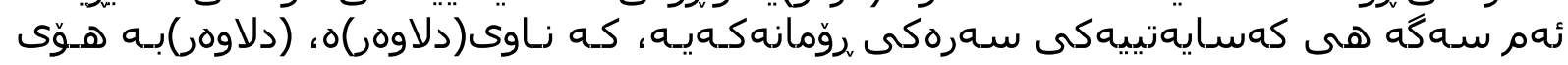

International Journal of Kurdish Studies Vol.5/1 ( January 2019) 


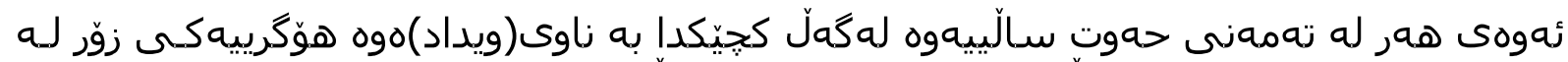

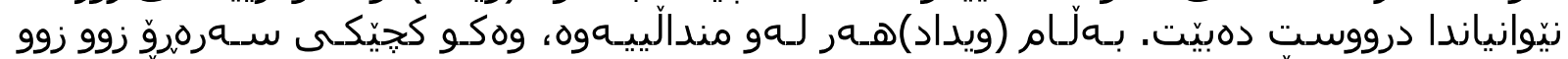

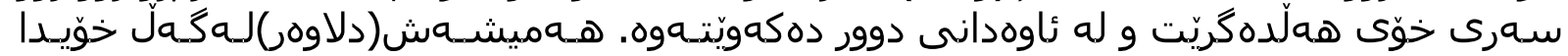

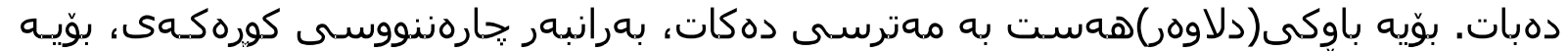

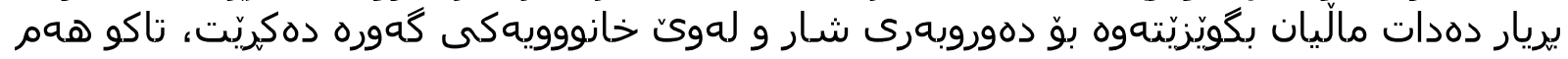

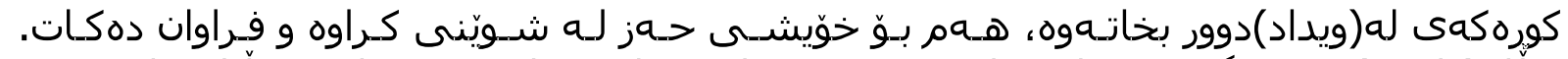

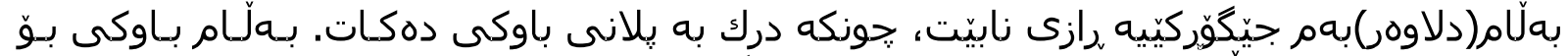

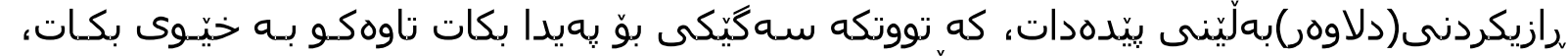

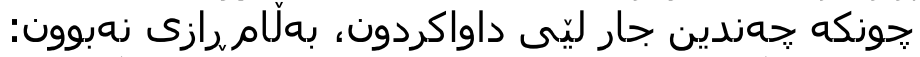

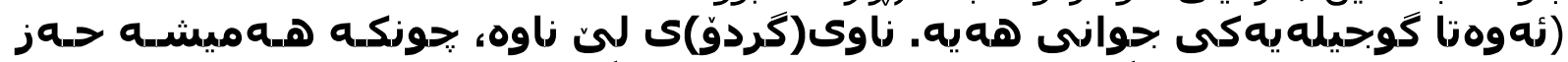

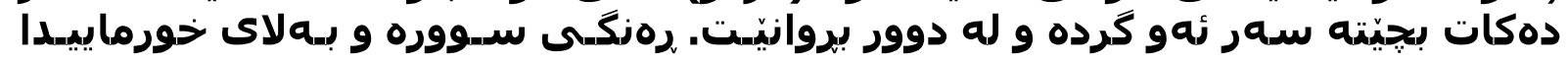

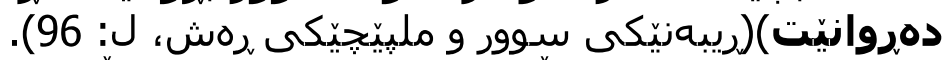

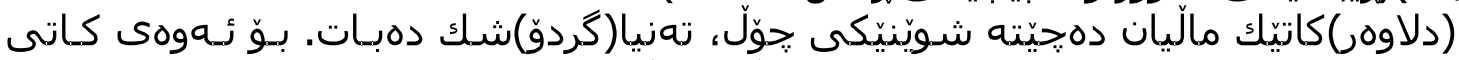

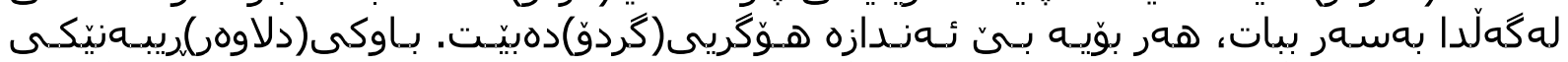

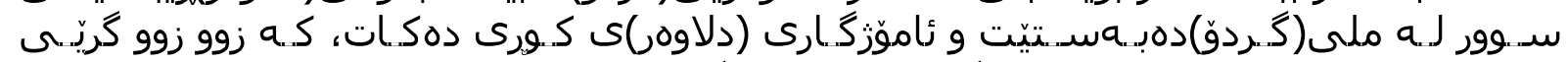

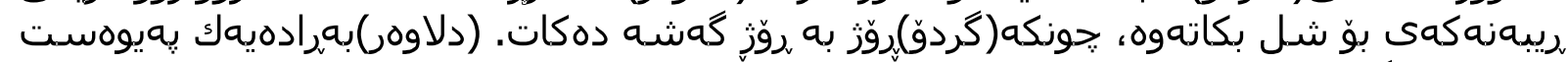

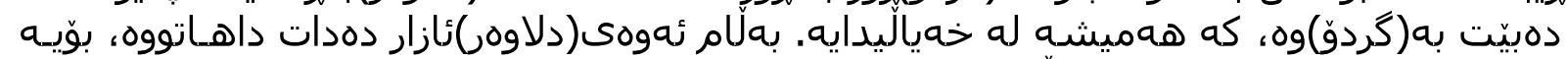

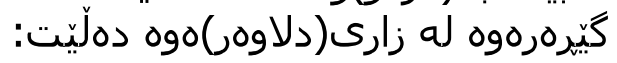

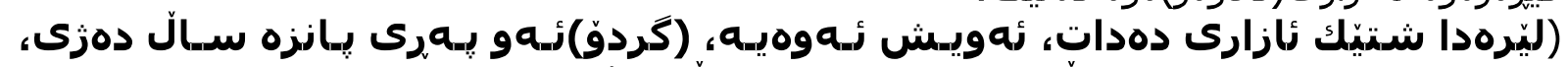

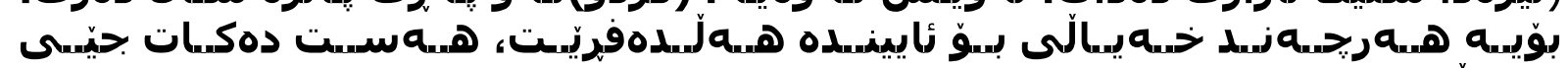

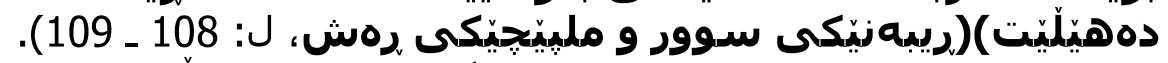

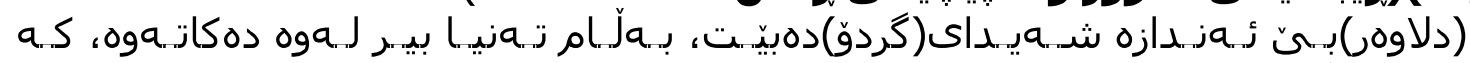

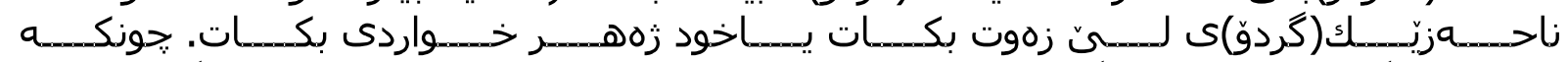

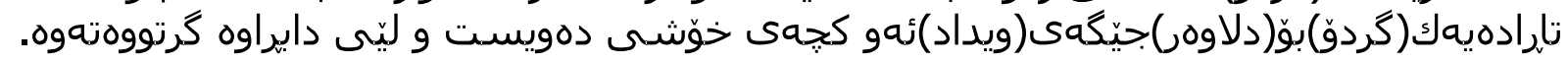

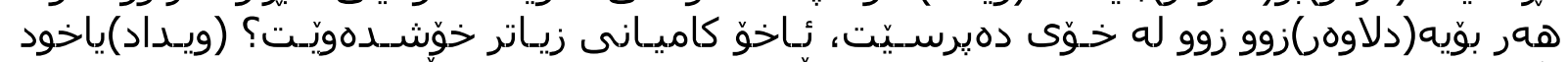

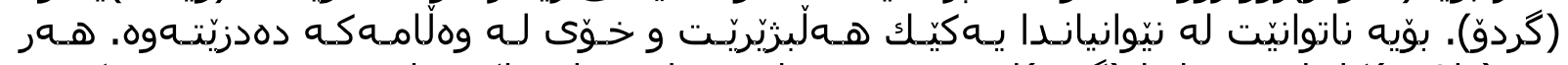

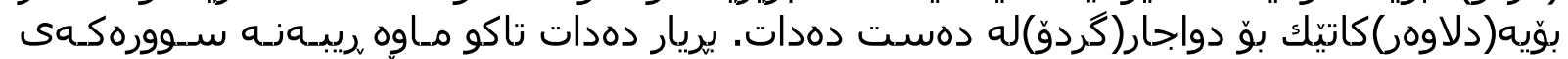

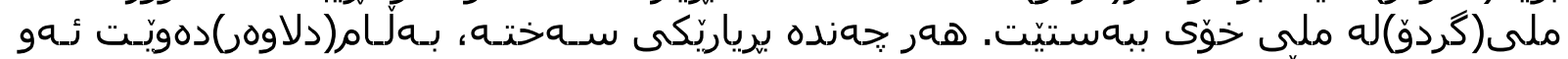

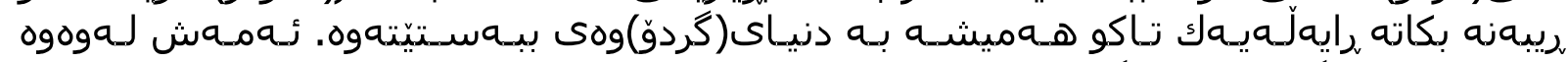

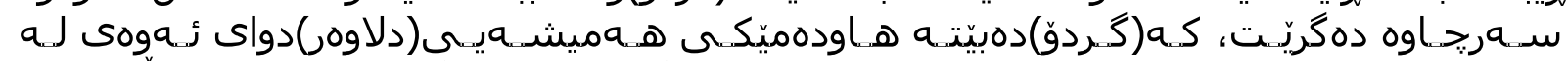

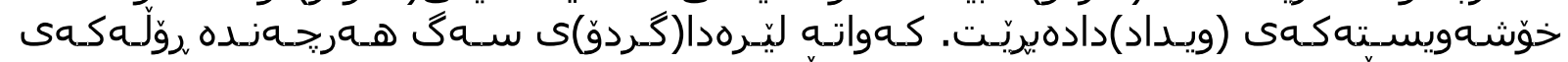

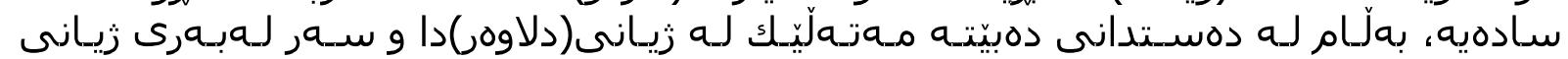

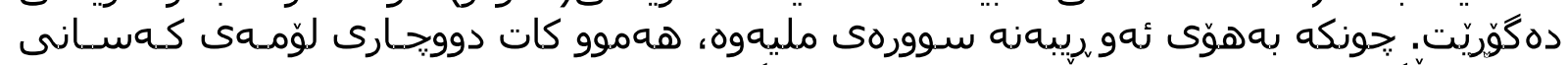

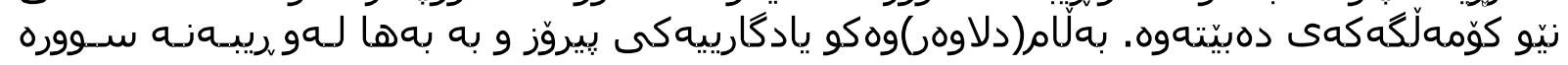

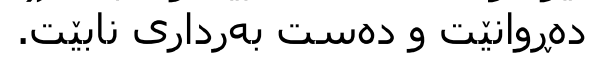




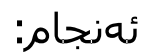

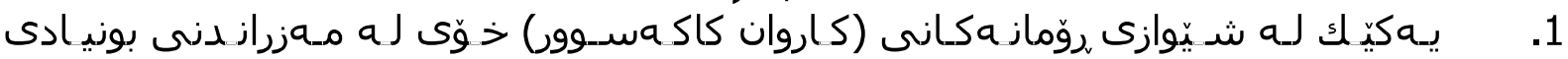

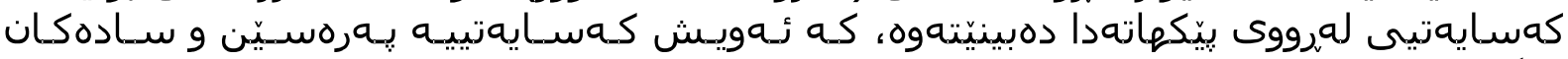

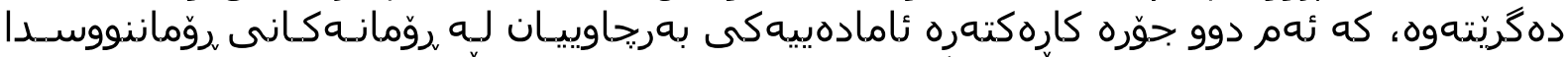

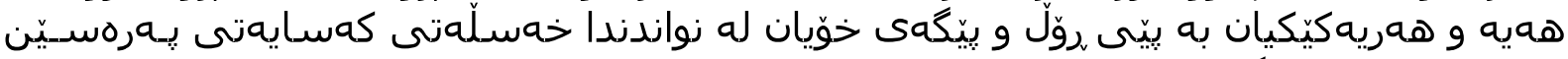

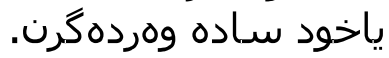

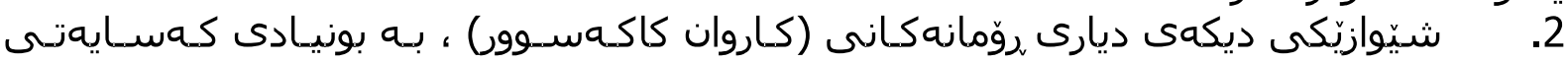

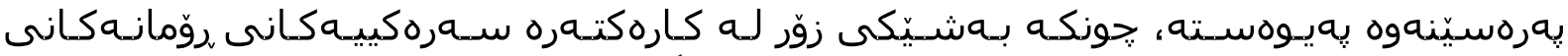

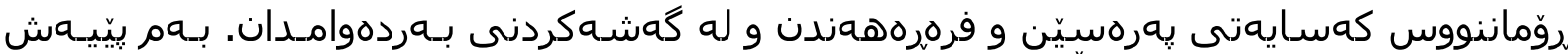

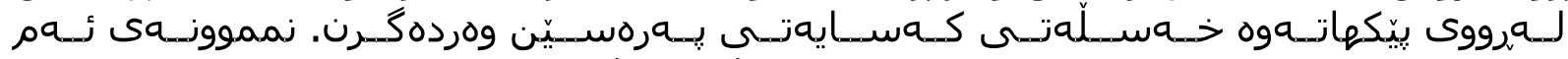

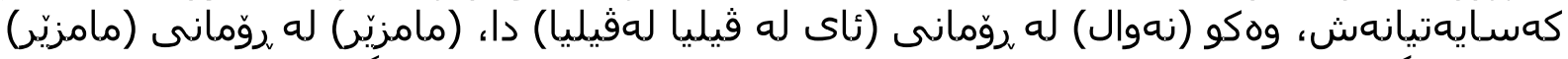

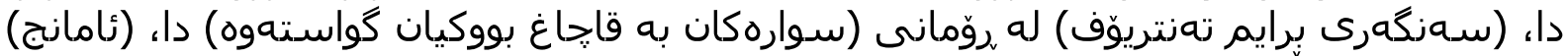

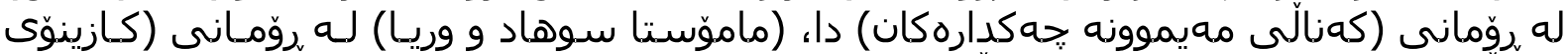

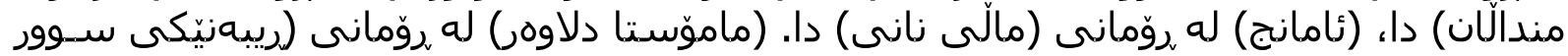

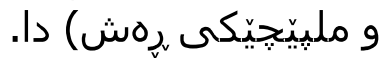
3.

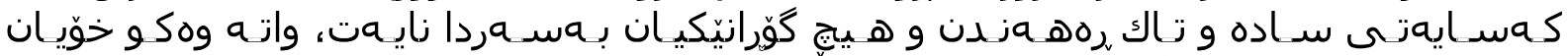

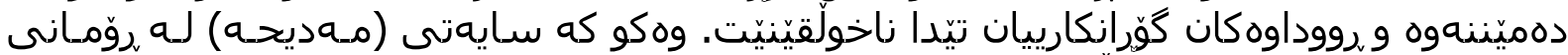

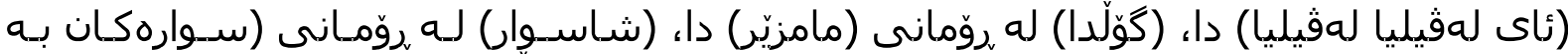

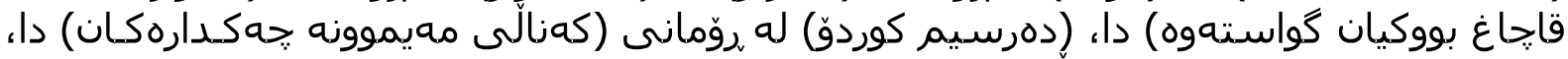

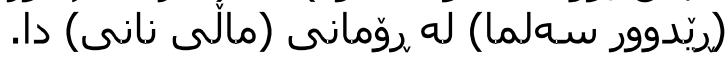

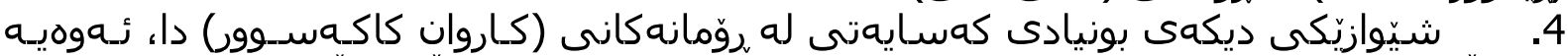

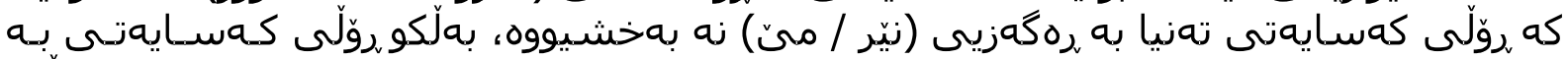

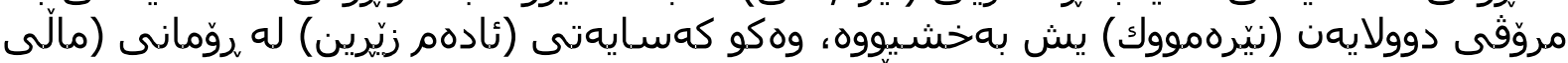

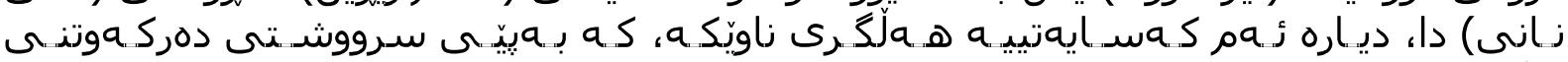

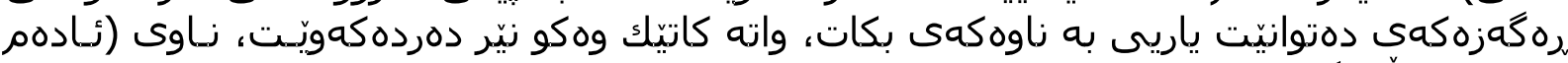

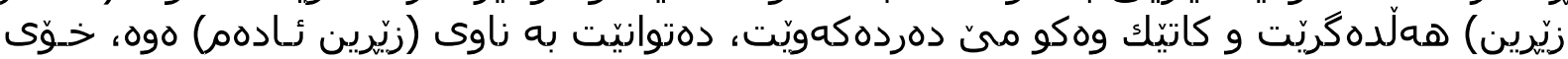
نمايش بكات.

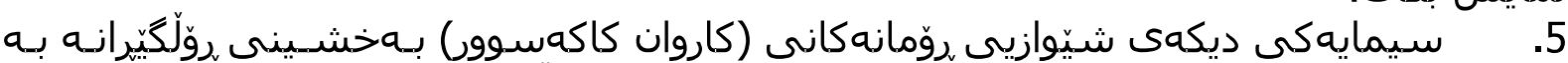

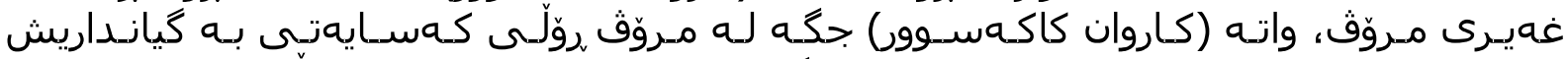

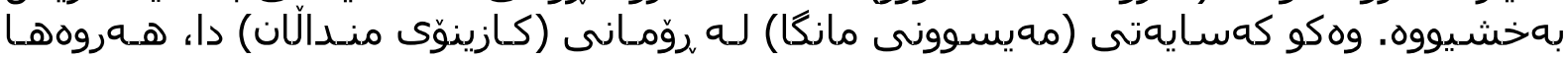

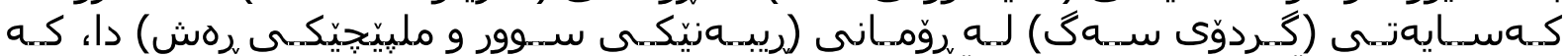

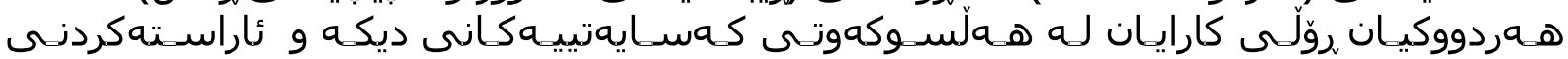

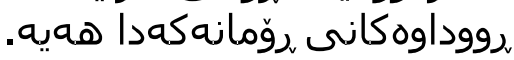

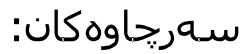

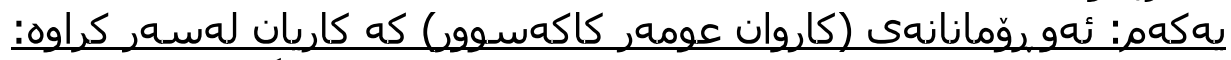

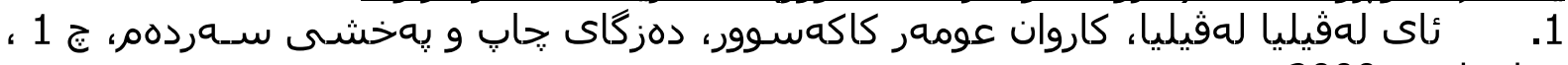
سليّمانى،

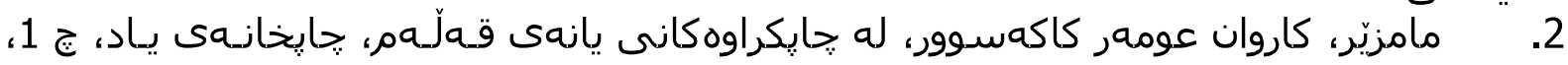
سليّمانى،

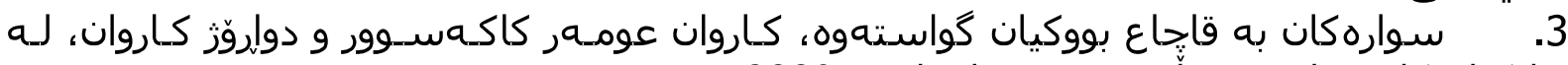

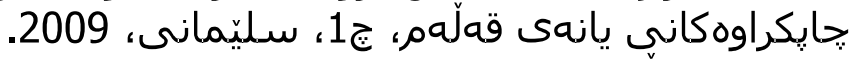

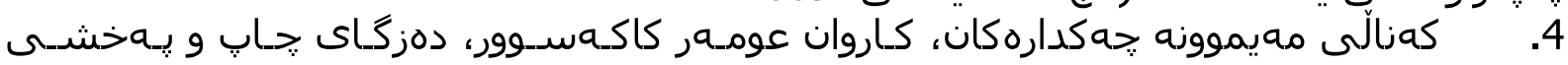
سهردهر، ج2، سليّمانى، مئورنه 2012. 


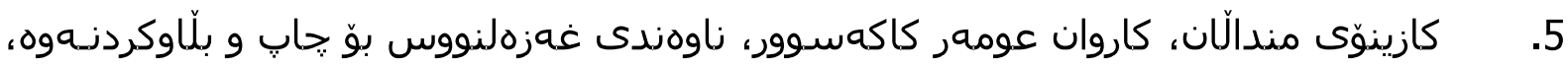

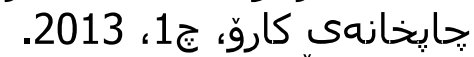

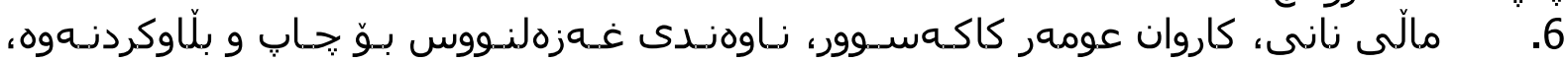
يإِخانaى تاران، ج1،

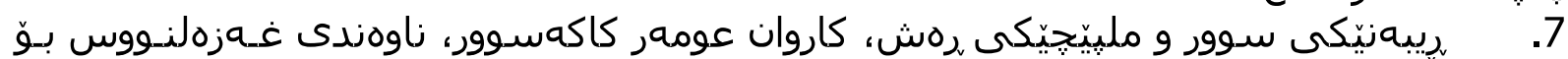

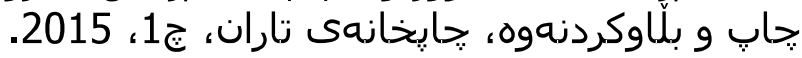
دووهم: به زمانى كوردى: كتيّب:

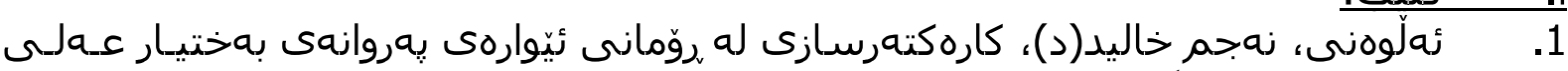

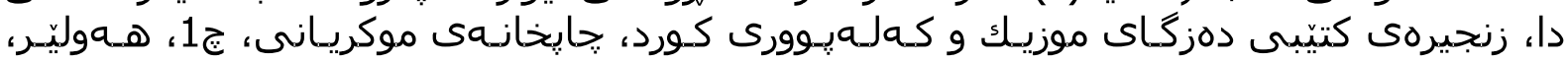
2009.

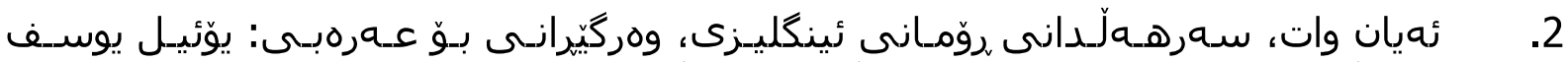

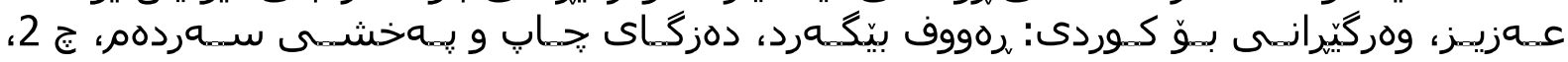
سليّمانى، 2009.

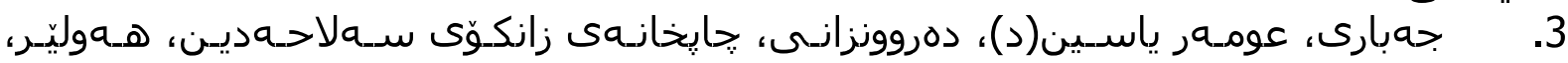
2000.

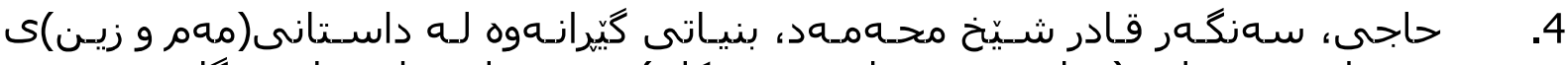

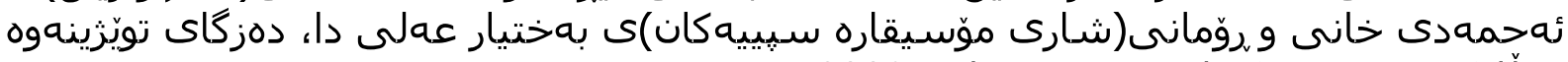

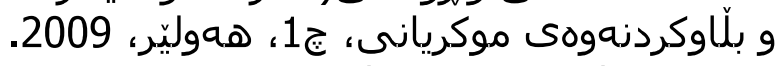

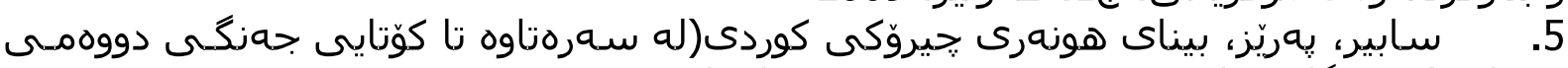

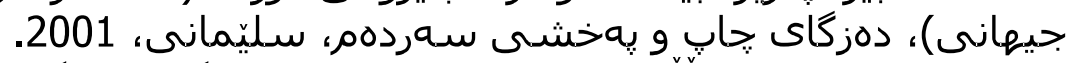

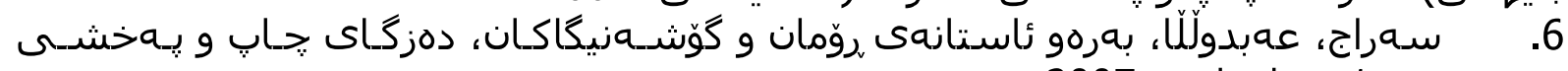

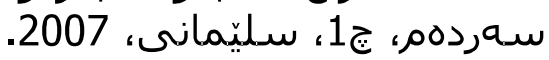
7.

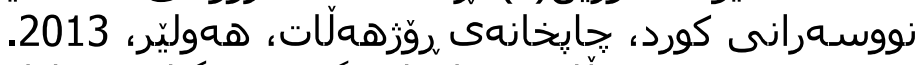

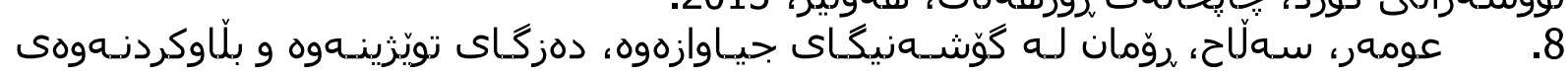
موكريانى، ج1، هوموليّر، 2010.

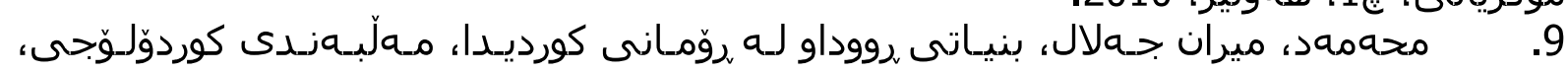

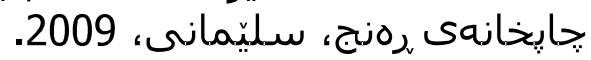
10.

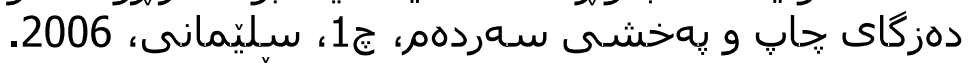
11.

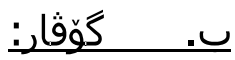

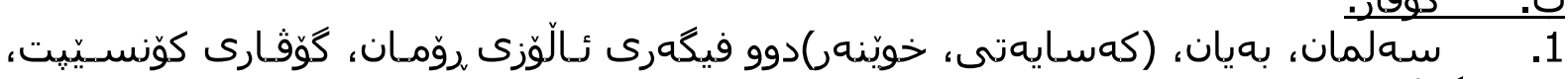

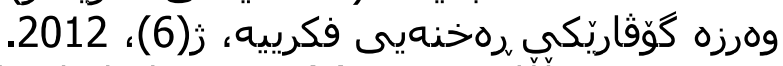

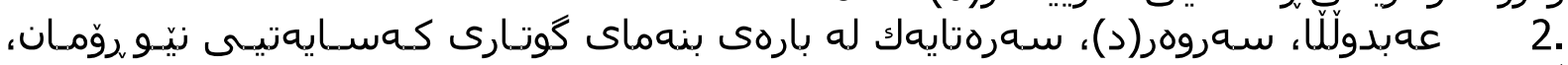
كُوَّارى ،رامان، زُ(75)، 2002.

نامa ئ كas

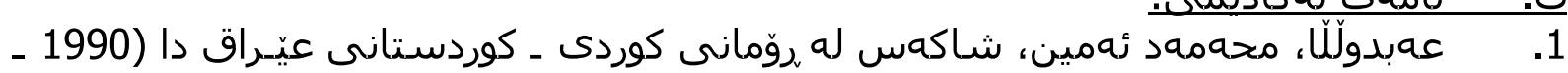

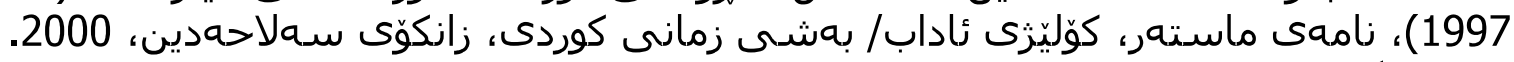
2.

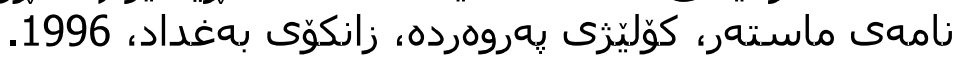

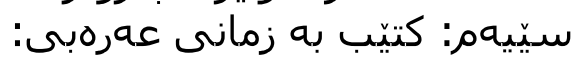

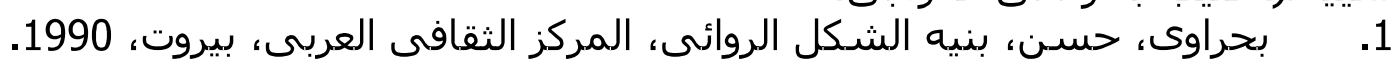
2. القاهرة، 


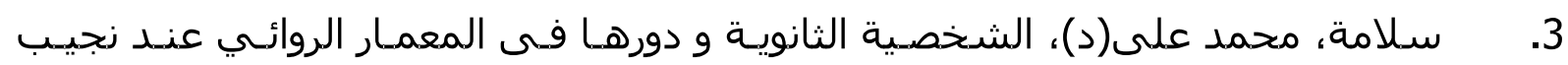

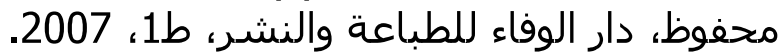

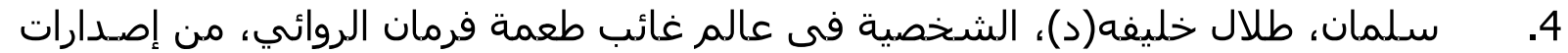

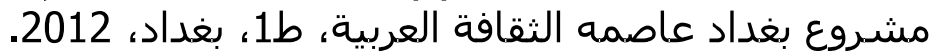
5. 1990. 6. مرتاض، عبدالملك(د)، فى نظريه الرواية(بحِ في تقنيات السرد)، سلسـلة كتـب عـالم المعرفة، الكويت، 1998. 7.

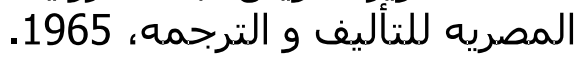

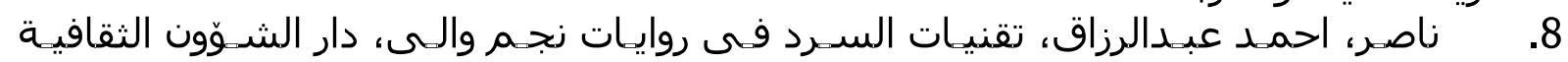

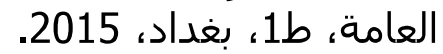
9. هلال، محمد غنغ غنيمى(د)، النقد الادبى الحديث، دار الثقافه، لبنان، 1973.

\section{References}

\section{A. Novels}

Ay, Lavila (2000). Karwan KakaSwr, Sardam Publisher, 1st Edition, Sulaimani Mamzir, (2008). Karwan KakaSwr, Yad Printing, 1st Edition, Sulaimani

Swarkan, Baqachkh Bwkyan Gwastawa, (2009). Karwan KakaSwr and Dwarozh Karwan, Qalam Publisher, 1st Edition, Sulaimani

Kanaly, Maimwna Chakdarakan, (2012). Karwan KakaSwr, Sardam Publisher, 2st Edition, Sulaimani

Kazainoy, Mndalan, (2013). Karwan KakaSwr, Ghazalnws Publisher, $1^{\text {st }}$ Edition

Maly, Nany, (2014). Karwan KakaSwr, Ghazalnws Publisher, $1^{\text {st }}$ Edition

Rebaneky, Swr Mpecheky Rash, (2015). Karwan KakaSwr, Ghazalnws Publisher, $1^{\text {st }}$ Edition

\section{B. Books}

Aleid, Yumna, (1990). Novel narrative techniques in the light of the structural approach, Al Farabi, $1^{\text {st }}$, Beirut

Alwany, Najm Khalid, (2009). Characterization in the novel of Ewary Parwana, Mukriani Printing, $1^{\text {st }}$ Edition, Erbil

Bahrawi, Hassan, (1990). The Structure of novel form, The Central Arabic Culture, Beirut Hadi, Siamand, (2004). The history of novels, Teshik Printing, Sulaimani 
Hajy, Sanger Qadr Sheikh Muhammed, (2009). The Structure of Narration in Ahmady Khany's (Mam w Zin) and Bakhtyar Ali's novel (The City of White Musicians), Mukriani Establishment for Research and Publication, $1^{\text {st }}$ Edition, Erbil

Hijazi, Samir Saeed, (2001). Dictionary of contemporary literary criticism, Dar Al- Afaq AlArabiya, Qairo

Hilal, Muhammed Ghunemi, (1973). The Modern literary criticism, The Cultural House, Beirut

Ian Watt, (2009). The Rise of the novel, translated to Kurdish by Rauf Begard, Sardam Publisher, 2st Edition, Sulaimani

Jabary, Omer Yasin, (2000). Phycology, Salahaddin University Printing, Erbil

Muhammed, Miran Jalal, (2009). Event Structure in Kurdish Novels, Kurdology Center, Ranj Printing, Sulaimani

Muir, Adwin, (2000). The structure of Novel, Translated by Ebrahim Al-Saerafi, Dar AlMisraia

Munif, Abdul Rahman, (1965). Tishkek bo Sar Roman, Translated to Kurdish by Shereen K., Sardam Publisher, 1st Edition, Sulaimani

Murtaz, Abdul Malik, (1998). The Narration Theory, Al-Alam Al-Maerafa, Kuwait

Nasr, Ahmad Abdul Razaq, (2015). The Techniques narration in novels of Najm Wali, The Cultural House, $1^{\text {st }}$ Edition, Baghdad

Omer, Salah, (2010). Novels in different point views, Mukriani Establishment for Research and Publication, $1^{\text {st }}$ Edition, Erbil

Salama, Muhammed Ali, (2007). The Secondary character and its role in the architectural novels with Naguib Mahfouz, Alwafa for Printing and Publishing, $1^{\text {st }}$ Edition

Sabir, Parez, (2001). The structure of Kurdish Story, Sardam Publisher, Sulaimani

Salman, Talal Khalifa, (2012). Personality in an absent world in Tama Ferman's novels, the project of Baghdad cultural Arabic capital, $1^{\text {st }}$ Edition, Baghdad

Saraj, Abdullah, (2007). Towards Novels and Point views, Sardam Publisher, 1st Edition, Sulaimani

Slewa, Hawzhin, (2013). Psychology Dimension of Latef Halmat's Poetry, Kurdish Writers Union, Rozh Halat Printing, Erbil

\section{Journals}


Abdullah, Sarwar, (2002). Introduction to the fundamentals of personality in novels, Raman, (75)

Salman, Bayan, (2012). Personality and Reader the two character of complex of novels, The Concept, (6)

\section{Master and Doctoral Thesis}

Abdullah, Muhammed Amin, (2000). Hero in Kurdish Novels between 1990-1997, Master Thesis, the College of Arts, Kurdish Department, Salahaddin University, Erbil

Garmiyani, Adel Majeed Muhammed, (1996). Reality in Modern Kurdish Novels, Master Thesis, The College of Education, Baghdad University 